\title{
Multienzymes activity of metals and metal oxide nanomaterials: applications from biotechnology to medicine and environmental engineering
}

Negar Alizadeh ${ }^{1}$ and Abdollah Salimi ${ }^{1,2^{*}}$

\begin{abstract}
With the rapid advancement and progress of nanotechnology, nanomaterials with enzyme-like catalytic activity have fascinated the remarkable attention of researchers, due to their low cost, high operational stability, adjustable catalytic activity, and ease of recycling and reuse. Nanozymes can catalyze the same reactions as performed by enzymes in nature. In contrast the intrinsic shortcomings of natural enzymes such as high manufacturing cost, low operational stability, production complexity, harsh catalytic conditions and difficulties of recycling, did not limit their wide applications. The broad interest in enzymatic nanomaterial relies on their outstanding properties such as stability, high activity, and rigidity to harsh environments, long-term storage and easy preparation, which make them a convenient substitute instead of the native enzyme. These abilities make the nanozymes suitable for multiple applications in sensing and imaging, tissue engineering, environmental protection, satisfactory tumor diagnostic and therapeutic, because of distinguished properties compared with other artificial enzymes such as high biocompatibility, low toxicity, size dependent catalytic activities, large surface area for further bioconjugation or modification and also smart response to external stimuli. This review summarizes and highlights latest progress in applications of metal and metal oxide nanomaterials with enzyme/multienzyme mimicking activities. We cover the applications of sensing, cancer therapy, water treatment and anti-bacterial efficacy. We also put forward the current challenges and prospects in this research area, hoping to extension of this emerging field. In addition to therapeutic potential of nanozymes for disease prevention, their practical effects in diagnostics, to monitor the presence of SARS-CoV-2 and related biomarkers for future pandemics will be predicted.
\end{abstract}

Keywords: Nanozyme, Metal, Metal oxide, Sensing and biosensing, Cancer, Therapeutic, Diagnostics

\section{Introduction}

Enzymes, as biological macromolecules, are mainly composed of proteins, which can efficiently and selectively catalyze a diverse biochemical reactions $[1,2]$. They play a notable function in various fields, such as energy production processes, biosensing, the food industry, and

*Correspondence: absalimi@uok.ac.ir

${ }^{1}$ Department of Chemistry, University of Kurdistan,

66177-15175 Sanandaj, Iran

Full list of author information is available at the end of the article biofuels [3-6]. However, they have some drawbacks, such as product complexity, harsh catalytic conditions and low operational stability because of digestion and denaturation. In addition, it has high costs in preparation and purification $[7,8]$. To address these issues, nanomaterial with enzyme-like characteristics (nanozyme) was applied as a novel alternative candidate. Artificial enzymes have attracted the significant attention of researchers due to their higher stability, low cost, flexibility and tunable catalytic activities [9-11]. Compared with other artificial enzymes, nanozymes possess outstanding properties 
such as their size and structure dependent catalytic activities, multi enzyme activity, large surface area, smart response and self-assembly capability $[12,13]$. On the basis of these outstanding properties, nanozymes have been widely utilized for disease diagnosis and treatment, chemical sensing, environmental protection and antibacterial agents [7, 14-17]. Up to now, lots of nanomaterials have been uncovered to mimic several natural enzymes, such as peroxidase, oxidase, catalase, superoxide dismutase (SOD), phosphatase, nuclease, esterase, protease and ferroxidase [18]. Since the finding of $\mathrm{Fe}_{3} \mathrm{O}_{4}$ nanoparticles as peroxidase mimics in 2007 [19], a large amount of studies on metal and metal oxide nanozymes have been reported. For example, $\mathrm{Au}, \mathrm{Pt}, \mathrm{Pd}, \mathrm{Co}_{3} \mathrm{O}_{4}$, $\mathrm{CeO}_{2}, \mathrm{CuO}, \mathrm{MnO}_{2}, \mathrm{NiO}, \mathrm{V}_{2} \mathrm{O}_{5}$ nanocomposites have been shown to possess a unique enzyme-like property [20-28]. Metal and metal oxide nanomaterial played great role in progress and development of enzyme mimic technology, due to their unique combination of redox chemistry, optical and electrical properties [29-32]. Interestingly, some nanomaterial can mimic the function of two or three enzymes. It has been reported that the simultaneous expression of multiple enzymes is more effective than single expression to remove harmful reactive oxygen species [33]. When designing a cascade reaction, it is often appropriate to use multiple nanozyme as the cascade catalyst. In this review, we present a comprehensive review of applications of metal and metal oxide nanozyme in terms of chemical sensing and biosensing, cancer treatment, water purification and anti-bacterial efficiency (Table 1). We also highlight some recent examples of multi-enzyme applications in catalysis. Because of the space limit, we could not cover all the related publications. However, we summarize recent research works on metal and metal oxide based nanozyme in Table 1 . In the last section, the current challenges and future opportunities of metal and metal oxide-based nanozymes are also discussed. We hope that the present review will be of great benefit for development of novel nanozymes in the fields of medicine, chemistry, biology and nanotechnology.

\section{Nanozymes for sensing application}

Metal and metal oxide-based nanozymes with substantial properties have been widely applied for several analytical purposes. The principle detection is divided into two categories: (1) the target activates or deactivates a reaction between the nanozyme and the agent, (2) the presence of the nanozyme and its reaction with the agent indirectly indicates the amount of target. According to previous reports, the application of such nanozymes includes detection of a variety of important targets, such as tumor markers, small biomolecules and metal ions [18, 28, 34].

\section{Tumor markers}

Synthesize nanomaterials within cage-like protein templates has been demonstrated to be a suitable approach to produce uniform [35]. Ferritin nanocages provide surface modification and specific targeting abilities for synthesizing ferritin-based nanozymes [36]. Biomineralization synthesis of cobalt nanozyme in SP94-ferritin nanocage was reported for prognostic diagnosis of hepatocellular carcinoma (HCC) [37]. In this report, ferritin-based cobalt nanozyme $\left(\mathrm{HccFn}\left(\mathrm{Co}_{3} \mathrm{O}_{4}\right)\right)$ was designed for $\mathrm{HCC}$ diagnosis and therapy. SP94 peptide was modified onto the exterior surface of ferritin nanocage $(\mathrm{HccFn})$ for specifically binding to $\mathrm{HCC}$ cells. $\mathrm{HccFn}\left(\mathrm{Co}_{3} \mathrm{O}_{4}\right)$ nanozymes specifically bound to $\mathrm{HCC}$ tissues and catalyze the oxidation of peroxidase substrate diaminobenzidine (DAB) to produce deep brown colorimetric reaction. In comparison with $\mathrm{Fn}\left(\mathrm{Co}_{3} \mathrm{O}_{4}\right)$ control group, $\mathrm{HccFn}\left(\mathrm{Co}_{3} \mathrm{O}_{4}\right)$ nanozymes specifically recognized and visualized $\mathrm{HCC}$ tissues and could distinguish tumor cells from normal tissues (Fig. 1).

The nanomaterial-mediated colorimetric sensor is an attractive system for advance instrument-free bioanalysis due to its unique advantages of simplicity in operating analysis via camera or smartphone [38, 39]. Several colorimetric assays based on the 3,3,5,5 tetramethylbenzidine (TMB) $-\mathrm{H}_{2} \mathrm{O}_{2}$ system catalyzed by enzyme mimic nanomaterials have been extensively developed for immunoassay [40-42]. For instance, Alizadeh et al. present a paper-based microfluidic colorimetric immunosensor for the detection of carcinoembryonic antigen (CEA), using $\mathrm{Co}_{2}(\mathrm{OH})_{2} \mathrm{CO}_{3}-\mathrm{CeO}_{2}$ nanocomposite with extraordinary intrinsic peroxidase like activity [43]. The proposed immunosensor facilely prepared by modifying mixture of ionic liquid and chitosan functionalized primary antibodies $\left(\mathrm{Ab}_{1}\right)$ on the surface of paper. $\mathrm{Co}_{2}(\mathrm{OH})_{2} \mathrm{CO}_{3}-\mathrm{CeO}_{2}$ peroxidase mimicking enzyme was functionalized secondary antibodies $\left(\mathrm{Ab}_{2}\right)$ and used as a signal tag. $\mathrm{Co}_{2}(\mathrm{OH})_{2} \mathrm{CO}_{3}-\mathrm{CeO}_{2}$ nanocomposite catalyzed the oxidation of 3,3',5,5'-tetramethyl benzidine in the presence of $\mathrm{H}_{2} \mathrm{O}_{2}$, resulting in a color change, which acquired as the immunosensor response. The color change was distinct by the naked eye and analyzed by an installed application on the smartphone (Fig. 2).

In colorimetric assays, color changes and photothermal effect of TMB- $\mathrm{H}_{2} \mathrm{O}_{2}$ colorimetric system have been prospected [44]. In this regard, nanoparticle (NPs)-mediated photothermal immunoassay platform was developed for detection of prostate-specific antigen (PSA) using a common thermometer as the quantitative signal reader [45]. The iron oxide NPs-labeled antibody was applied as the detection probe, on basis of sandwich-type proof-ofconcept immunoassay. In the immunoassay, iron oxide artificial enzyme demonstrated color changes and also a 
Table 1 Current metal and metal oxide nanozymes, their typical applications and representative references

\begin{tabular}{|c|c|c|c|}
\hline Enzyme & Nanomaterial & Application & References \\
\hline Peroxidase & $\operatorname{HccFn}\left(\mathrm{CO}_{3} \mathrm{O}_{4}\right)$ & Sensing & [37] \\
\hline Peroxidase & $\mathrm{CO}_{2}(\mathrm{OH})_{2} \mathrm{CO}_{3}-\mathrm{CeO}_{2}$ & Sensing & [43] \\
\hline Peroxidase & Iron oxide & Sensing & [45] \\
\hline Peroxidase & PtPd & Sensing & [49] \\
\hline Oxidase & $\mathrm{Ag}-\mathrm{CoFe}_{2} \mathrm{O}_{4} / \mathrm{rGO}$ & Sensing & [55] \\
\hline Peroxidase & $\mathrm{CuO} / \mathrm{Pt}$ & Sensing & [56] \\
\hline Peroxidase & $(\mathrm{rGO})-\mathrm{PdAu}$ & Sensing & [60] \\
\hline Peroxidase & $\mathrm{Au}$ & Sensing & [61] \\
\hline GSH-oxidase and peroxidase & $\mathrm{CuO}$ & Sensing & [65] \\
\hline Peroxidase & Au@Pt & Sensing & [70] \\
\hline Peroxidase & GO-AuNP & Sensing & [71] \\
\hline Peroxidase & $\mathrm{Cu}_{2} \mathrm{O} / \mathrm{rGO}$ & Sensing & [74] \\
\hline Oxidase & $\mathrm{CoOOH}$ & Sensing & [77] \\
\hline Peroxidase & $\mathrm{FeMnO}_{3}$ & Sensing & [80] \\
\hline Peroxidase & $\mathrm{CuFe}_{2} \mathrm{O}_{4} / \mathrm{Cu}_{9} \mathrm{~S}_{8} / \mathrm{PPy}$ & Sensing & [81] \\
\hline Peroxidase & $\mathrm{CuO}$ & Sensing & [85] \\
\hline Peroxidase & $\mathrm{Fe}_{3} \mathrm{O}_{4} \mathrm{NPs} / \mathrm{rGO} / \mathrm{MoS}_{2}$ & Sensing & [86] \\
\hline Peroxidase & $\mathrm{CuO} / \mathrm{WO}_{3}-\mathrm{GO}$ & Sensing & [91] \\
\hline Peroxidase & Pt-Pd & Sensing & [97] \\
\hline GSH-oxidase and peroxidase & $\mathrm{MnO}_{2}$ & Therapeutics & [110] \\
\hline Peroxidase & FcPW & Therapeutics & [114] \\
\hline Peroxidase & Copper peroxide & Therapeutics & [116] \\
\hline Peroxidase & $\mathrm{SnFe}_{2} \mathrm{O}_{4}$ & Therapeutics & [118] \\
\hline Peroxidase & $\mathrm{Fe}_{3} \mathrm{O}_{4} @ \mathrm{MSN}$ & Therapeutics & [122] \\
\hline Catalase & $\mathrm{MnFe}_{2} \mathrm{O}_{4}$ & Therapeutics & [130] \\
\hline Catalase & $\mathrm{MnO}_{2}$ & Therapeutics & {$[132,133]$} \\
\hline Catalase & Pt & Therapeutics & [134] \\
\hline Catalase and oxidase & $\mathrm{MoO}_{3}-\mathrm{x}$ & Therapeutics & [136] \\
\hline Peroxidase and oxidase & Au@HCNs & Therapeutics & [144] \\
\hline Catalase and superoxide dismutase & $\mathrm{NCeO}_{2}-\mathrm{PEI}-\mathrm{MoS}_{2}$ & Therapeutics & [145] \\
\hline Catalase & Pt-CuS & Therapeutics & [151] \\
\hline Peroxidase and oxidase & GQD/AgNP & Antibacterial & [159] \\
\hline Oxidase, peroxidase and catalase & $\mathrm{Pt} / \mathrm{Ag}$ & Antibacterial & [160] \\
\hline Oxidase and peroxidase & MSN-Au & Antibacterial & [164] \\
\hline Peroxidase & $\mathrm{CuO}$ & Antibacterial & [167] \\
\hline Oxidase and peroxidase & $\mathrm{Pd}$ & Antibacterial & [170] \\
\hline Peroxidase & $\mathrm{Fe}_{3} \mathrm{O}_{4}$ & Water purification & {$[182,185,188]$} \\
\hline Peroxidase & $\mathrm{Fe}_{2} \mathrm{O}_{3}$ & Water purification & [183] \\
\hline Peroxidase & $\mathrm{CuFe}_{2} \mathrm{O}_{4}$ & Water purification & [184] \\
\hline Peroxidase & $\mathrm{Fe}_{2.79} \mathrm{Nb}_{0.19} \mathrm{O}_{4}$ & Water purification & [187] \\
\hline
\end{tabular}

strong NIR laser-driven photothermal effect, simultaneously. The oxidized TMB acted as a highly sensitive photothermal probe to convert the immunoassay signal into heat via its photothermal effect (Fig. 3).

Aptamers are artificial synthetic single-stranded DNA or RNA oligonucleotides, which can bind with various targets such as protein, peptide, organic/inorganic molecule, and cell with high affinity and specificity. Aptamer with superiority to antibodies, including high stability, ease of synthesis, low cost and easy chemical modification, have attracted a lot of attention in biomedical and bioanalysis research [46-48]. Zhao et al. selected three hairpin anti-MUC1 DNA aptamers for construction of a sensitive electrochemical aptasensor based on 


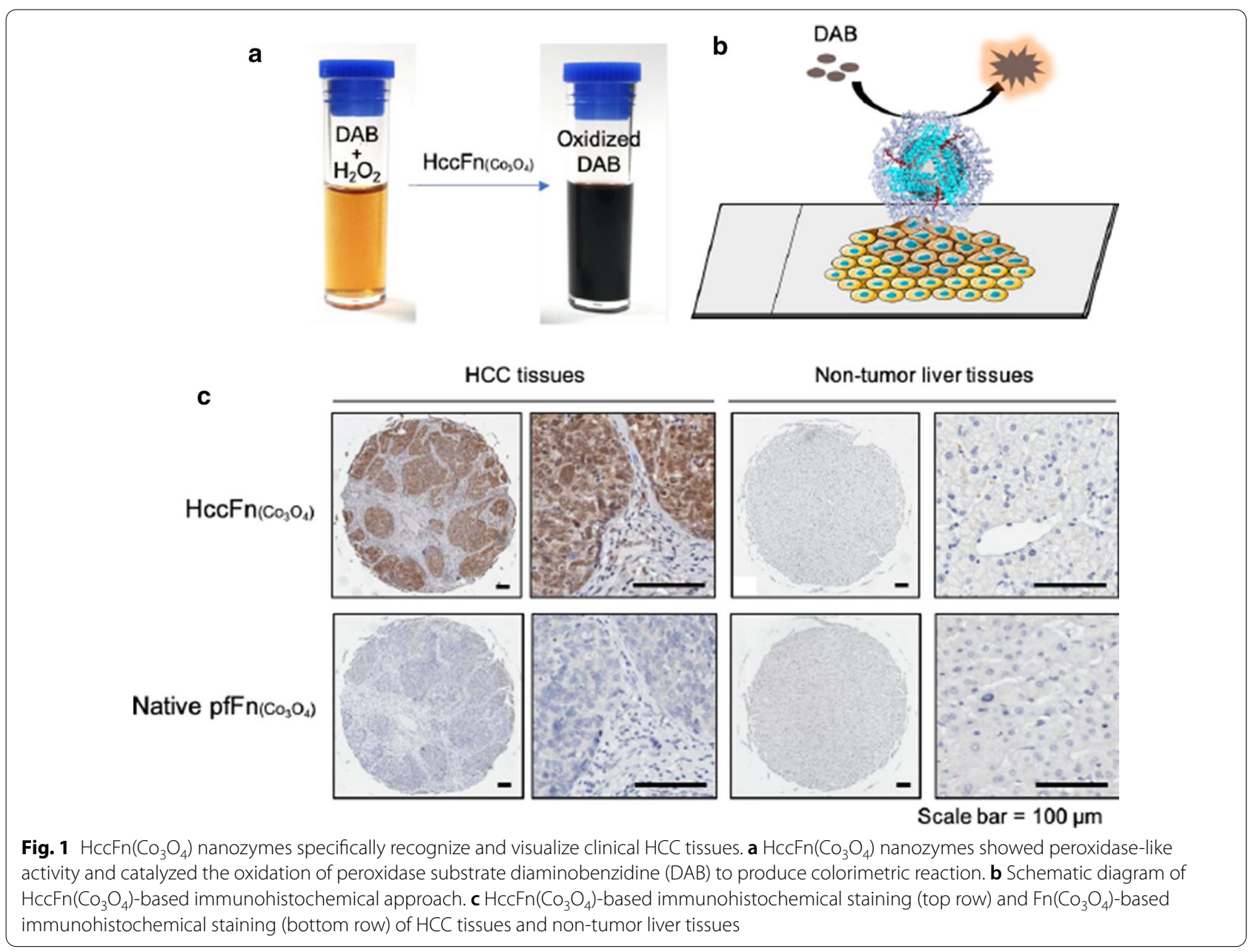

catalytic hairpin assembly coupled with PtPdNPs peroxidase-like activity [49]. After binding with target protein, Apt-HP1 containing aptamer sequence was opened and MUC1-aptamer binding complex formed (Fig. 4). Next, the exposed segment of HP1 would attack HP2 immobilized on the electrode to form a double strand structure. Then, the new exposed segment of HP2 hybridized with the toehold of PtPdNPs modified HP3. Finally, MUC1-A was released via the strand displacement process, and the released MUC1-A could participate in the subsequent reaction cycles. The carried PtPdNPs, as a mimic peroxidase probe, catalyzed the TMB by $\mathrm{H}_{2} \mathrm{O}_{2}$, leading to the electrochemical signal generation.

\section{Metal ions}

Most studies on metal ions sensing with nanozymes have been devoted to mercury ions $\left(\mathrm{Hg}^{2+}\right)[9,50,51]$. Mercury is a toxic metal ion that in the environment can produce several harmful effects on people's health like brain, heart, kidneys and central nervous system damages [52, 53]. Through the bacteria action in a lake and ocean,
$\mathrm{Hg}^{2+}$ converts into more toxic organic mercury and accumulates in aquatic organisms [54]. Thereupon, it can accumulate continuously in the body through water and food. In a report, dual colorimetric and SERS detection of $\mathrm{Hg}^{2+}$ was developed based on the stimulus of intrinsic oxidase-like catalytic activity of $\mathrm{Ag}-\mathrm{CoFe}_{2} \mathrm{O}_{4} / \mathrm{rGO}$ nanocomposites [55]. $\mathrm{CoFe}_{2} \mathrm{O}_{4}$ nanoparticles in $\mathrm{Ag}-\mathrm{CoFe}_{2} \mathrm{O}_{4} /$ rGO nanocomposites exhibited an oxidase-like activity, which can quickly catalyze the oxidation of typical chromogenic substrates 3,3',5,5'-tetramethylbenzidine (TMB) in the presence of dissolved oxygen. The introduction of $\mathrm{Hg}^{2+}$ led to enhancement in oxidase-like activity of the $\mathrm{Ag}-\mathrm{CoFe}_{2} \mathrm{O}_{4} / \mathrm{rGO}$ nanocomposites due to the formation of the Ag-Hg alloy. Owing to the existence of the Ag nanoparticles the prepared nanocomposites have also been demonstrated to be efficient SERS substrate. In another report, colorimetric detection of $\mathrm{Hg}^{2+}$ in various groundwater samples was successfully performed using $\mathrm{CuO} / \mathrm{Pt}$ Nanoflowers (NFs). In the presence of $\mathrm{Hg}^{2+}$, the peroxidase activity of $\mathrm{CuO} / \mathrm{Pt}$ NFs was hindered, because the formation of the $\mathrm{CuO} / \mathrm{Pt}-\mathrm{Hg}$ trimetallic amalgam [56]. 


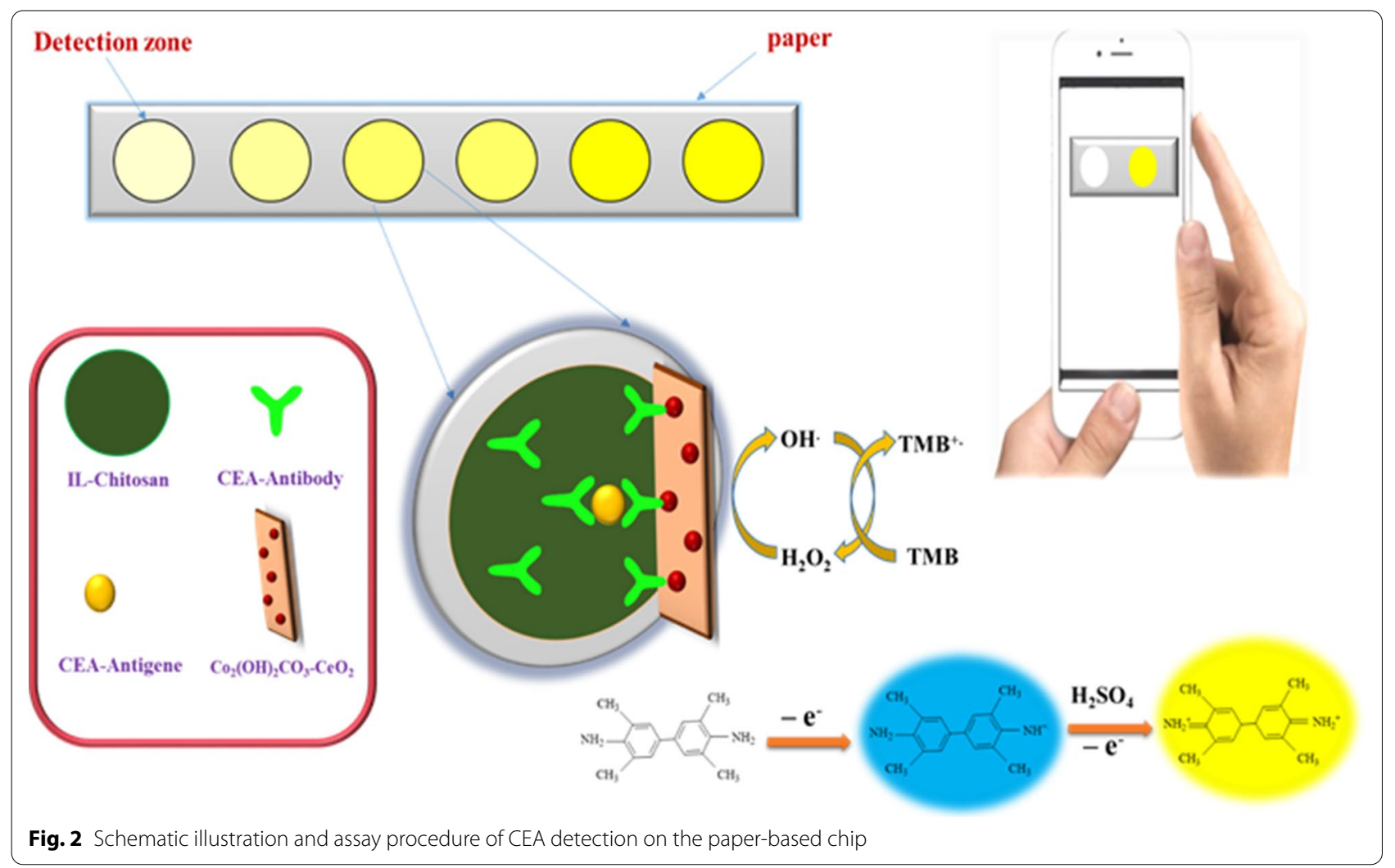

Lead $\left(\mathrm{Pb}^{2+}\right)$ is known as a non-biodegradable, toxic and perdurable metal ion. It has a strong negative effect on children's behavior and serious damage to the brain, immune system of many life tissues including liver, brain, kidney and also immune and central nervous system [57-59]. Xu et al. reported colorimetric and electrochemiluminescence dual mode sensing of lead ion biomolecules using graphene oxide (rGO)-PdAu probe [60]. $\mathrm{Pb}^{2+}$-specific DNAzyme was immobilized onto rGO-PdAu-glucose oxidase (GOx). The thiol modified $\mathrm{Pb}^{2+}$-dependent DNAzyme was self-assembled onto the surface of the flower-like Au NPs modified ECL detection zone to hybridize with rGO-PdAu-GOx labeled oligonucleotide. Upon introducing of $\mathrm{Pb}^{2+}$ into the prepared system, the double helix structure of DNA was cleaved, resulting in the release of $\mathrm{GGO}-\mathrm{PdAu}-\mathrm{GOx}$ probe to catalyze the oxidation and color change of TMB. Meanwhile, the concentration of $\mathrm{H}_{2} \mathrm{O}_{2}$ is proportional to the luminol ECL system, which constitutes a new mechanism for ECL detection of $\mathrm{Pb}^{2+}$ (Fig. 5).

Inspired by the aggregation-induced emission (AIE) properties, the catalytic activity of metal nanozyme could be altered upon aggregation, because both optical and catalytic properties of metal nanocomposites are highly dependent on their size and morphology. It was found that the $\mathrm{Pb}^{2+}$-induced aggregation can greatly accelerate the peroxidase-like activity of $\mathrm{Au}$ nanoclusters (Au-NCs) [61]. In the absence of $\mathrm{Pb}^{2+}, \mathrm{Au}-\mathrm{NCs}$ could catalyze the TMB oxidation by $\mathrm{H}_{2} \mathrm{O}_{2}$ in a relatively slow reaction rate. After the $\mathrm{Pb}^{2+}$-induced aggregation, the peroxidase activities of Au-NCs toward oxidation of TMB substrate in the presence of $\mathrm{H}_{2} \mathrm{O}_{2}$ are nearly tenfold increased.

Some cascade reactions were configured between enzyme-like nanomaterials and natural enzymes [62, 63]. This cascade catalytic system must be carried out in two steps, because the optimal $\mathrm{pH}$ conditions for each enzyme is different. To address the limitation of different conditions, a single nanomaterial with dual activity has been constructed to mimic enzyme cascade reaction [64]. He et al. described a self-cascade system based on cupric oxide nanoparticles as dual-functional enzyme mimics for ultrasensitive detection of silver ions [65]. Cupric oxide nanoparticles ( $\mathrm{CuO} \mathrm{NPs})$, as the dual-functional nanozyme, demonstrated the intrinsic GSH-oxidase and peroxidase-like activity coupling with terephthalic acid (TA) and GSH to construct a self-cascade fluorescent system. $\mathrm{CuO}$ NPs effectively catalyze the oxidation of GSH by oxygen to produce glutathiol (GSSG) and hydrogen peroxide, following to catalyze the decomposition of hydrogen peroxide into hydroxyl. Then, a highly fluorescent product $\mathrm{TAOH}$ was formed by oxidation of terephthalic acid (TA) in the presence of hydroxyl radical. Thus, 


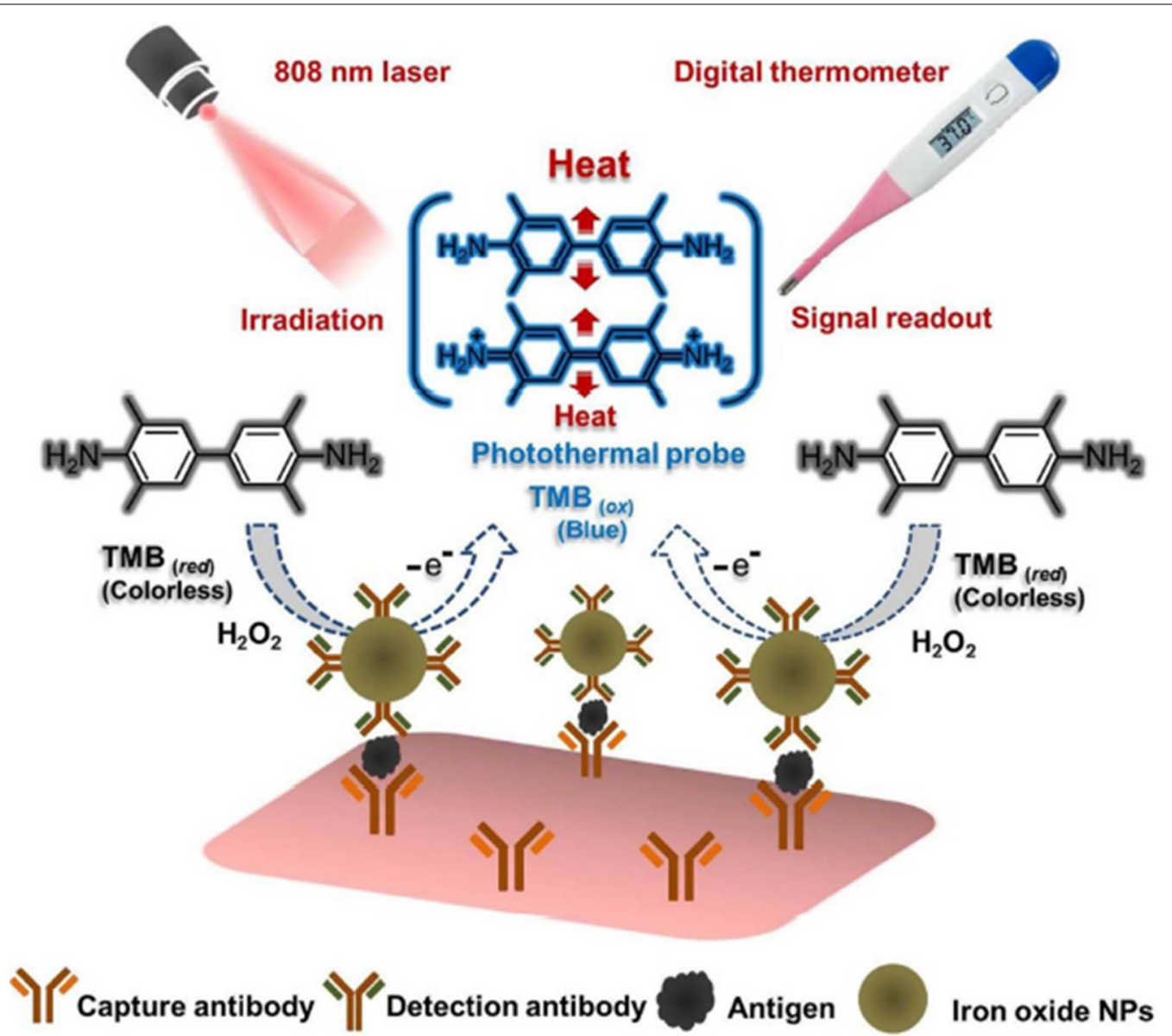

Fig. 3 Schematic illustration of the photothermal immunoassay platform based on the photothermal effect of the iron oxide NPs mediated TMB- $\mathrm{H}_{2} \mathrm{O}_{2}$ colorimetric system

in the presence of GSH, the turn-on fluorescence signal of oxidation hydroxyterephthalate $(\mathrm{TAOH})$ is created. Introduction of the $\mathrm{Ag}^{+}$ions cause to inhibition of the fluorescence of $\mathrm{H}_{2} \mathrm{O}_{2}$-TA-CuO NPs reaction system. It is due to that $\mathrm{Ag}^{+}$ions can react with the $\mathrm{H}_{2} \mathrm{O}_{2}$ intermediate product resulted from the oxidation of GSH.

Until now, many assays for single heavy metal ions have been reported [66-68]. However, some efforts have been made to develop simultaneous detection of metal ions. $\mathrm{Hg}^{2+}$ and $\mathrm{Ag}^{+}$are usually coexisting in water, soil and even biological systems [69]. Peng et al. prepared coreshell Au@Pt nanoparticles for simultaneous colorimetric detection of $\mathrm{Hg}^{2+}$ and $\mathrm{Ag}^{+}$[70]. Both $\mathrm{Hg}^{2+}$ and $\mathrm{Ag}^{+}$were found to intensively inhibit the catalytic activity of $\mathrm{Au} @ \mathrm{Pt}$ NPs. The complexation of sodium dodecyl sulfate (SDS) shields interference metal ions such as $\mathrm{Mn}^{2+}, \mathrm{Sr}^{2+}, \mathrm{Zn}^{2+}$, $\mathrm{Fe}^{3+}, \mathrm{Co}^{2+}, \mathrm{Cu}^{2+}$ and $\mathrm{Bi}^{3+}$, to obtain specific respond of $\mathrm{Hg}^{2+}$ and $\mathrm{Ag}^{+}$. As well as, $\mathrm{L}$-cysteine can be used to mask $\mathrm{Hg}^{2+}$ in the presence of $\mathrm{Ag}^{+}$. In another study, Colorimetric detection of $\mathrm{Hg}^{2+}$ and $\mathrm{Pb}^{2+}$ was achieved based on peroxidase-like activity of graphene oxide-gold (GO-AuNP) nanohybrids [71]. Single-stranded DNA (ssDNA) were stable against the salt-induced aggregation of GO-AuNP nanohybrids, whereas double stranded DNA (dsDNA) did not hinder salt-induced GO-AuNP nanohybrids aggregation. On the basis of the ability of GO-AuNP nanohybrids to differentiate between ssDNA and dsDNA, label-free colorimetric method for the detection of $\mathrm{Hg}^{2+}$ and $\mathrm{Pb}^{2+}$ was developed. With addition of $\mathrm{Hg}^{2+}$ or $\mathrm{Pb}^{2+}$, ssDNA formed a hairpin-like or a quadruplex structure, and these conformational changes led to the salt-induced aggregation of GO AuNP nanohybrids. After addition of TMB and $\mathrm{H}_{2} \mathrm{O}_{2}$, the colorimetric signal was significantly decreased compared to that in the absence of $\mathrm{Hg}^{2+}$ or $\mathrm{Pb}^{2+}$.

\section{Biomolecules}

Glucose is the main energy source for cellular metabolism and function of human bodies. However, people with glucose excessive suffer from diabetes mellitus. 


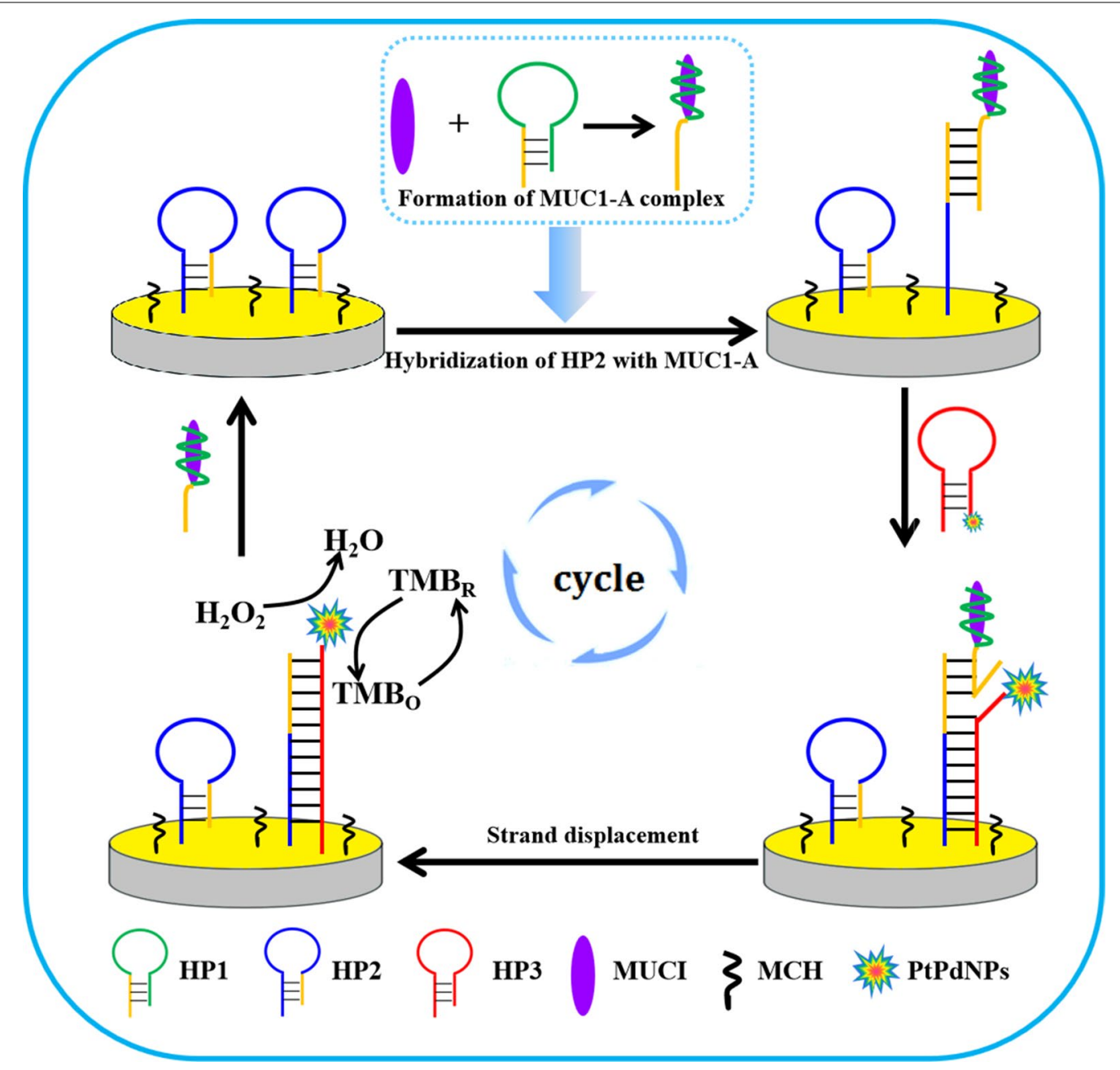

Fig. 4 Schematic representation of the aptasensor for the detection of MUC1

Diabetes can cause serious health problems, such as strokes, heart attacks, high blood pressure, and even blindness or death [72, 73]. Guo and co-workers fabricated $\mathrm{Ag}-\mathrm{Cu}_{2} \mathrm{O} /$ reduced graphene oxide nanocomposites with peroxidase-like catalytic reaction for (Surface-enhanced Raman spectroscopy) SERS detection of glucose [74]. SERS facilitate highly sensitive and selective identification of analytes such as glucose. Ag$\mathrm{Cu}_{2} \mathrm{O} / \mathrm{rGO}$ nanocomposites operate as both peroxidase nanozyme and SERS substrates; they speed up the reaction between TMB and $\mathrm{H}_{2} \mathrm{O}_{2}$. A SERS method has been designed based on the ability of glucose oxidase (GOx) to catalyze the oxidation of glucose to gluconolactone and $\mathrm{H}_{2} \mathrm{O}_{2}$. In this method, glucose was determined by the catalytic oxidation of TMB in the presence of GOx and glucose. Discern between diabetic and normal individuals by determining the glucose levels within a fingerprint is the most important feature of this work (Fig. 6).
Ascorbic acid (AA) neurochemicals, used as an enzyme cofactor and antioxidant. Meanwhile, AA plays a critical role of anti-oxygenation and resists the cells damage from free radicals. High level of AA can selectively kill colorectal cancer cells as a pro-oxidant anticancer agent $[75,76]$. Therefore, methods for simple, fast, and effective AA assay suitable for the biological systems are required. Ding et al. the CoOOH-TMB oxidative system for colorimetric and test strip based detection of ascorbic acid [77]. $\mathrm{CoOOH}$ nanoflakes directly oxidize TMB (colorless) to blue oxTMB with a characteristic absorption peak at $652 \mathrm{~nm}$. In the presence of ascorbic acid (AA), the absorbance decreased because AA reduces oxTMB. Furthermore, the $\mathrm{CoOOH}-\mathrm{TMB}$ systems can be further developed into a paper-strip-based assay for determination of AA in rat brain (Fig. 7).

By reacting with $\mathrm{H}_{2} \mathrm{O}_{2}$, some small bioactive molecules like dopamine and glutathione $(\mathrm{GSH})$ have 


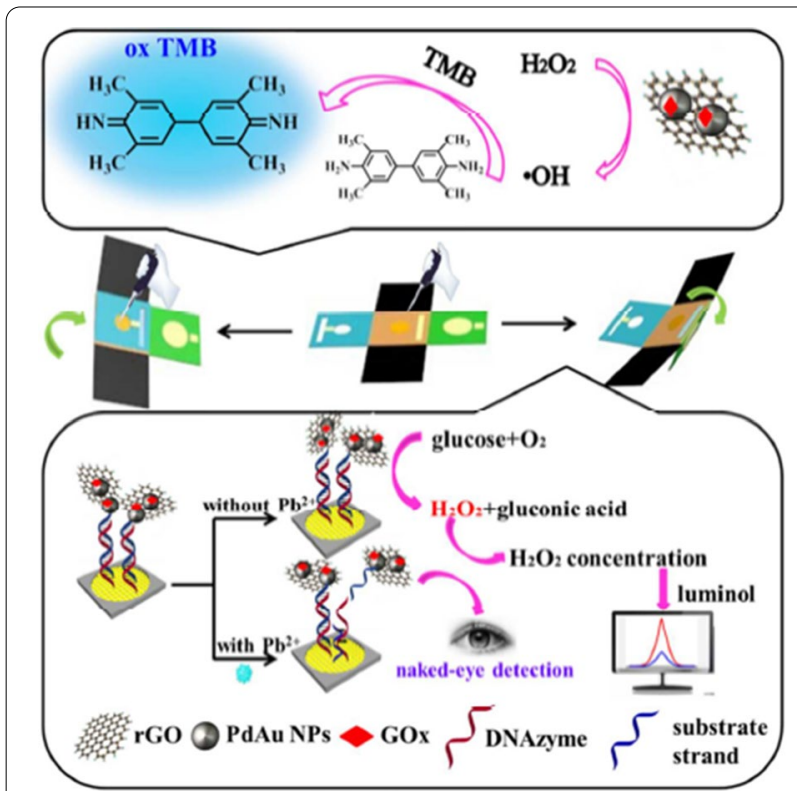

Fig. 5 Schematic representation of fabrication procedures of the lab-on-paper device and dual mode sensing mechanism

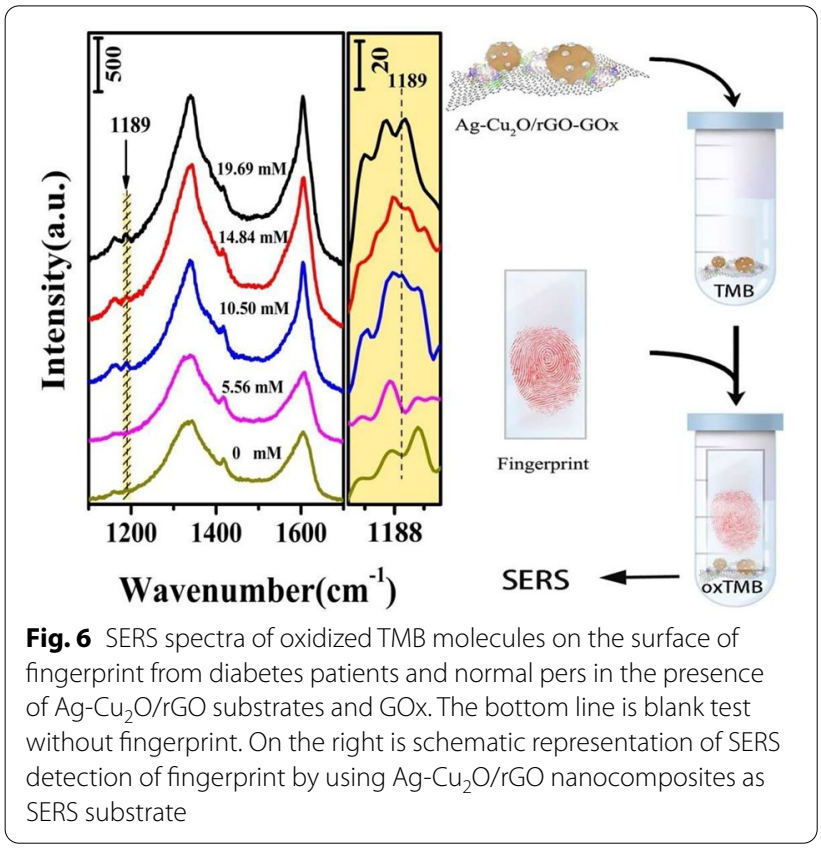

been determined based on their inhibition effects on peroxidase enzyme mimics [78, 79]. For example, GSH in human serum samples was determined using $\mathrm{FeMnO}_{3}$ nanoparticles-filled polypyrrole nanotubes as peroxidase mimic [80]. More, with Yang's sensing strategy, selective colorimetric detection of dopamine was successfully executed in real samples [81].

\section{Cancer cell and bacteria}

Cancer is one of the fatal sicknesses and has become a major public worry in the world [82]. Presently, early diagnosis has been made to be the most effective way to raise survival rate [83]. Thus, it is highly needed to develop sensitive, rapid and specific methods to detect and quantification of cancer cells at early stage [84]. The conjugation of aptamer or a ligand with nanozymes can be employed for cancer cells detection. For instance, MCF-7 circulating tumor cells were detected by an electrochemical cytosensor with effective surface recognition between specific mucin 1 protein (MUC-1) over-expressed on the MCF-7 cell membranes and MUC-1 aptamer [85]. The $\mathrm{CuO}$ nanozyme was used as a signal-amplifying nanoprobe with reduced graphene oxide/gold nanoparticles composites (rGO/AuNPs composites) as a support material (Fig. 8I). The fabricated "sandwich" structure can help to reach on the acceptable sensitivity of the proposed cytosensor.

The immunomagnetic sensor was also developed for electrochemical detection of MCF-7 circulating tumor cells [86]. $\mathrm{Fe}_{3} \mathrm{O}_{4}$ NPs magnetic beads act as both separation and enrichment CTCs and as enzyme mimics with $\mathrm{rGO} / \mathrm{MoS}_{2}$ synergistic catalysis (Fig. 8II). The CTCs could be separated and enriched on the magnetic glassy carbon electrode (MGCE) by $\mathrm{Fe}_{3} \mathrm{O}_{4}$ NPs coated aptamer. Electrochemical current of TMB redox product was generated via $\mathrm{Fe}_{3} \mathrm{O}_{4} \mathrm{NPs} / \mathrm{rGO} / \mathrm{MoS}_{2}$ catalytic ability.

Recently, several studies reported that folate-modified nanozymes could detect cancer cells with over-expressed folate receptor [87-90]. In Alizadeh and co-workers' study, the novel method was developed for electrochemical cancer cell detection using $\mathrm{CuO} / \mathrm{WO}_{3}$ nanoparticle decorated graphene oxide nanosheet $\left(\mathrm{CuO} / \mathrm{WO}_{3}-\mathrm{GO}\right)$ conjugated with folic acid (FA) [91]. In the absence of cancer cells, $o$-Phenylenediamine (OPD) oxidized on the $\mathrm{Au}$ electrode in the presence of $\mathrm{H}_{2} \mathrm{O}_{2}$, while $\mathrm{FA} / \mathrm{CuO} /$ $\mathrm{WO}_{3}-\mathrm{GO}$ with peroxidase like activity reacted with folate receptor of cancer cells seeded on 96-well plate, catalyzed the oxidation of OPD in presence of $\mathrm{H}_{2} \mathrm{O}_{2}$ (Fig. 9). Actually, in the presence of cancer cells, the response signal decreased, because some amount of $\mathrm{H}_{2} \mathrm{O}_{2}$-OPD system participated in chemical reaction and removed from the electrode. In this way, cancer cells detected in wide linear range and a low detection limit.

Infectious diseases induced by bacteria considered a cause of more than $25 \%$ of all global deaths [92]. Pathogen detection is an important step in the inhibition of these types of infectious and deadly diseases [93]. Several studies have been employed for bacteria detection using nanozymes as probing elements [94-96]. Recently, Cheng et al. reported nanozyme mediated dual-immunoassay integrated with smartphone for use in simultaneous 


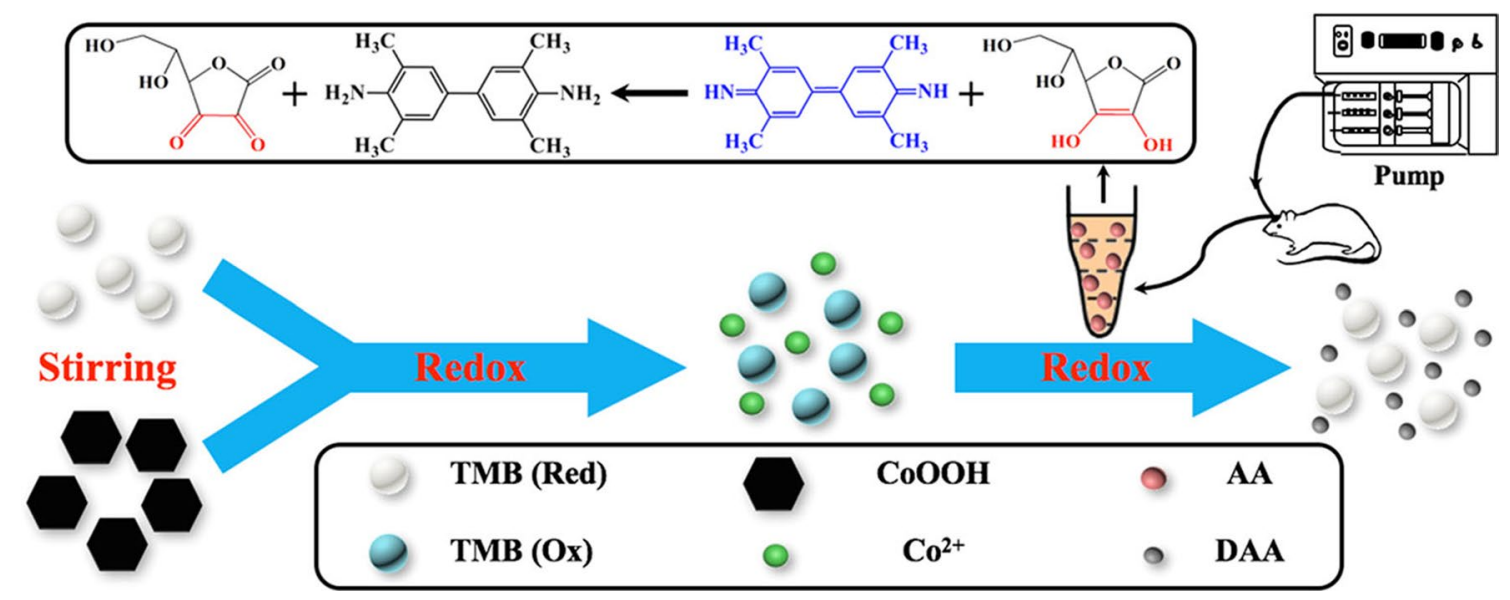

Fig. 7 Schematic of colorimetric assay mechanism and platform for the detection of AA in rat brain by the CoOOHTMB system

detection of pathogens [97]. They applied platinum-palladium (Pt-Pd) nanoparticles as a signal amplifier in a dual-lateral flow immunoassays (LFIA) and for simultaneous colorimetric detection of Salmonella Enteritidis and E. coli O157:H7. Smartphone-based device and its ability to image provide a portable and cost-effective platform for tracking bacterial contamination along the entire food chain.

\section{Nanozymes for therapeutics application}

Reactive oxygen species (ROS), is a general expression that describes the chemical species generated upon incomplete reduction of oxygen [98]. ROS including hydrogen peroxide, superoxide anion, hydroxyl radical and singlet oxygen have the potential to kill cancer cells by destroying biomolecules such as DNA, proteins and lipids [99]. In recent years, substantial achievements have been made in ROS-based nanomedicine, especially in cancer and bacterial infection [100-102]. The development of nanotechnology has favored the production of several ROS-generation materials with enzyme-mimic characteristics [103]. Metal and metal oxide nanozymes with peroxidase- and catalase- like activities, can convert endogenous biological $\mathrm{H}_{2} \mathrm{O}_{2}$ into highly cytotoxic $\mathrm{OH}$ and $\mathrm{O}_{2}{ }^{-}$species [104]. Furthermore, developing nanotechnology and nanozymes with special ROS-regulating properties solve the problem of the instability of ROSbased therapeutics. In this section, nanozymes catalytic mediated cancer therapies are discussed, which cover (photodynamic therapy) PDT, chemodynamic therapy (CDT), sonodynamic therapy (SDT) and photothermal therapy (PTT). Furthermore, the Metal and metal oxide-based nanozymes for antimicrobial therapies are summarized.

\section{Chemodynamic therapy (CDT)}

Chemodynamic therapy (CDT) is an emerging cancer treatment strategy that damage tumor cells with a localized Fenton reaction. In CDT process iron mediated Fenton reaction induces intracellular oxidative stress by converting less reactive $\mathrm{H}_{2} \mathrm{O}_{2}$ into $\mathrm{OH}$., one of the most detrimental ROS $[105,106]$. Up to now, iron oxide and other metal oxide nanocomposite enzyme mimic are capable of decomposing $\mathrm{H}_{2} \mathrm{O}_{2}$ into $\mathrm{OH}$. through Fenton-like reactions [107]. Researchers have been widely studied CDT treatment method because of its high tumor specificity, lower side effects and minimal invasiveness. Generally, transition metal ions (e.g., Fe, Co, $\mathrm{Ni}, \mathrm{Cu}$, and $\mathrm{Mn}$ ) used as the CDT agents to catalyze the decomposition of hydrogen peroxide $\left(\mathrm{H}_{2} \mathrm{O}_{2}\right)$ and produce high-toxicity hydroxyl radicals $(\cdot \mathrm{OH})$ (Typical reaction: $\left.\mathrm{Fe}^{2+}+\mathrm{H}_{2} \mathrm{O}_{2} \rightarrow \mathrm{Fe}^{3+}+\cdot \mathrm{OH}+\mathrm{OH}^{-}\right)$. Biomolecular substances including nucleic acids, lipids and proteins in tumor cells are destroyed as a result of oxidative stress $[108,109]$. Conceivably, some challenges like overexpressed glutathione (GSH) and nicotinamide adenine dinucleotide phosphate (NADPH) in tumor cells, low $\mathrm{H}_{2} \mathrm{O}_{2}$ concentration and requirement of strong acidic chemical environment obstacles CDT. Lin et al. reported enhanced chemodynamic therapy based on $\mathrm{MnO}_{2}$ nanoagent with Fenton-like $\mathrm{Mn}^{2+}$ delivery and GSH depletion properties [110]. The $\mathrm{MnO}_{2}$ was established on the surface of thiol-functionalized mesoporous silica (MS) NPs, leading to the formation of $\mathrm{MnO}_{2}$-coated MS NPs (MS@ $\mathrm{MnO}_{2} \mathrm{NPs}$ ). Upon uptake of the $\mathrm{MS} \mathrm{MnO}_{2} \mathrm{NPs}$ by cancer cells, the $\mathrm{MnO}_{2}$ layer would simultaneously release $\mathrm{Mn}^{2+}$ with superior Fenton-like activity to transform endogenous $\mathrm{H}_{2} \mathrm{O}_{2}$ produced into the highly toxic $\mathrm{OH}$. and deplete intracellular GSH to inhibit $\mathrm{OH}$. scavenging (Fig. 10a, b). As well as, the potential of $\mathrm{MnO}_{2}$ shell as a 


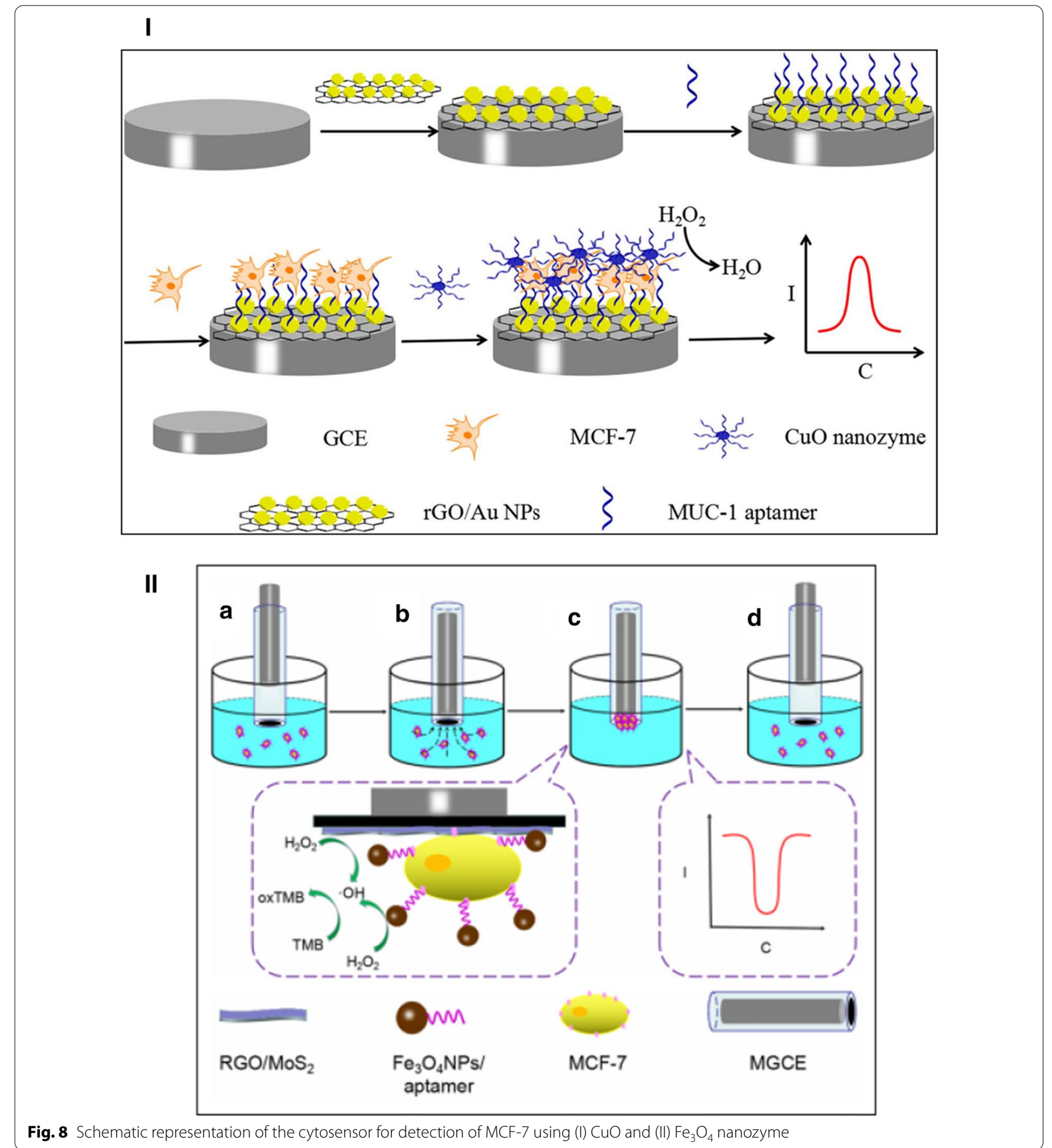

gatekeeper for controlled drug release showed by loading hydrophobic anticancer drug camptothecin (CPT) into the PEGylated MS@MnO 2 NPs. Hematoxylin and eosin $(\mathrm{H} \& \mathrm{E})$-stained images demonstrated that tumor tissues treated with $\mathrm{MS} @ \mathrm{MnO}_{2}$-CPT suffered more intense damage than other control group, which indicates enhanced chemodynamic efficacy of $\mathrm{MS} @ \mathrm{MnO}_{2}-\mathrm{CPT}$ for theranostic applications (Fig. 10c).

Until now, almost all developed CDT agents are acidity dependent (optimum Fenton reaction $\mathrm{pH}$ : 2-4) and a few studies have been carried out to develop wide $\mathrm{pH}$ rangeresponsive CDT agents [111]. However, the neutral-pH 


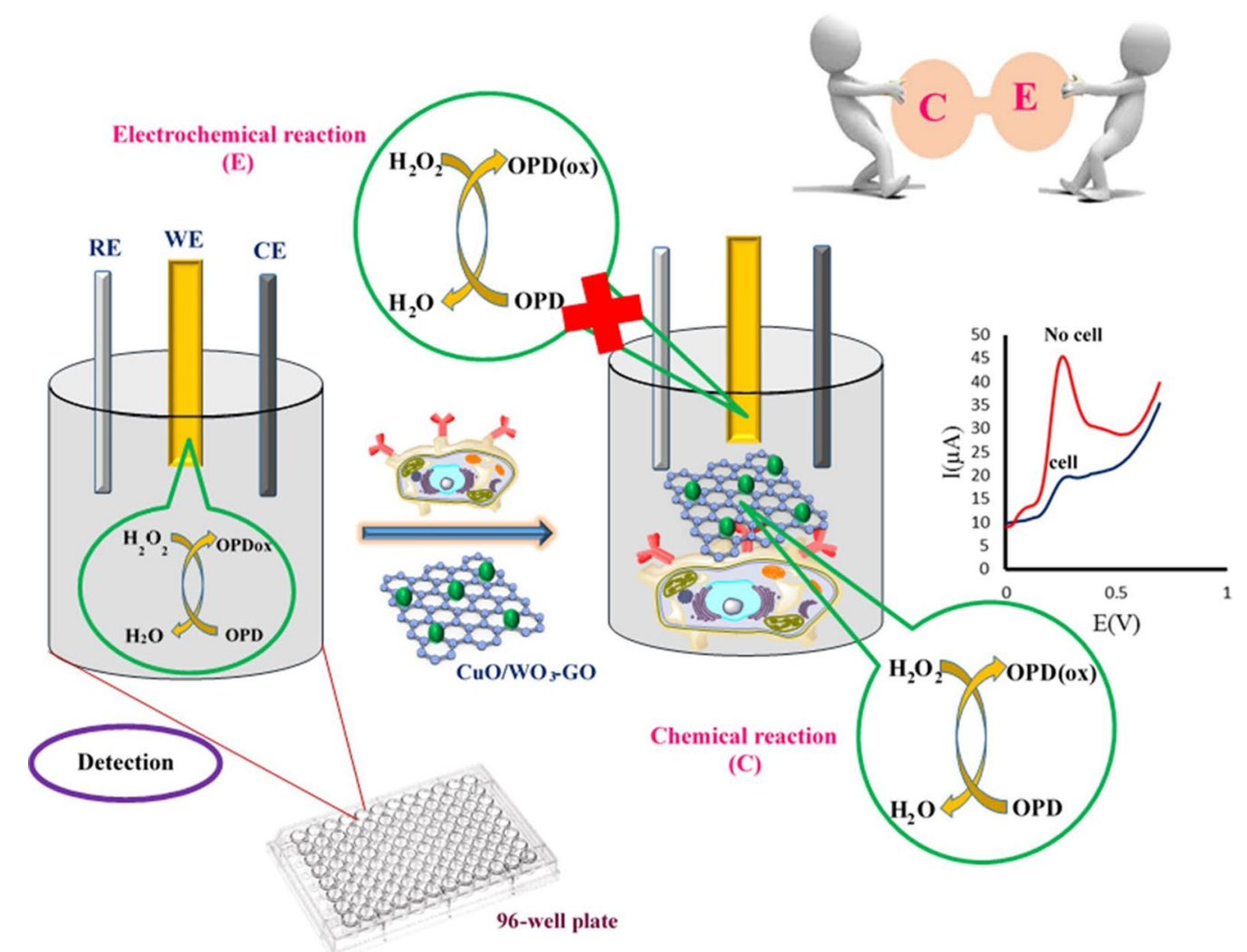

Fig. 9 Schematic illustration of obtained chemical /electrochemical reactions and peroxidase activity of $\mathrm{CuO} / \mathrm{WO}_{3}$ - $\mathrm{GO}$ for cancer cell detection

conditions at the solid tumor surface resulting from abundant vessel distribution and sufficient oxygen supply undo the effect of acidity-activated nanoagents and even induce tumor recurrence and metastasis after treatment [112, 113]. Zhao's group synthesized Ferrous-cysteinephosphotungstate nanoagent for enhanced cancer chemodynamic therapy that breaks through the limitation of a neutral $\mathrm{pH}$ [114]. The advantages from the addition of phosphotungstate and cysteine to formation of a $\mathrm{Fe}^{3+}$ chelating complex inhibited the formation of inert $\mathrm{Fe}(\mathrm{OH}) \mathrm{x}$, and accelerate electron transfer between ferric and ferrous ions, respectively (Fig. 11a).

To investigate the $\mathrm{OH}$. generation ability of the ferrouscysteine-phosphotungstate nanoparticles (FcPWNPs), electron spin resonance (ESR) spectroscopy is conducted. As can be seen in Fig. 11b, FcPWNPs show representative hydroxyl radicals with $\mathrm{pH}$-dependent tendency. The strong cytotoxicity against cancer cells with an $\mathrm{H}_{2} \mathrm{O}_{2}$ dose-dependent tendency was achieved inspired by the high $\mathrm{OH}$ - production performance across a wide $\mathrm{pH}$ range, (Fig. 11c).

Although, compared with normal cells, many types of tumor cells have higher intracellular $\mathrm{H}_{2} \mathrm{O}_{2}$ levels, the endogenously generated $\mathrm{H}_{2} \mathrm{O}_{2}$ is still inadequate to obtain improved CDT efficacy [115]. Thereafter, their anticancer efficiency could be enhanced by the introduction of $\mathrm{H}_{2} \mathrm{O}_{2}$-supplementing functionality into CDT agents. Lin et al. developed copper peroxide nanodots for $\mathrm{H}_{2} \mathrm{O}_{2}$ self-supplying chemodynamic therapy [116]. Copper peroxide $\mathrm{CP}$ nanodots were prepared through the binding of $\mathrm{H}_{2} \mathrm{O}_{2}$ to $\mathrm{Cu}^{2+}$ in the presence of poly (vinylpyrrolidone) (PVP) as stabilizer at room temperature. This Fenton-type peroxide nanomaterial utilized as an activatable agent for enhanced CDT by self-supplying $\mathrm{H}_{2} \mathrm{O}_{2}$ (Fig. 12a). Upon acid treatment, the reversible decomposition of $\mathrm{CP}$ nanodots into Fenton catalytic $\mathrm{Cu}^{2+}$ and $\mathrm{H}_{2} \mathrm{O}_{2}$ occurred.

$2^{\prime}, 7^{\prime}$-dichlorofluorescin diacetate (DCFHDA), the fluorescent ROS indicator, was applied to evaluate the production of $\mathrm{OH}$. by $\mathrm{CP}$ nanodots at the cellular level. Deacetylation of DCFH-DA and formation of nonfluorescent DCFH was accomplished by intracellular esterases, which can be oxidized by ROS and then emits green fluorescence [117]. It was shown in Fig. 12.B that U87MG cancer cells incubated with CP nanodots exhibited significantly higher green fluorescence than untreated control cells, indicating the ability of $\mathrm{CP}$ nanodots to generate $\mathrm{OH}$. within tumor cells. 


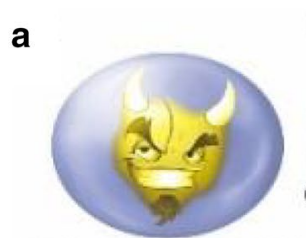

Cell with potent ADS

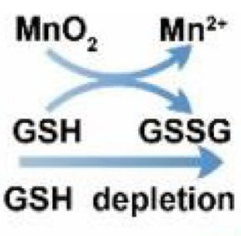

GSH depletion

b Cell with impaired ĀDS

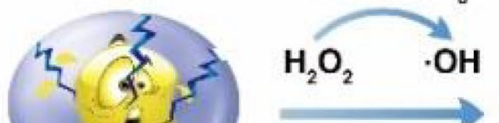

Enhanced CDT
Cell death

\section{Cell death}

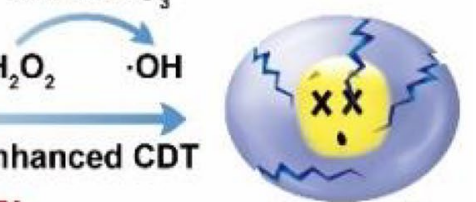

$\mathrm{MS} @ \mathrm{MnO}_{2} \mathrm{NPS}$

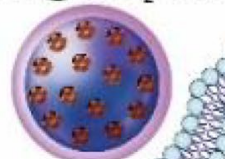

\section{ADS}

-

$\mathrm{Mn}^{2+} / \mathrm{HCO}_{3}^{-}$

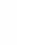

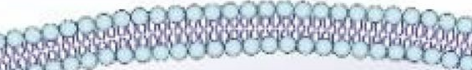

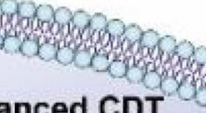

1. GSH depletion-enhanced CDT

$\mathrm{HCO}_{3}$.
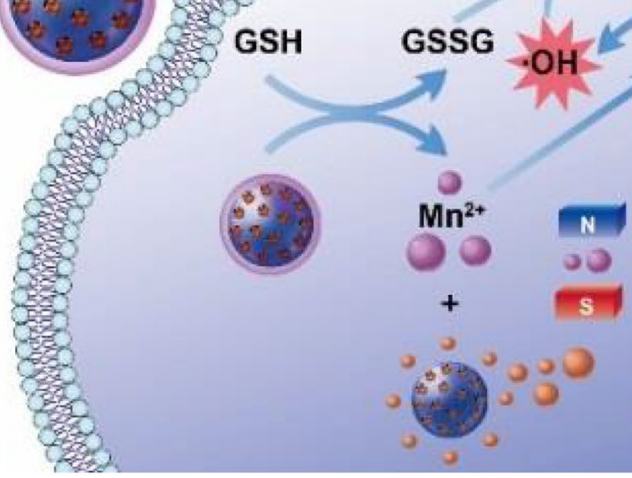

2. Activatable MRI

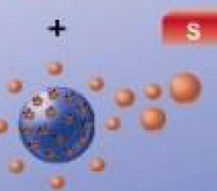

3. Controlled drug release

C

PBS

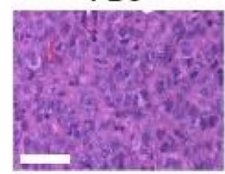

MS NPS

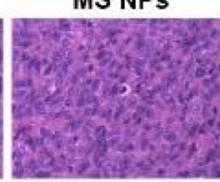

Free CPT

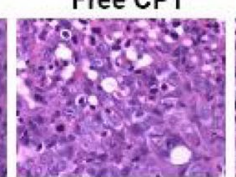

$\mathrm{MS} @ \mathrm{MnO}_{2} \mathrm{NPS}_{2} \times \mathrm{MS} @ \mathrm{MnO}_{2} \mathrm{NPS} \mathrm{MS} @ \mathrm{MnO}_{2}-\mathrm{CPT}$

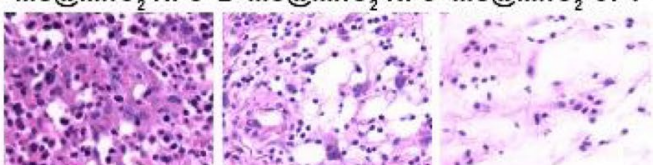

Fig. 10 a The mechanism of $\mathrm{MnO}_{2}$ as a smart chemodynamic agent for enhanced CDT of cancer. Upon endocytosis, the $\mathrm{MnO}_{2}$ can react with intracellular GSH to produce GSSG and $\mathrm{Mn}^{2+}$, which exerts excellent Fenton-like activity to generate highly reactive $\mathrm{OH}$. from endogenous $\mathrm{H}_{2} \mathrm{O}_{2}$ in the presence of physiological HCO3-. The impairment of antioxidant defense system (ADS) resulting from GSH depletion makes cancer cells more vulnerable to $\mathrm{OH}$. formed in $\mathrm{Mn}^{2+}$-mediated Fenton-like process, enabling enhanced CDT. b Schematic illustrating the application of ${\mathrm{MS} @ \mathrm{MnO}_{2}}$ NPs for MRI-monitored chemo-chemodynamic combination therapy. $\mathbf{c}$ H\&E-stained images of tumor sections from different groups. Scale bar, $100 \mu \mathrm{m}$

Therapeutic selectivity, characteristic differences between healthy and cancer cells, is one of the critical factors in development of cancer therapies. Due to rapidly proliferating, cancer cells have high $\mathrm{H}_{2} \mathrm{O}_{2}$ levels with a low catalase level in comparison with normal cells. In this regard, $\mathrm{SnFe}_{2} \mathrm{O}_{4}$ nanocrystals were employed for selective killing of lung cancer cells by catalase-modulating heterogeneous Fenton reaction [118]. A working mechanism of this developed assay is the inhibition of the heterogeneous Fenton reaction in normal cells with catalase through decomposition of $\mathrm{H}_{2} \mathrm{O}_{2}$ (Fig. 13a). Furthermore, the sonicated $\mathrm{SnFe}_{2} \mathrm{O}_{4}$ nanocrystals demonstrated much higher efficiency than the non-sonicated nanocrystals to produce the hydroxyl radicals. Therefore, the sonicated $\mathrm{SnFe}_{2} \mathrm{O}_{4}$ nanocrystals in presence of catalase exhibited low cell viability compared with test cells treated with non-sonicated nanocrystals without catalase (Fig. 13b).

In cancer therapy, DOX can activate nicotinamide adenine dinucleotide phosphate (NADPH) oxidases (NOXs) for transportation of electrons across the membrane. The activated NOXs can catalyze NADPH into $\mathrm{NADP}^{+}$along with the release of electrons. Thus, the oxygen captures the electrons to produce the superoxide anion radical $\left(\mathrm{O}_{2}^{-}\right.$.) and afterward product the $\mathrm{H}_{2} \mathrm{O}_{2}$ by disproportionation reaction with superoxide dismutase (SOD) enzyme 

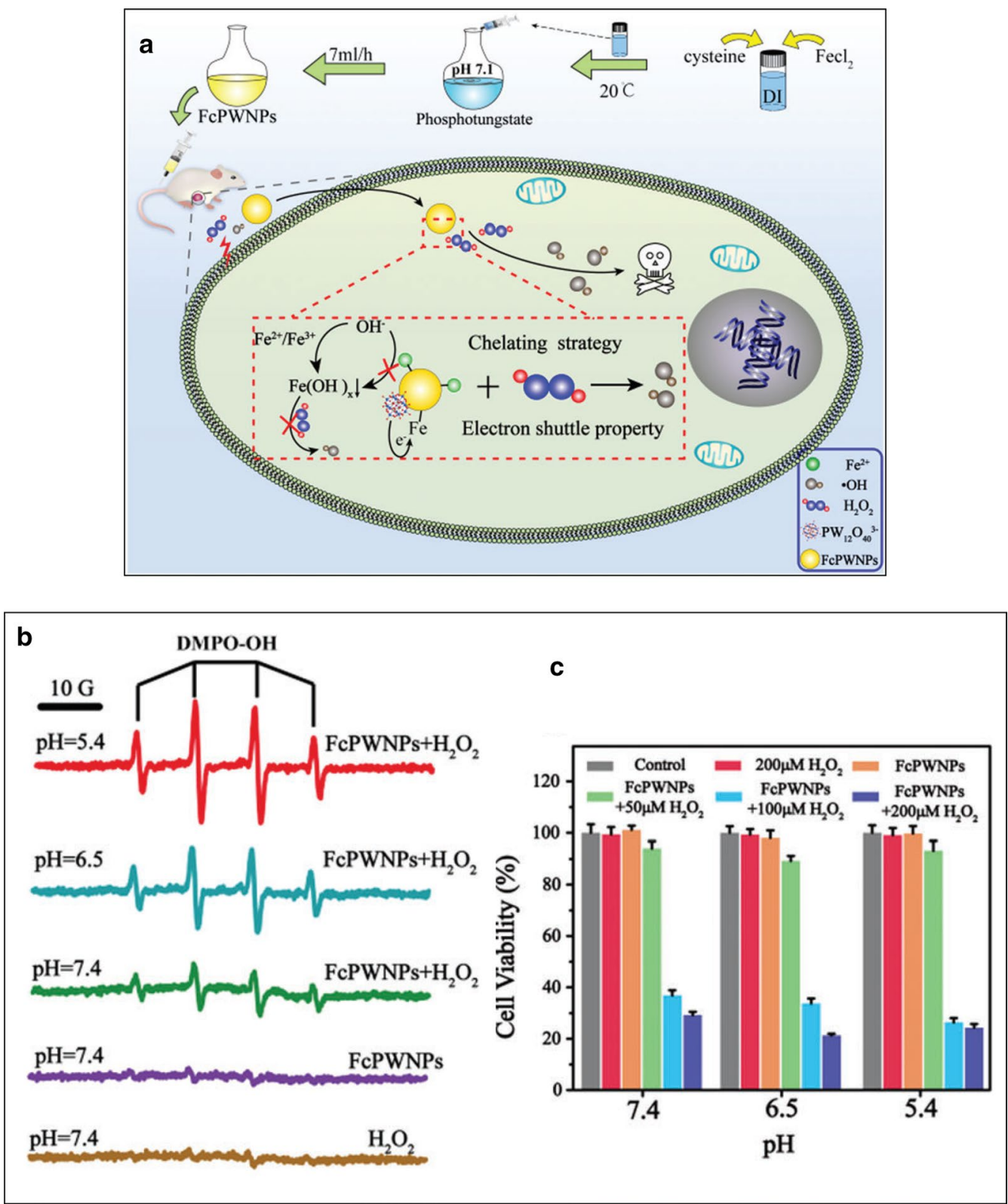

Fig. 11 a Schematic illustrating the synthesis process and mechanism for FcPWNP mediated pH independent high efficiency CDT, b ESR spectra of different groups treated with DMPO; FcPWNPs: Fe concentration of 80 ppm, and $\mathrm{H}_{2} \mathrm{O}_{2}: 1 \mathrm{mM}$. c The growth inhibition effect on 4T1 cells of different groups after $24 \mathrm{~h}$ of incubation. (Fe element: 40 ppm, $\mathrm{H}_{2} \mathrm{O}_{2}: 200,100$ and $50 \mathrm{mM}, \mathrm{pH} 7.4,6.5$ and 5.4). ( $n=6$, mean \pm SD)

[119-121]. In Fenton reactions, iron oxide core-shell mesoporous silica $\left(\mathrm{Fe}_{3} \mathrm{O}_{4} @ \mathrm{MSN}\right)$ nanocarrier promoted oxygen species levels reactive for cancer therapy [122]. $\mathrm{Fe}_{3} \mathrm{O}_{4} @ M S N-T P P / P E G-F A$ was formed by conjugation of $\mathrm{Fe}_{3} \mathrm{O}_{4} @ \mathrm{MSN}$ with folate (PEG-FA) and mitochondrial targeting triphenylphosphonium (TPP). Then, $\mathrm{Fe}_{3} \mathrm{O}_{4} @$ MSN-TPP/PEG-FA encapsulated doxorubicin (DOX) and 3-amino-1,2,4-triazole (AT) for cancer therapy
(Fig. 14I). AT, as a catalase inhibitor inhibits the catalase activity to save the production of $\mathrm{H}_{2} \mathrm{O}_{2}$. The assessment of ROS level induced by DOX/AT-loaded $\mathrm{Fe}_{3} \mathrm{O}_{4} @ \mathrm{MSN}$ TPP/PEG-FA in MCF-7 and MGC-803 cells showed that green fluorescence was gradually improved after different incubation times (Fig. 14II). The results proved the significant elevation of the intracellular ROS level stimulated

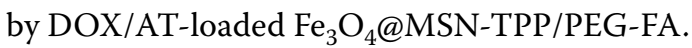




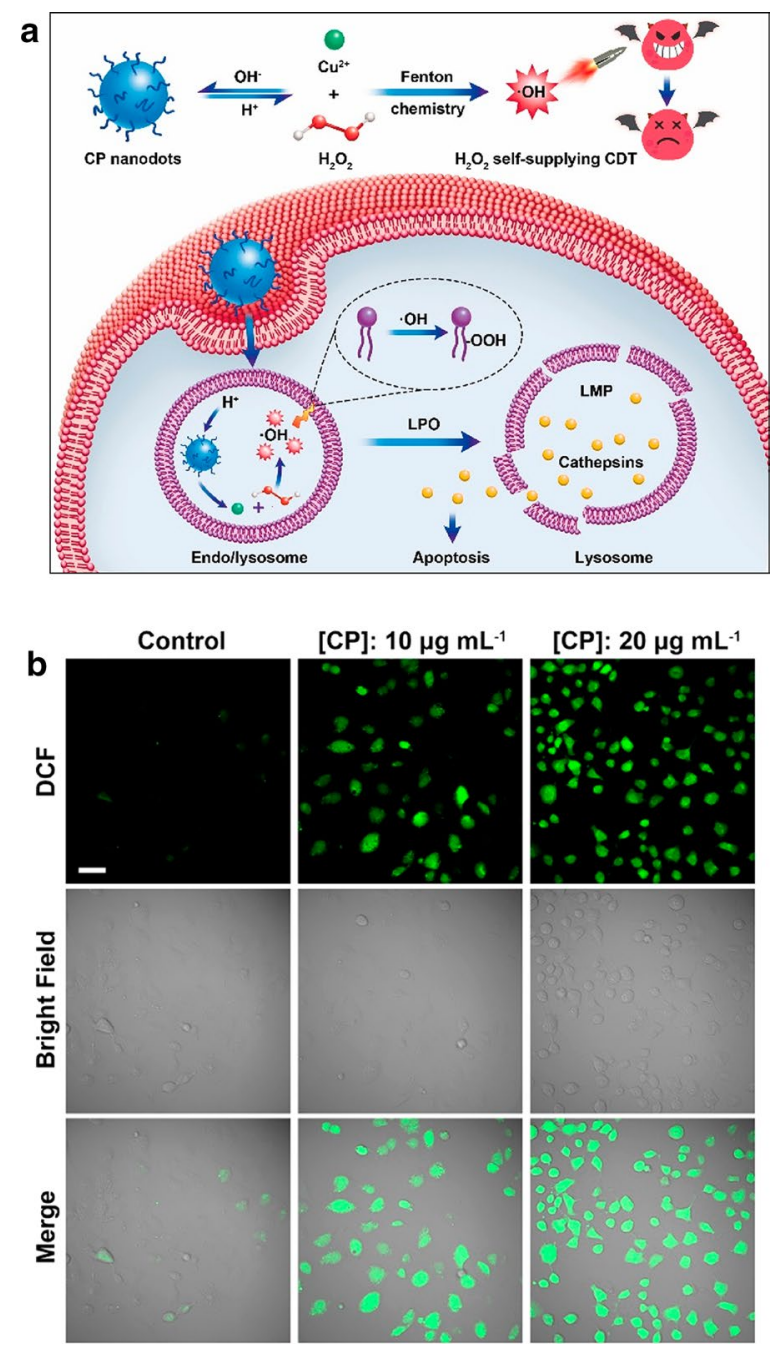

Fig. 12 a Formation of CP Nanodots for $\mathrm{H}_{2} \mathrm{O}_{2}$ Self-Supplying CDT, b Fluorescence images of DCFH-DA-stained U87MG cancer cells after exposure to different concentrations of $\mathrm{CP}$ nanodots for $4 \mathrm{~h}$. The scale bar represents $50 \mu \mathrm{m}$

\section{Photodynamic therapy (PDT)}

Photodynamic therapy (PDT) is the most versatile minimal invasive manner of cancer therapy, which involves the production of cytotoxic reactive oxygen species (ROS) by light activation of photosensitizers [123, 124]. The produced ROS induce cell apoptosis or necrosis, microvascular damage and immune responses. Aggressive proliferation of cancer cells and an insufficient blood supply in tumors decrease $\mathrm{O}_{2}$ concentration. The $\mathrm{O}_{2}$ deficiency in tumors leads to a significantly reduced antitumor efficacy of PDT [125-127]. In PDT, $\mathrm{O}_{2}$ employs to produce ROS, so, hypoxia obviously arises during PDT. Hypoxia, yielded from the imbalance between oxygen supply and consumption, is a great indicator of cancer progression. Since, $\mathrm{O}_{2}$ is a necessary component in PDT and hypoxia prevents effective cancer treatments [128, 129]. In view of this, tremendous attention has been attracted to overcome tumor hypoxia. Recently, various nanomaterials with catalase like activity, have been employed to catalytically generate $\mathrm{O}_{2}$ to mitigate cancer hypoxia. For example, manganese ferrite nanoparticle-anchored mesoporous silica nanoparticles to eliminate hypoxia and efficient photodynamic therapy [130]. Manganese ferrite nanoparticles (MFNs) act as a Fenton catalyst for decomposition of $\mathrm{H}_{2} \mathrm{O}_{2}$ and continuous $\mathrm{O}_{2}$ generation. The level of hypoxia can be examined based on HIF- $1 \alpha$ amounts, because hypoxia-inducible factor (HIF-1 $\alpha$ ) protein is adjusted under hypoxic condition [131]. As can be seen in Fig. 15, when the cancer cells were treated with manganese ferrite nanoparticle-anchored mesoporous silica nanoparticles (MFMSNs), the fluorescence intensity of HIF- $1 \alpha$ has decreased in concentration dependent manner, suggesting the capability of MFMSNs to reducing hypoxia via $\mathrm{O}_{2}$ production after cellular uptake.

In another study, Zhang et al. used $\mathrm{MnO}_{2}$ nanodots to promote dissolved oxygen concentration and overcome hypoxia limitations [132]. The PDT nanoplatform is fabricated by one-pot encapsulating g- $\mathrm{C}_{3} \mathrm{~N}_{4}$ and DOX in ZIF8, then loading $\mathrm{MnO}_{2}$ nanodots and surface-modifying F127 (F127-MnO2-ZIF@DOX/C3N4, donated as FMZ/ DC). F127 with excellent biocompatibility and amphiphilic nature is chosen as a stabilizing agent. Encapsulation into $\mathrm{pH}$-dependent ZIF-8 carrier reduces the side effects of DOX induced by nonspecific drug release. In addition, g-C3N4, a prominent visible-light photocatalyst, could efficiently generate ROS and kill cancer cells (Fig. 16a, b). The efficacy of the tested materials to the living body was confirmed by measuring the tumor sizes of mice during the healing process (Fig. 16c, d).

$\mathrm{MnO}_{2}$ biomimetic nanozyme could be integrated glucose oxidase (GOx) enzyme for improved starvation and photodynamic therapy [133]. GOx can oxidize glucose to gluconic acid and $\mathrm{H}_{2} \mathrm{O}_{2}$, which is capable of tumor starvation therapy. Meanwhile, $\mathrm{MnO}_{2}$ accelerated $\mathrm{O}_{2}$ production with the aid of a large amount of $\mathrm{H}^{+}$from oxidation product gluconic acid. This $\mathrm{O}_{2}$ supply decreases tumor hypoxia and promotes PDT effectiveness (Fig. 17).

To achieve more stability and hinder the aggregation of small size mimicking enzyme nanoparticles, Zhang's group decorated Pt nanozymes on photosensitizers integrated MOFs for enhanced photodynamic therapy [134]. Pt nanoparticles with catalase like activity were decorated on porous coordination network-224 (PCN-224). The PCN-224-Pt could assist the formation of ${ }^{1} \mathrm{O}_{2}$ in hypoxic tumor site via decomposition of $\mathrm{H}_{2} \mathrm{O}_{2}$ for producing $\mathrm{O}_{2}$, which could be employed for enhanced photodynamic therapy (Fig. 18I). Decreased in immonufluorescence intensity of HIF- $1 \alpha$ for treated tumor slices with 
a

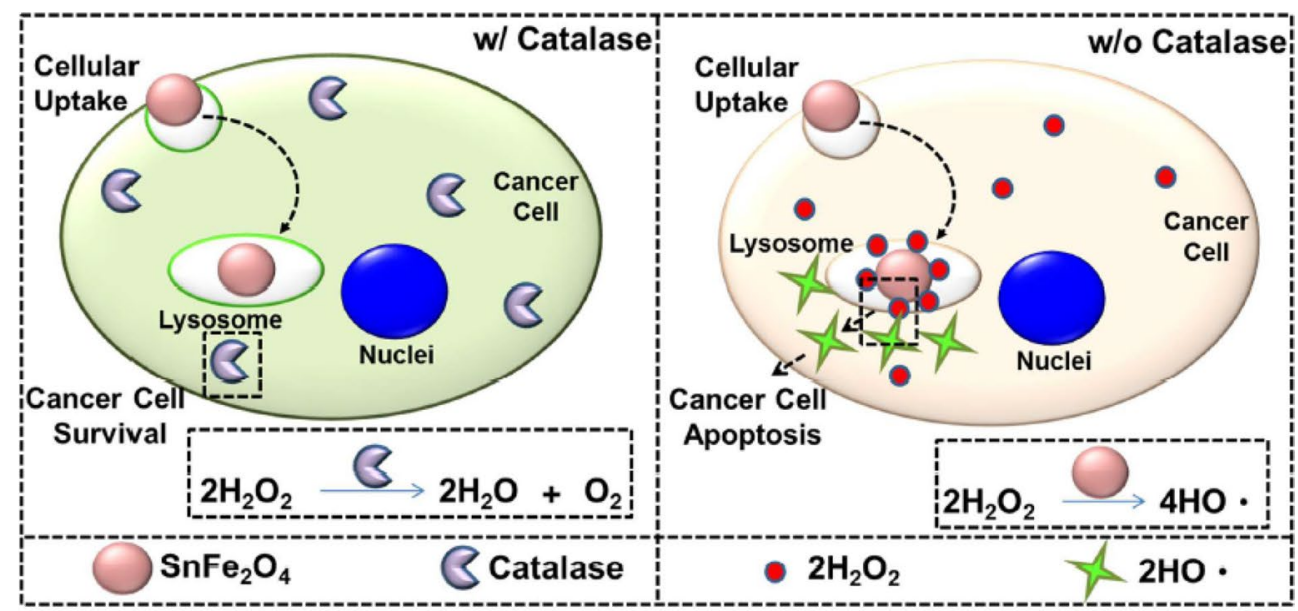

b

Non-Sonicated
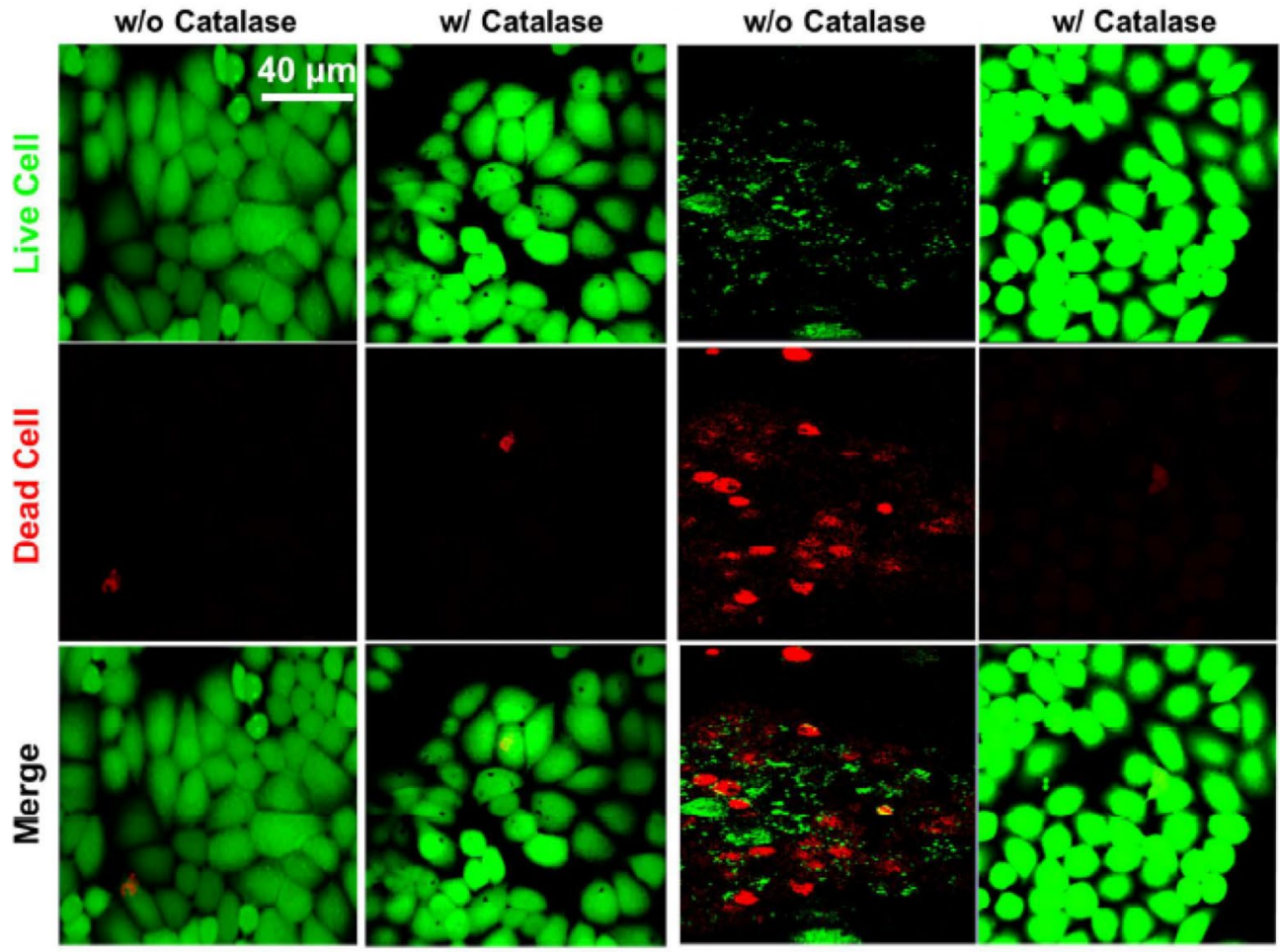

Fig. 13 a Illustration showing internalized $\mathrm{SnFe}_{2} \mathrm{O}_{4}$ nanocrystals performing cytotoxic effect on cancer cells intracellularly and non-cytotoxic effect on cancer cells in presence of catalase. $\mathbf{b}$ Fluorescent images of slices co-stained with LIVE(green)/DEAD(red), viability/cytotoxicity assay kit for test cells

PCN-224-Pt indicated remove the hypoxia limitation by Pt NPs on PCN-224-Pt (Fig. 1). In the case of tumors of mice injected with $\mathrm{PCN}-224$, tumor growth was completely inhibited after irradiation treatment (Fig. 18II).

It is reported that the activities of enzyme mimics are correlated with their nanostructures [135]. For instance,
$\mathrm{MoO}_{3}-\mathrm{x}$ nanourchins (NUs) exhibited a structuredependent enzymatic activity with therapeutic effect in tumor microenvironment via cascade catalytic reactions [136]. In this design, $\mathrm{MoO}_{3}-\mathrm{x}$ NUs possess high proportion of active $\mathrm{Mo}^{\mathrm{V}}$ atoms and large active surface area, induce catalase (CAT)-like activity to produce a 
I
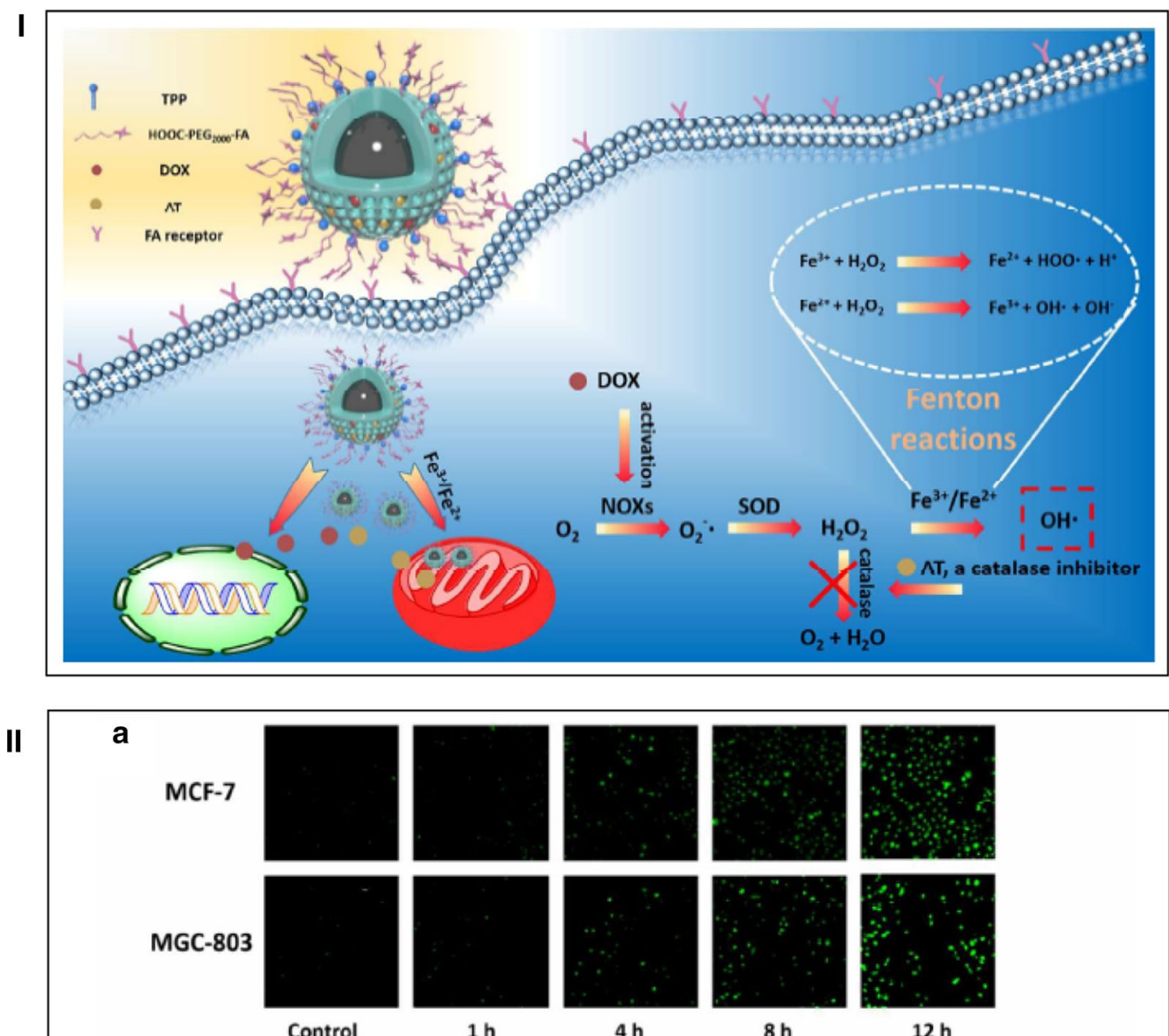

b
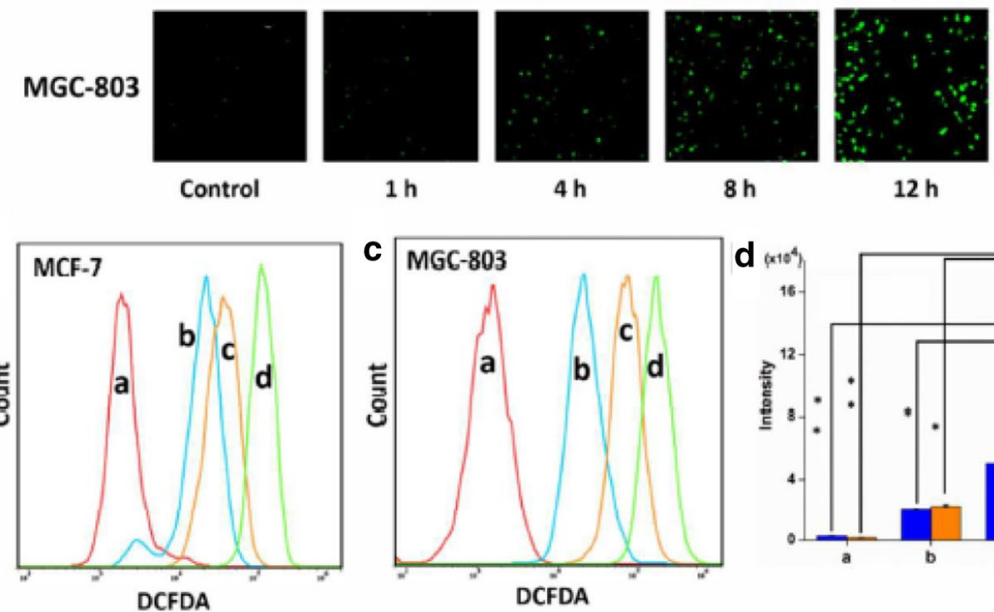

$1 \mathrm{~h}$

$4 \mathrm{~h}$

$8 \mathrm{~h}$

$12 \mathrm{~h}$
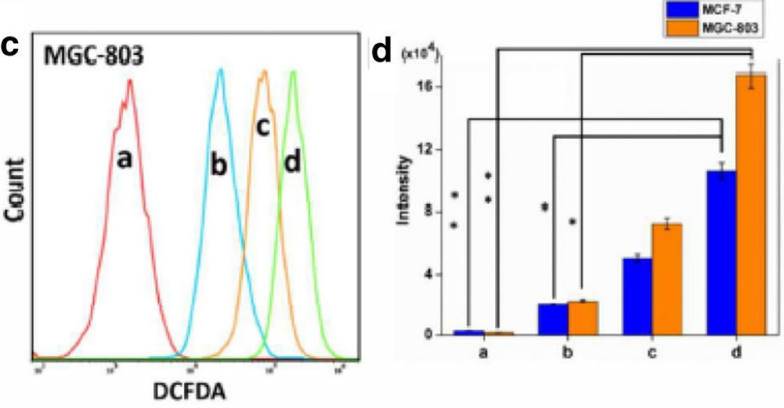

Fig. 14 IThe DOX/AT loaded Fe3O4@MSN-TPP/PEG-FA accumulated in the tumor cells by recognition of folate receptors and further targeted to mitochondria by TPP-mediated effect. In this study, excessively toxic $\mathrm{OH}$. which could induce cell death were generated by a series of biochemical reactions. II Evaluation of ROS generating capability of DOX/AT-loaded Fe $\mathrm{O}_{4} @$ @MSN-TPP/PEG-FA in vitro. (A) CLSM images of MCF-7 and MGC-803 cells incubated with DOX/AT-loaded Fe $\mathrm{O}_{4} @ M S N$-TPP/PEG-FA for different incubation time. Flow cytometry assay ROS level of MCF-7 cells (B) and

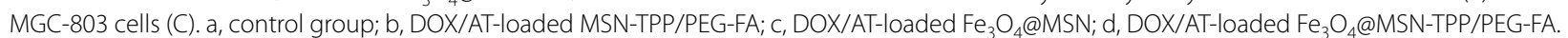
(D) The analysis of flow cytometry. $(n=3) .{ }^{*} P<0.05$ and ${ }^{*} P<0.01$

large amount of $\mathrm{O}_{2}$ for subsequent oxidase (OXD)-like reactivity (Fig. 19). The reactivity of $\mathrm{MoO}_{3}-\mathrm{x}$ NUs in acidic PBS is much higher than that in neutral or alkaline; thus, $\mathrm{MoO}_{3}-\mathrm{x}$ NUs would rapidly lose the enzymatic activity and leave normal tissues unharmed in a physiological environment ( $\mathrm{pH} \sim 7.4)$.

\section{Photothermal therapy (PTT)}

Photothermal therapy (PTT) is a treatment modality with minimum side effects, which involves the artificial elevation of the tissue temperature. PTT agents capture near-infrared (NIR) light and convert it into heat, causing 

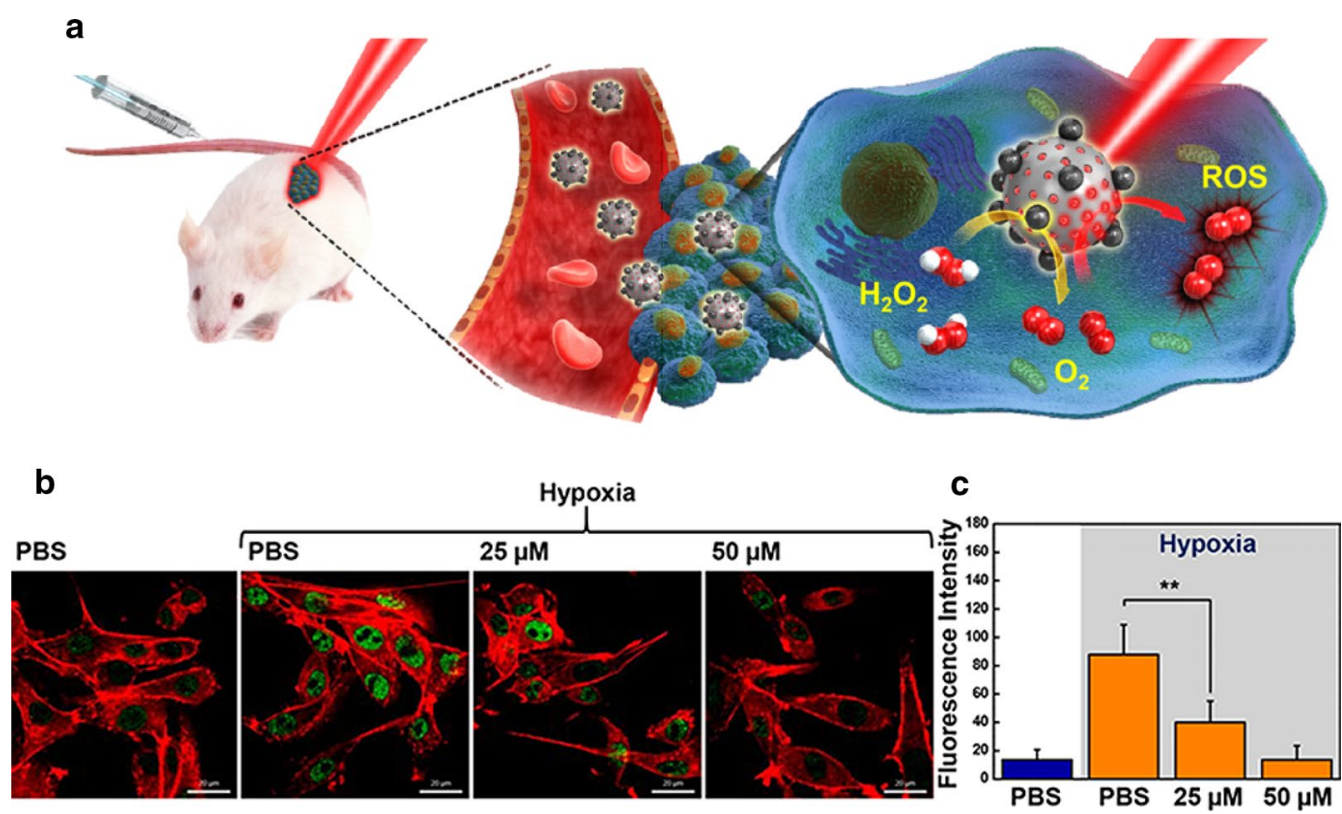

Fig. 15 a Schematic illustration of MFMSNs. b CLSM images of HIF-1a (green) and F-actin (red) in cells incubated with MFMSN under normoxic or hypoxic condition, and c corresponding fluorescence intensity $(n=3)$. Scale bar, $20 \mu \mathrm{m}$. ${ }^{*} P<0.01$

tumor cells apoptosis [137-139]. Without any laser exposure,

PTT agents are nontoxic and relatively safe to cells. In compare with traditional tumor treatment models including radiotherapy, surgery, and chemotherapy, PTT is attractive because of certain advantages, such as reduced invasiveness and high specificity [140, 141]. Nevertheless, tumor cells usually cannot be completely killed by photothermal treatment alone, finally resulting in tumor recurrence [142]. Thus, to further enhance the therapeutic performance of PTT, the enzyme-mimicking performance of nanozymes can be employed.

Au nanoparticles (Au NPs) are one of the most widely studied photothermal agents owing to their effective local heating upon excitation of surface plasmon oscillations. Besides, many studies displayed that Au NPs possess enzyme-like activities [143]. In this regard, Fan's group utilized yolk-shell gold@carbon nanozymes Tumor catalytic-photothermal therapy [144]. A hollow carbon nanospheres with porous shell (Au@HCNs) exhibited high oxidase-like and peroxidase-like activity enzyme activities. Meanwhile, Au@HCNs outstanding near-infrared light (NIR) absorbing agents for convert light into heat for tumor photothermal therapy (PTT). The enzyme-mimicking functions significantly improved by the photothermal effect, leading to large amounts production of ROS to destruct cancer cells. Tumor mice have been exposed with different groups of agents with or without NIR irradiation. The results showed that the tumors treated with Au@HCNs under 808-nm laser irradiation were completely destroyed without recurrence during the treatment (Fig. 20).

Nanoceria $\left(\mathrm{NCeO}_{2}\right)$ decorated flower-like $\mathrm{MoS}_{2}$ nanoflakes reported as a nanozyme for cancer photothermal therapy (PTT) [145]. Polyethylenimine (PEI) coated flower-like $\mathrm{MoS}_{2}$ nanoflakes surface decorated with cerium oxide NPs to formation of $\mathrm{NCeO}_{2}$-PEI-MoS $\mathrm{M}_{2}$. The $\mathrm{NCeO}_{2}$ decoration considerably enhanced the photoconversion effectiveness (PCEs) of $\mathrm{MoS}_{2}$ nanoflakes. The different effects of $\mathrm{NCeO}_{2}-\mathrm{PEI}-\mathrm{MoS}_{2}$ nanoflakes on cancer and normal cells were due to multi-enzyme mimics of $\mathrm{NCeO}_{2}$. Normal cells protect against oxidative damage via neutralization of free superoxide radicals and hydrogen peroxide by superoxide dismutase (SOD) and catalase enzyme mimic to decompose $\mathrm{H}_{2} \mathrm{O}_{2}$ into water and $\mathrm{O}_{2}$. Although, in acidic cancer cell $\mathrm{NCeO}_{2}$ work as a Fenton-like catalyst that dismutates $\mathrm{H}_{2} \mathrm{O}_{2}$ to $\mathrm{OH}$. Next, $\mathrm{O}_{2}{ }^{--}$and $\mathrm{H}_{2} \mathrm{O}_{2}$ are formed by dismutating $\mathrm{CO}_{2}$ or ordinary molecular oxygen $\left(\mathrm{O}_{2}\right)$. The formed.

ROS species $\left(\mathrm{OH} \cdot \mathrm{O}_{2-} \cdot\right.$ and $\left.\mathrm{H}_{2} \mathrm{O}_{2}\right)$ induce oxidative stress leading to cell death or apoptosis in cancer cells (Fig. 21).

\section{Sonodynamic therapy (SDT)}

Ultrasound (US) can penetrate biological tissues, capable of activating sonosensitizers to generate toxic ROS molecules for cancer therapy modality named 
a

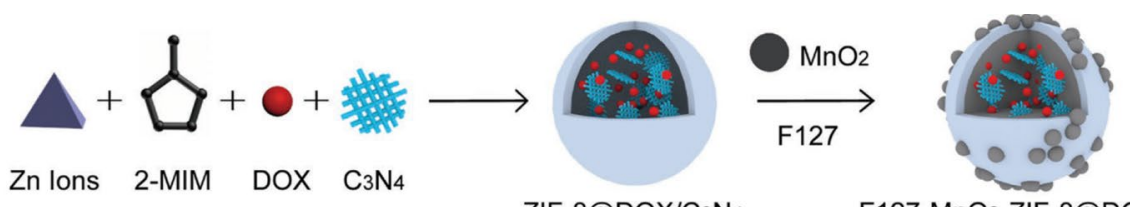

F127-MnO2-ZIF-8@DOX/C3N4

b

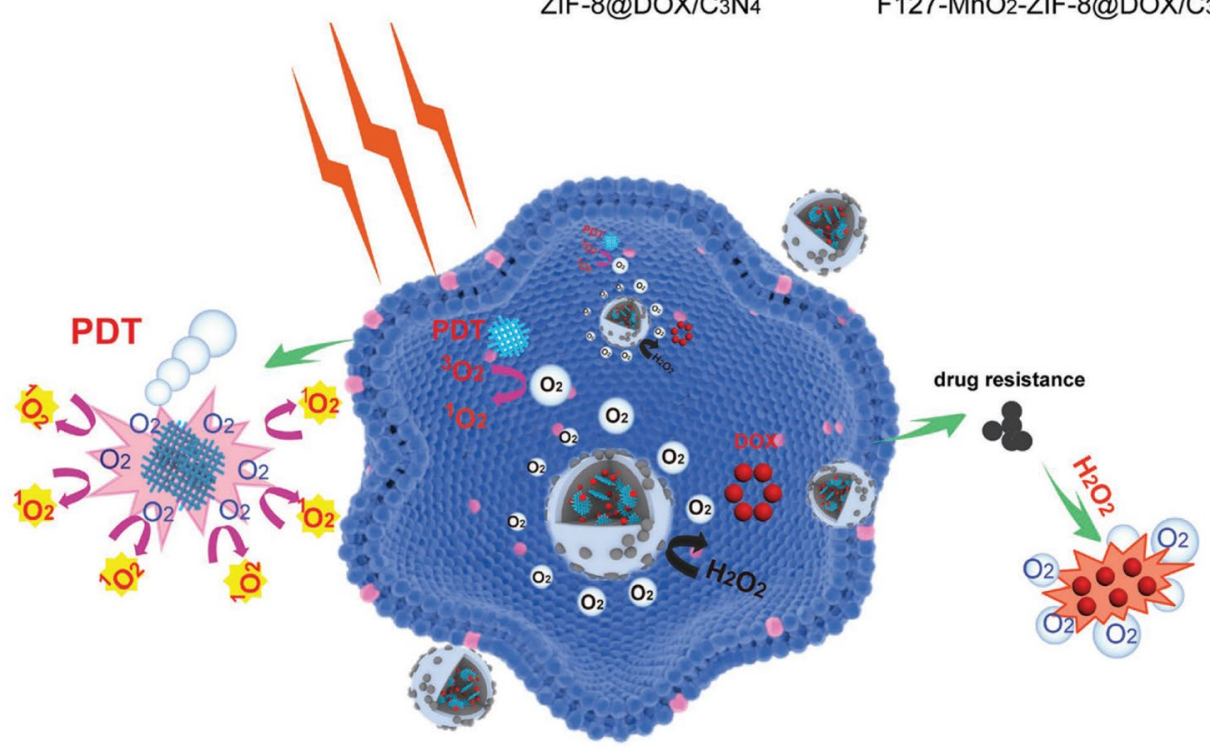

C

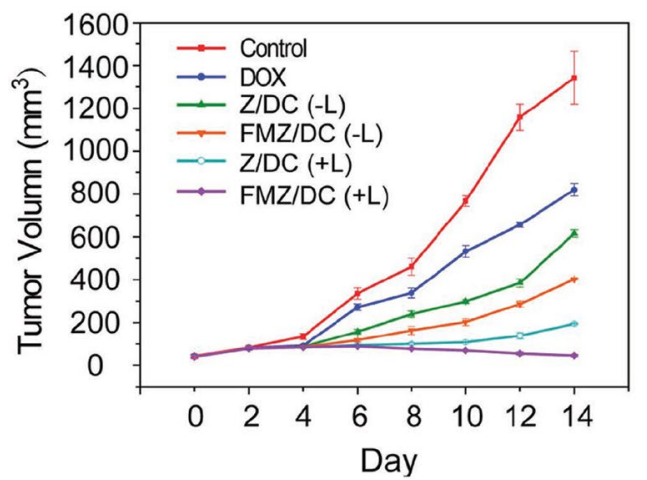

d

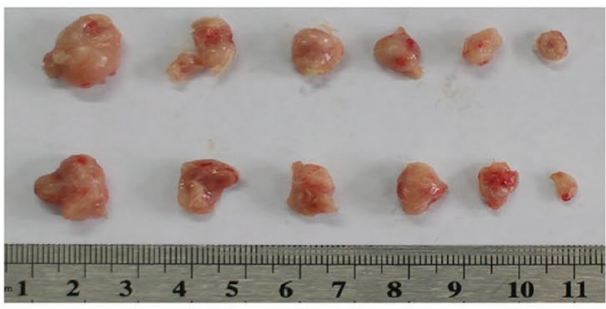

A $\quad$ B $\quad C \quad$ D $\quad E \quad F$

Fig. 16 a Schematic illustration of the fabrication of FMZ/DC nanocomposites. The diagram is not drawn to scale. b Schematic illustration of FMZ/ DC with oxygen generation enhancing the chemo-photodynamic therapy under $660 \mathrm{~nm}$ light irradiation. In vivo combination therapy of FMZ/ DC by intravenous administration into a 4T1 tumor mouse model. c Tumor growth curves of different groups of 4T1 tumor-bearing mice. The laser irradiation ( $+\mathrm{L}$ ) was carried out under $660 \mathrm{~nm}$ light at the power density of $5 \mathrm{~mW} \mathrm{~cm}-2$ for $30 \mathrm{~min}$. Error bars were based on five mice in each group. $\mathbf{d}$ Images of tumors collected from different groups of mice $14 \mathrm{~d}$ after different treatment: a control; B DOX; C, Z/DC (-L); $\mathbf{d}$ FMZ/DC (- L); $\mathbf{e}$ $\mathrm{Z} / \mathrm{DC}(+\mathrm{L}) ; \mathbf{f} \mathrm{FMZ/DC}(+\mathrm{L})$

sonodynamic therapy (SDT). SDT can obviate the severe issue of low tissue-penetrating depth of traditional phototriggered therapies, but the SDT efficiency is still not satisfactory in battling cancer [146-148]. In SDT, ultrasound (US) can trigger sonosensitizers to produce ROS, bubbles, cavitation and hyperthermia. it has a good therapeutic effect on the treatment of deep malignant tumors. SDT is a selective method for treatment of deep malignant tumors, because US can precisely focus on the tumor region, target to activate sonosensitizers, and minimize the damage to the adjacent normal organs and tissues [146, 149]. The solid tumor microenvironment (TME) appears when there is critical hypoxia because of $\mathrm{O}_{2}$ consumption during SDT [150]. Thereby, enzyme mimic nanomaterials can also work as the synergistic agents to boost the therapy 


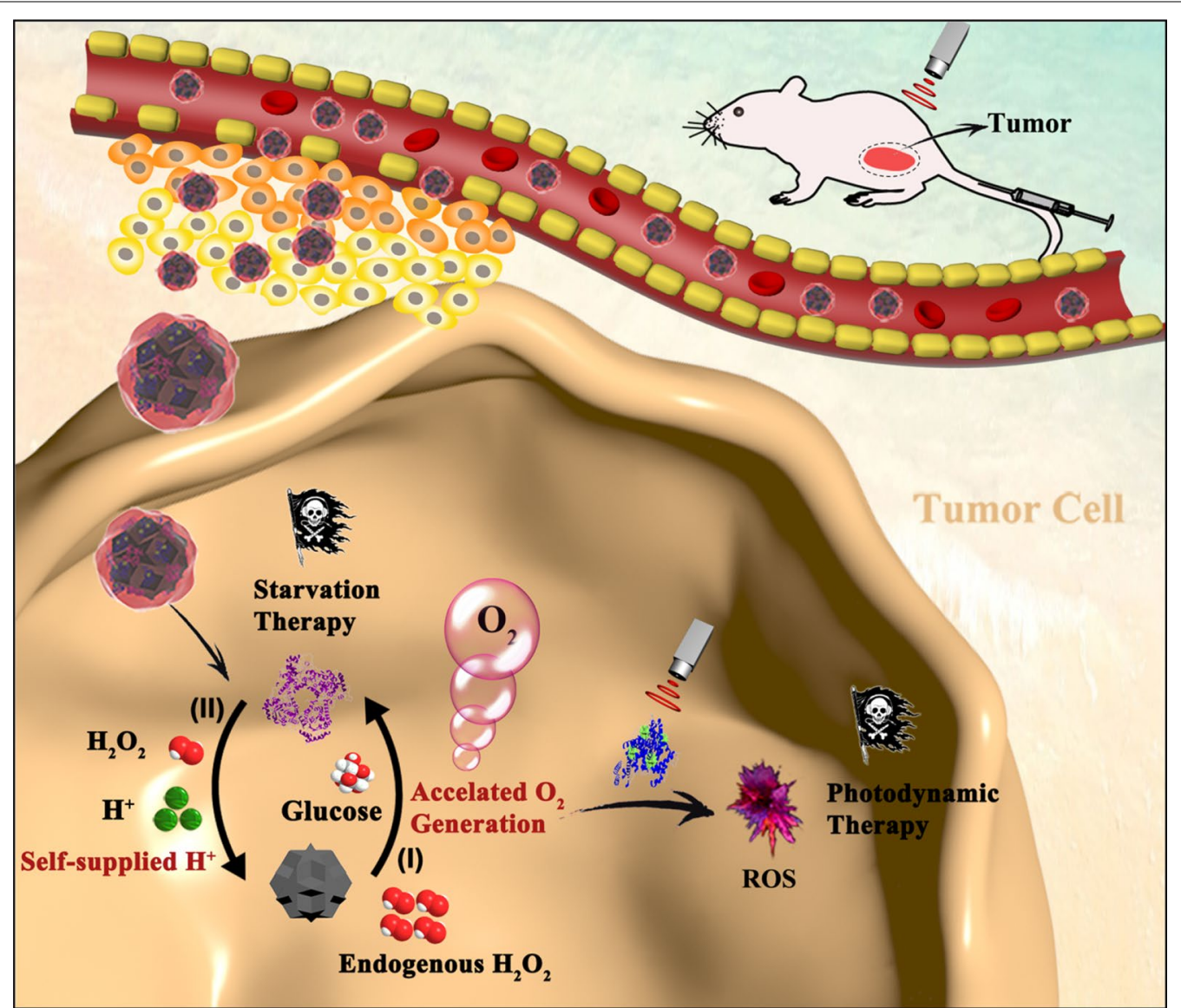

Fig. 17 The scheme of $\mathrm{MnO}_{2}$-GOx hybrid achieving self-supplied $\mathrm{H}^{+}$and accelerating $\mathrm{O}_{2}$ generation for alleviating tumor hypoxia and enhancing PDT and starvation therapy against hypoxic tumors

efficiency by alleviating tumor hypoxia. Nanoenzymes can convert the tumor-overexpressed hydrogen peroxide $\left(\mathrm{H}_{2} \mathrm{O}_{2}\right)$ molecules into oxygen and enhancing the tumor oxygen level to boost SDT-induced ROS production. Liang et al. employed hollow Pt-CuS janus architecture for synergistic catalysis-enhanced sonodynamic and photothermal cancer therapy [151]. Sonosensitizer molecules (tetra-(4-aminophenyl) porphyrin, TAPP) loaded on inner cavities of hollow $\mathrm{CuS}$ to fulfillment SDT. Metallic Pt with enzyme like-activity catalyzed decomposition of endogenous overexpressed $\mathrm{H}_{2} \mathrm{O}_{2}$ to produce $\mathrm{O}_{2}$ and facilitates SDT efficacy (Fig. 22). Nanozymes can act as a carrier effectively deliver a sonosensitizer to the lesions and also provide a sonosensitizer with rich oxygen by their enzyme activities. It was found that the modification of a sonosensitizer onto Pd@Pt could significantly block the catalase-like activity of Pd@Pt, whereas upon US irradiation, the nanozyme activity was effectively recovered to catalyze oxygen generation [152]. Such "blocking and activating" enzyme activity decreases the potential toxicity and side effects of nanozymes on normal tissues and helps realize controllable, active, and disease-loci-specific nanozyme activity behavior.

\section{Antibacterial applications}

Infectious diseases caused by bacteria are the most growing global health problem, infecting millions of people every year [153]. Until now, a number of antibacterial materials, such as antibiotics, quaternary ammonium ion, metal ions, and biocides have been developed to counter the growth of dangerous bacteria [154, 155]. However, owing to high cost of the above materials, antibiotic resistance, and complex chemical processing, the provision of alternative antimicrobials is of particular importance [156]. It was found that artificial enzyme mimics are able to function as an antimicrobial against both Gram-positive and Gram-negative bacteria via increasing the transformation of $\mathrm{H}_{2} \mathrm{O}_{2}$ into $\mathrm{ROS}[157,158]$. Chen and coworkers have found that graphene quantum dot/silver nanoparticle (GQD/AgNP) hybrids with peroxidase and oxidase like functions demonstrate high 
(See figure on next page.)

Fig. 18 I Schematic illustration of (A) the preparation process of PCN-224-Pt and (B) the use of PCN-224-Pt for enhanced photodynamic therapy, II Photodynamic therapy of PCN-224-Pt by intratumoral injection in a subcutaneous tumor model. A) HIF-1a staining of tumor tissues collected from mice in different groups. B) Photographs of the $\mathrm{H} 22$ tumor-bearing mice before treatment and on day 14 after the various treatments. C) Representative photographs of the tumor dissection. D) Relative tumor volume after various treatments indicated. Asterisks indicate significant differences $\left({ }^{*} P<0.05,{ }^{* *} P<0.01,{ }^{* * *} P<0.001\right)$

antibacterial properties against both Gram-negative and Gram-positive bacteria via using oxygen instead of $\mathrm{H}_{2} \mathrm{O}_{2}$ [159]. The GQD/AgNP hybrids could induce release of ROS to oxidize the lipids in the cell membrane. After distribution of GQD/AgNP hybrids around the bacteria the surface morphology of the bacteria exhibited an evident conversion from a smooth cell membrane to a roughened and wrinkled appearance, denoting that the cell membrane had been destroyed and lost its original barrier action (Fig. 23I). The oxidization of the lipids in the cell membrane and disruption the cell metabolism result in bacteria death.

Cai et al. also fabricated porous $\mathrm{Pt} / \mathrm{Ag}$ nanoparticles with excellent multifunctional enzyme mimic activities to exert excellent antibacterial effects [160]. The multi-catalytic capability of Pt/Ag NPs as oxidase peroxidase and catalase, results in suppression of the bacteria growth (Fig. 23II).

Bacterial biofilms are determined as groups or clusters of bacteria, surrounded by a self-produced matrix of extracellular polymeric substances forming the threedimensional structure. Bacterial biofilms are associated with health problems and diseases including chronic infections, biofouling of implants, as well as tooth decay and biomedical devices. Biofilms are difficult to destroy, because the biofilm mode of growth exerts the protection effect [161-163]. Tao et al. have also demonstrated intrinsic oxidase and peroxidase catalytic functions of bifunctionalized mesoporous silica-supported gold nanoparticles for biofilm destruction [164]. Treatment with both MSN-AuNPs and $\mathrm{H}_{2} \mathrm{O}_{2}$ led to breaking down the existing biofilm (Fig. 23III).

Light-absorbing characteristics of nanomaterials have created salient opportunities in applying light to activate nanomaterials for control of biological processes. In particular, combining the use of light as a trigger with the nanozyme activity of nanomaterials offers remarkable potential to control the antibacterial property $[165,166]$. Karim's group showed the ability of visible light to work as an external trigger for controlling the antibacterial property of semiconducting $\mathrm{CuO}$ nanorods (NRs) [167]. In visible light illumination, the apparent binding affinity of $\mathrm{CuO}$ NRs to $\mathrm{H}_{2} \mathrm{O}_{2}$ increased by over four times in comparation with non-illuminated conditions, (Fig. 23IV). The outcome of this distinct feature is progression in the rate of ROS production, so that, antibacterial efficiency of photoilluminated $\mathrm{CuO}$ NRs improved by elevating the $\mathrm{OH}$ - radical formation even at low $\mathrm{H}_{2} \mathrm{O}_{2}$ concentrations.

The surface morphology of nanocomposites has a key role in adjusting their catalytic functions. Thus the enzyme-like activity of metal-based nanomaterials could be controlled by modulating their exposed facets $[168,169]$. Along these lines facet-dependent of palladium (Pd) nanocrystals have been demonstrated against Gram-positive and Gram-negative bacteria [170]. The antibacterial performance of Pd nanocrystals against Gram-positive bacteria is the consequence of the extent of their enzyme-like activity, that is $\{100\}$-faceted Pd cubes with higher activities destroy bacteria more effectively than $\{111\}$-faceted Pd octahedrons. This outcome has been corroborated with the dissociative energy profiles for the $\mathrm{O}_{2}$ molecule on the $\mathrm{Pd}\{111\}$ and $\{100\}$ surfaces. The $\mathrm{O}_{2}$ binding on the $\mathrm{Pd}$ $\{111\}$ facet has adsorption energy of $-0.85 \mathrm{eV}$, whereas for the $\mathrm{O}_{2}$ on the $\mathrm{Pd}\{100\}$ facet, the value is $-1.40 \mathrm{eV}$, indicating that the $\mathrm{Pd}\{100\}$ facet, present in the $\mathrm{Pd}$ cubes, exhibits a stronger affinity for the $\mathrm{O}_{2}$ molecule.

\section{Water purification}

Organic dyes are one of the widely used industrial products, which, their inseparable disposal poses serious risks to the environment [171]. Dyes generally cause water contamination and many problems to human health and environment, because they are toxic, mutagenic, carcinogenic and non-biodegradable. Therefore, the removal of dyes from wastewater is indispensable, particularly for securing aquatic life and mitigating the problem of water pollution $[172,173]$. Among different removal technologies available for the removal of dye-containing wastewater, advanced oxidation processes (AOP) has been suggested as an excellent strategy [174, 175]. Fenton process as a one of the advanced oxidation technologies is a strong catalytic reaction used for environmental restoration. In Fenton chemistry, $\mathrm{H}_{2} \mathrm{O}_{2}$ is decomposed by soluble $\mathrm{Fe}^{2+}$ ions to produce highly oxidative species, i.e., hydroxyl radicals, according to the Haber-Weiss mechanism in Eq. (1) [176, 177]:

$$
\mathrm{Fe}^{2+}+\mathrm{H}_{2} \mathrm{O}_{2} \rightarrow \mathrm{Fe}^{3+}+\mathrm{HO}+\mathrm{OH}^{-}
$$

The homogeneous Fenton process based on the aqueous mixture of ionic iron $\left(\mathrm{Fe}^{2+} / \mathrm{Fe}^{3+}\right)$ and hydrogen peroxide $\left(\mathrm{H}_{2} \mathrm{O}_{2}\right)$ suffers from sludge formation and $\mathrm{pH}$ 


\section{I a}

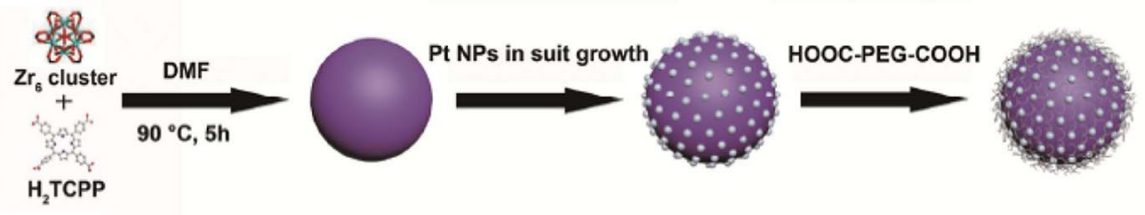

b

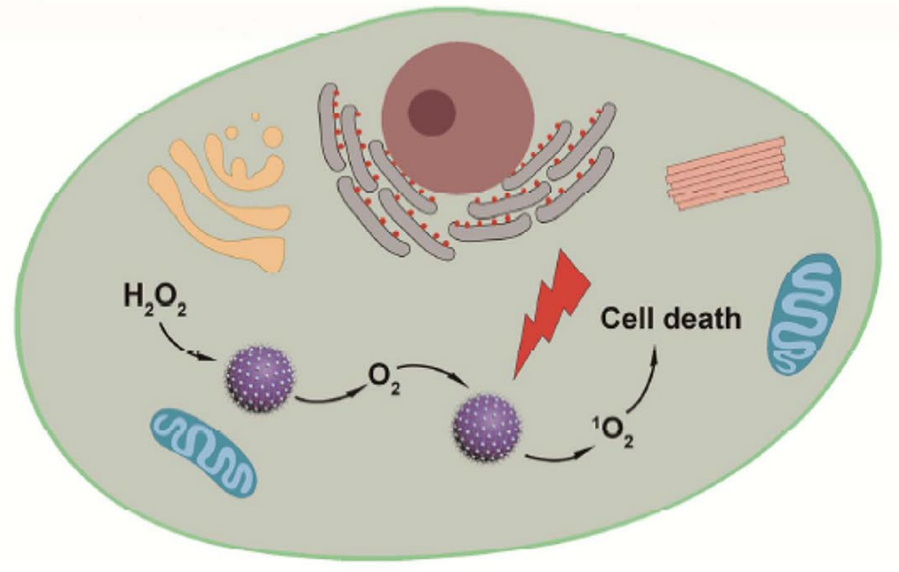

II $\mathbf{a}$

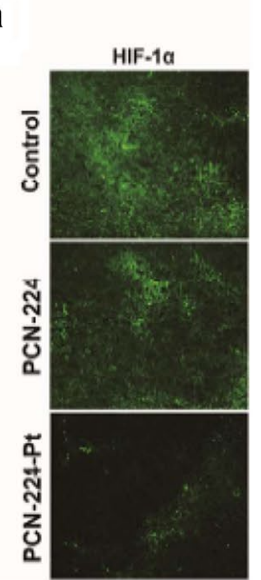

C

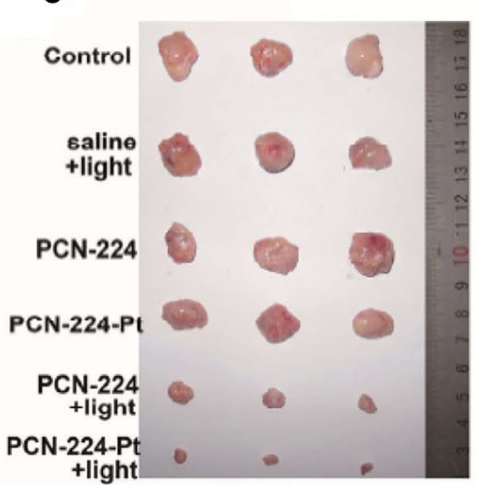

b
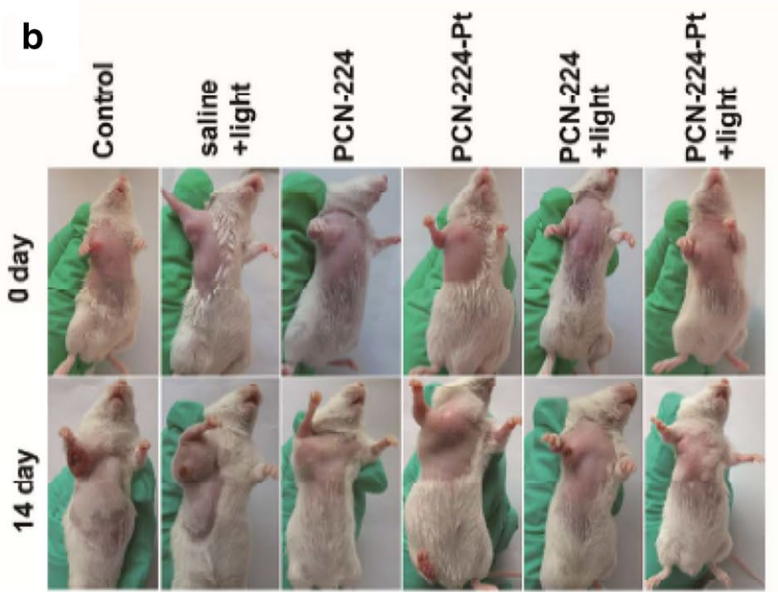

d

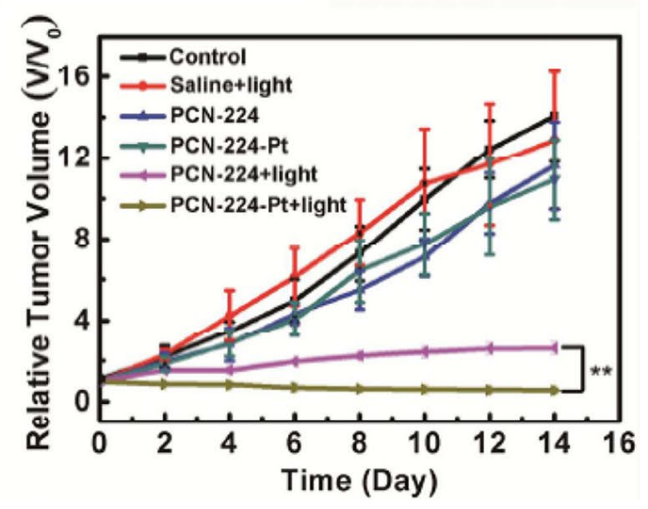




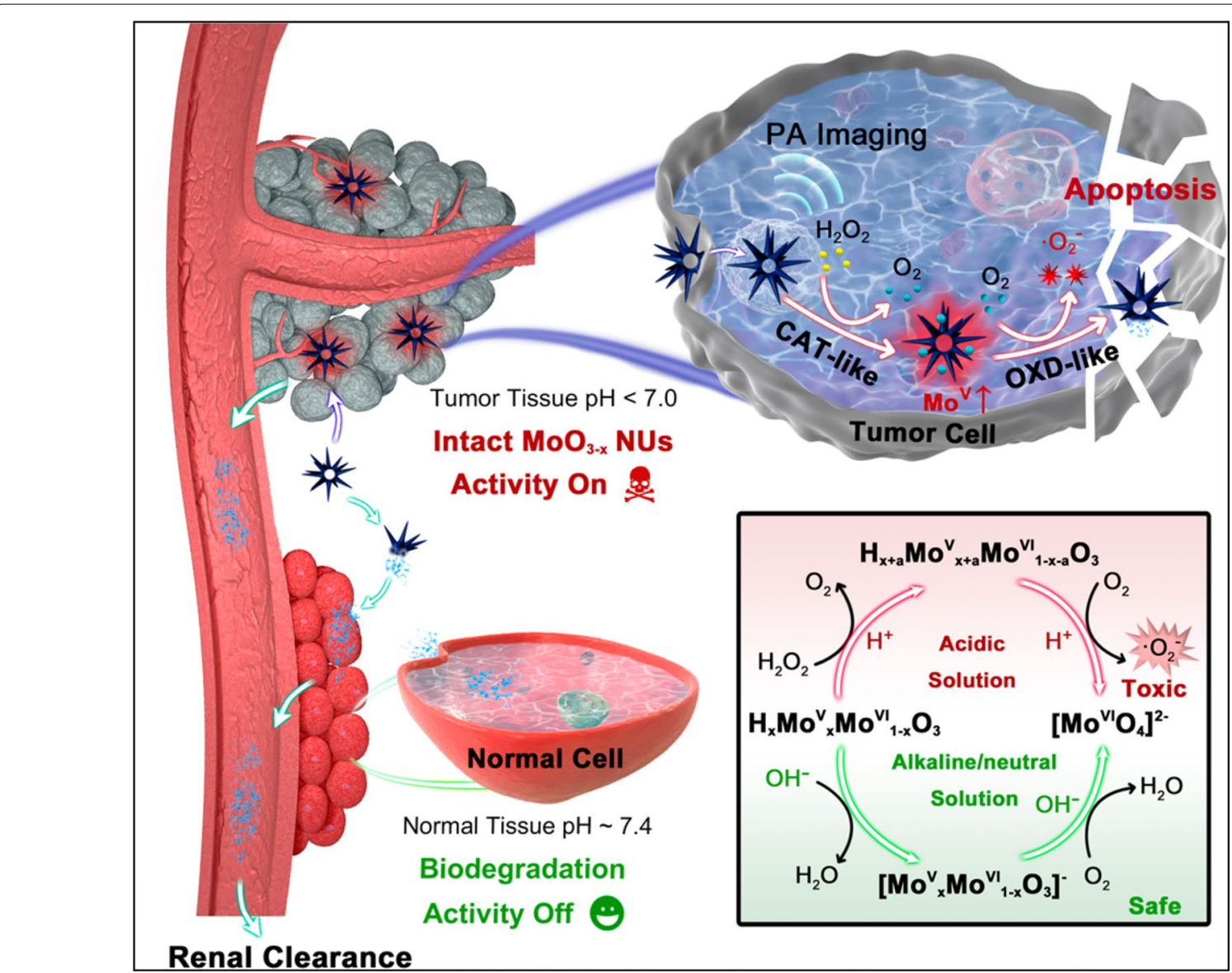

Fig. 19 Schematic Illustration of Biodegradation-Medicated Enzymatic Activity-Tunable Molybdenum Oxide Nanourchins (MoO3 - x NUs) with the Highly Specific Toxicity to Tumor Tissues via a Multienzyme Stepwise Cascade Catalysis in Acidic Tumor Microenvironment

limitations. Hence, much attempt has been devoted to the development of heterogeneous Fenton catalysts to address these issues $[178,179]$. In that respect, iron oxide nanocomposite has attracted much interest for their applications in catalytic degradation of organic pollutants with $\mathrm{H}_{2} \mathrm{O}_{2}[180,181]$. Various forms of iron oxides such as $\mathrm{Fe}_{3} \mathrm{O}_{4}, \mathrm{Fe}_{2} \mathrm{O}_{3}$ and $\mathrm{CuFe}_{2} \mathrm{O}_{4}$ have been used as catalysts to activate $\mathrm{H}_{2} \mathrm{O}_{2}$ and generate ROS to remove of organic pollutants [182-184]. However, long reaction time and high concentration of $\mathrm{H}_{2} \mathrm{O}_{2}$ are the limitations of the $\mathrm{H}_{2} \mathrm{O}_{2}$-iron oxide catalytic system [185]. Therefore, the peroxidase-like activity of catalyst should be enhanced. Transition metal substituted magnetite could be introduced to improve the degradation of organic pollutants via Fenton reaction [186]. It was found that the degradation of methylene blue could be significantly improved through incorporation of niobium with magnetite catalyst. This ascribed to the generated oxygen vacancies on the surface of catalysts. $\mathrm{Fe}^{2+}$ cations were regenerated by introduction of $\mathrm{Nb}$ cations in Fenton oxidation cycle [187]. An ionothermal synthesis approach has been reported to generate $\mathrm{Fe}_{3} \mathrm{O}_{4}$ MNPs with unique intrinsic catalytic activity. In this synthesis strategy a deep eutectic solvent (DES) was applied for $\mathrm{Fe}^{2+} / \mathrm{Fe}^{3+}$ co-precipitation. As compared to $\mathrm{Fe}_{3} \mathrm{O}_{4}$ particles prepared in conventional commonly used solvents (water and ethyleneglycol), $\mathrm{Fe}_{3} \mathrm{O}_{4}$ MNPs made in DES possessed the higher activity for catalytic degradation of Rhodamine $B(R h B)$ [188]. Utilization of some other Fenton catalyst was investigated for degradation of the organic dyes. Application of nanoceria, with excellent structural properties and high oxygen mobility, was studied for the removal of organic dyes. The proposed mechanism of Fenton-like reaction catalyzed by nanoceria is the activation of $\mathrm{H}_{2} \mathrm{O}_{2}$ by $\mathrm{Ce}^{4+} / \mathrm{Ce}^{3+}$ sites and then decompose into highly reactive hydroxyl radicals [189]. 

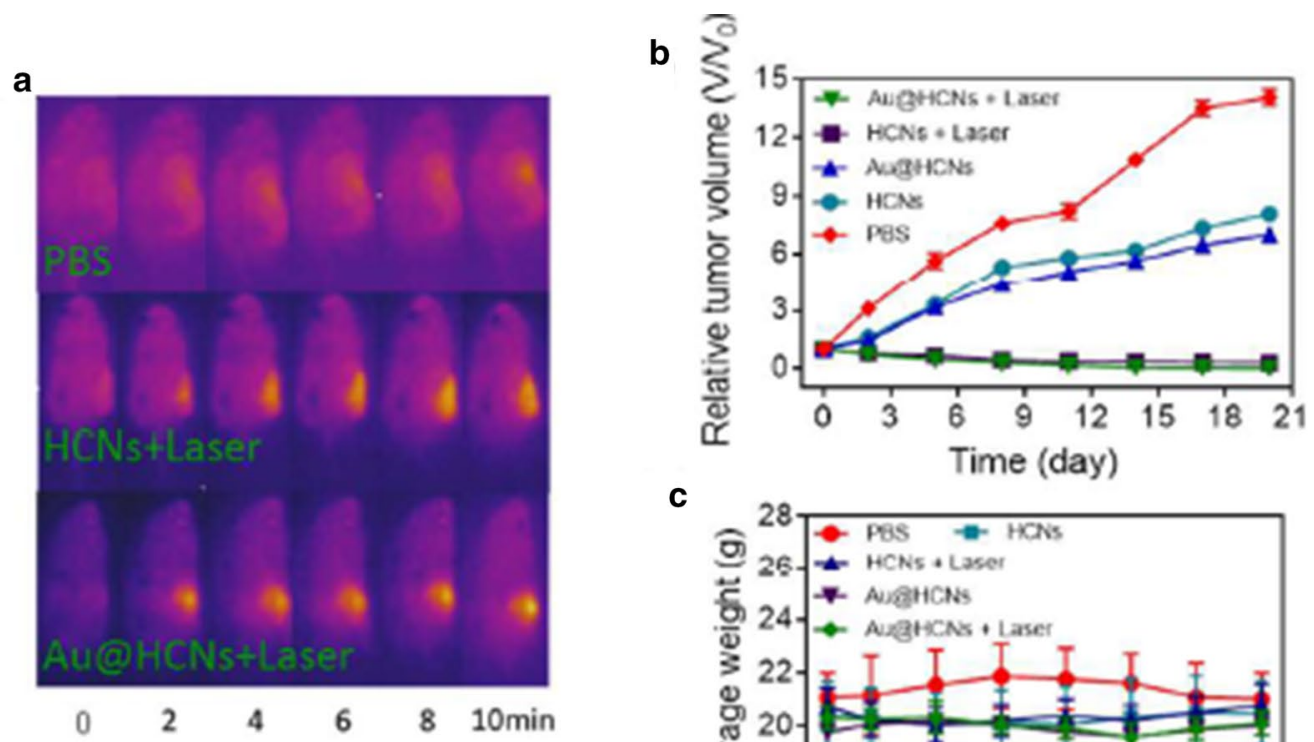

C
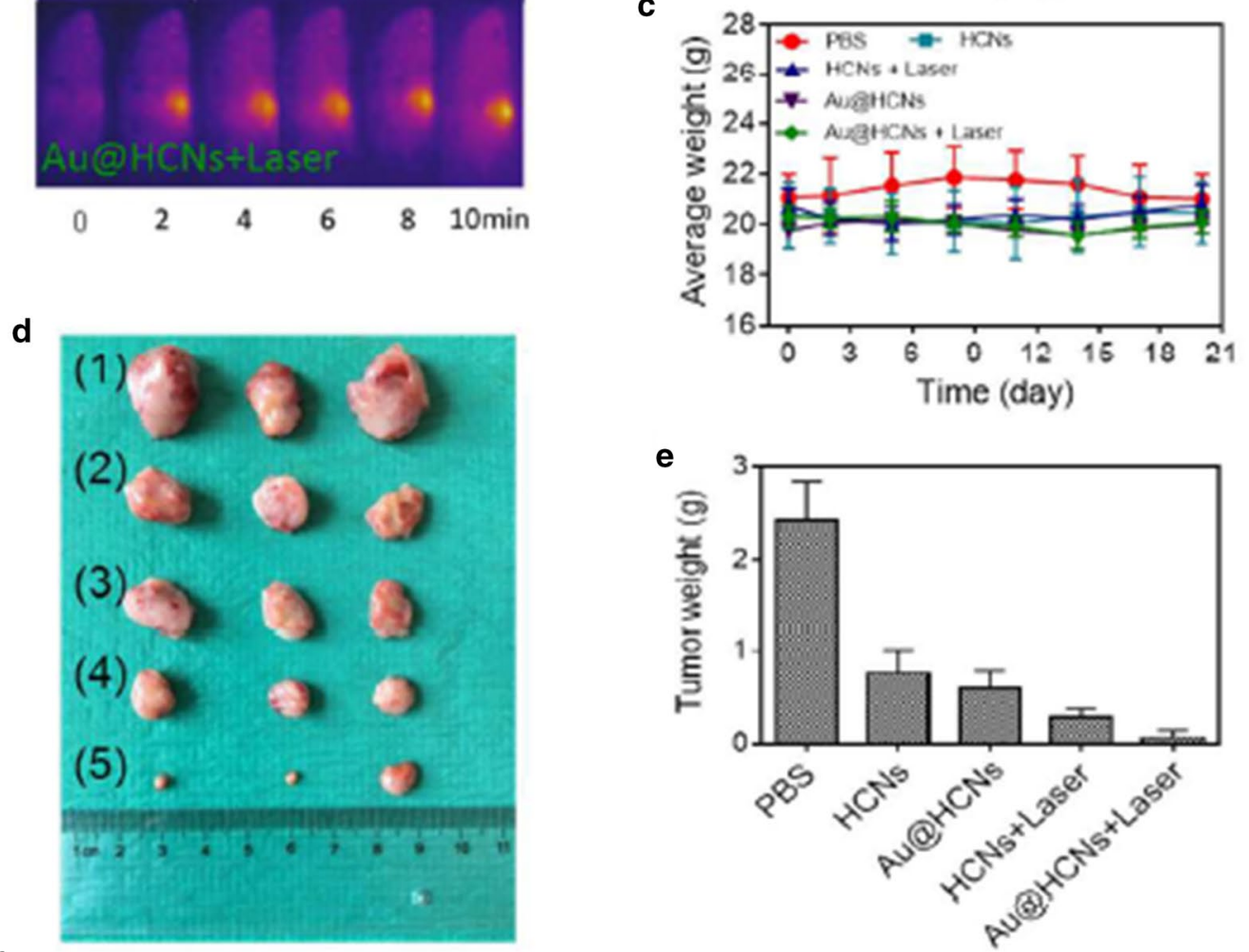

$\mathbf{f}$
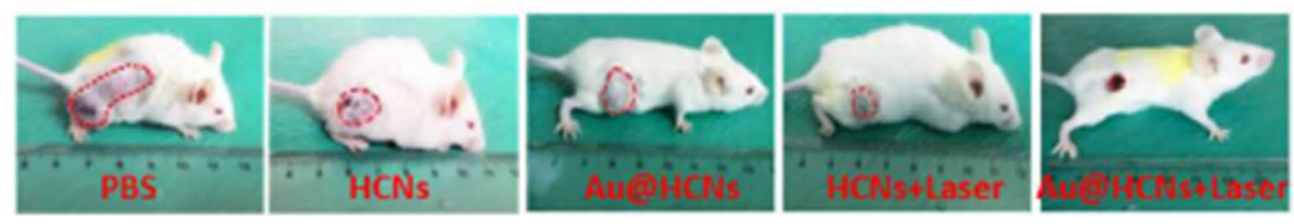

Fig. 20 In vivo catalytic-photothermal therapy of CT26 tumor bearing mice. a IR thermal images of CT26 tumor-bear mice with the NIR laser irradiation (808 nm, 2.0 W/cm², $10 \mathrm{~min}$ ) after intravenous injection with PBS, HCNs and Au@HCNs. b Tumor growth curves of different groups after treatment. c The body weight after various treatments during 21 days. d Photos of tumors from (1) control, (2) HCNs, (3) Au@HCNs, (4) HCNs + Laser, (5) Au@HCNs + Laser. $\mathbf{e}$ The Tumor weight after 21 days of treatment. $\mathbf{f}$ Representative photos of tumors on mice after various treatments after 21 day 


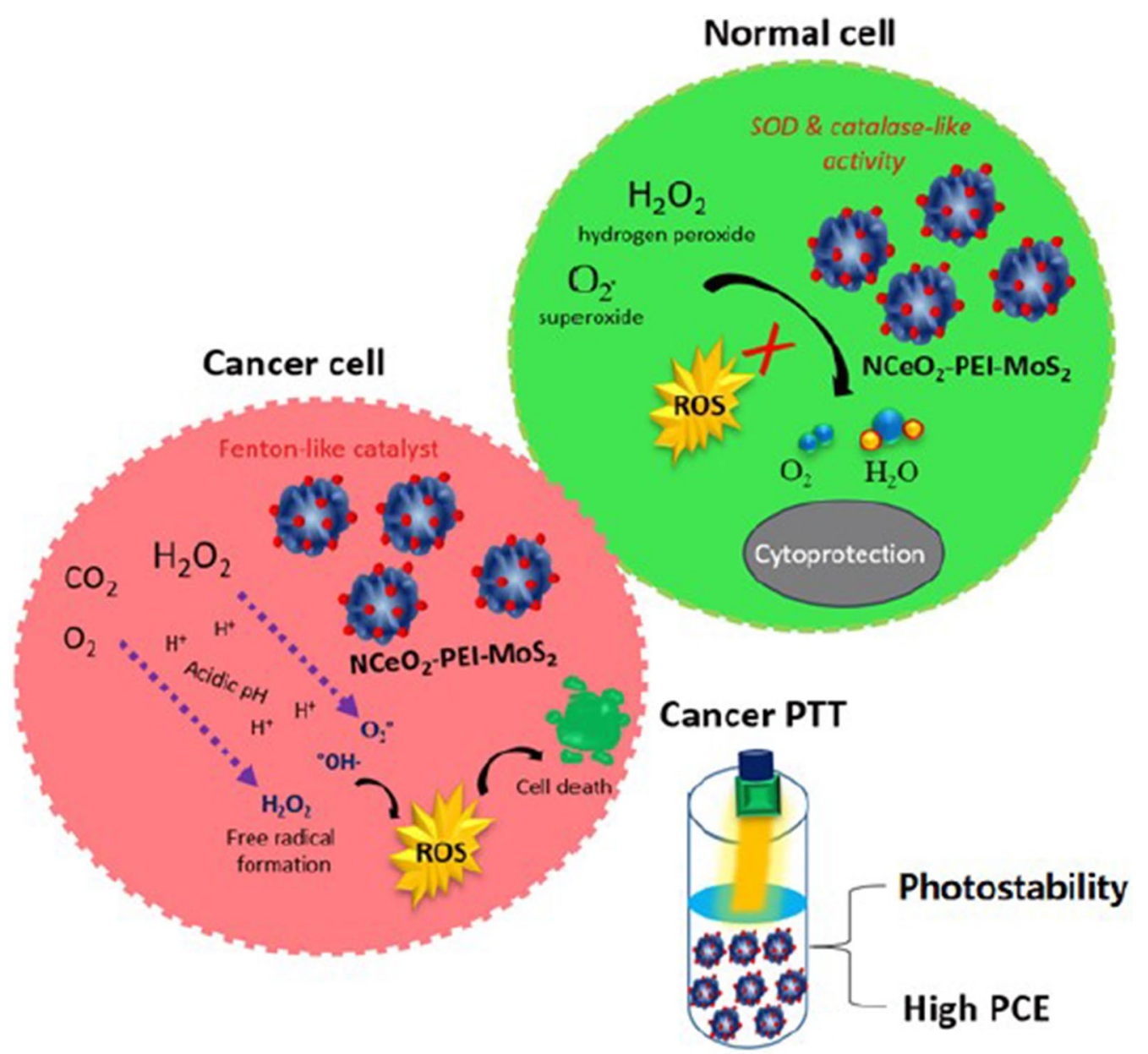

Fig. 21 Schematic illustration of the use of $\mathrm{NCeO}_{2}-\mathrm{PEI}-\mathrm{MoS}_{2}$ for selective enhanced photodynamic therapy

\section{Summery and prospect}

Since the discovery of $\mathrm{Fe}_{3} \mathrm{O}_{4}$ nanoparticles as peroxidase mimics in 2007, nanozymes as novel emerging and rapidly growing field have gained much attention. In this regard, metal and metal oxide nanomaterials are a good candidate to replace some complicated and expensive enzymes for using them as a novel and unique techniques in various areas such as bio nanotechnology and environmental governance. In comparison with natural enzyme, nanozymes encompasses many advantages including easy preparation, excellent stability, low cost, and good durability. In this review, we have summarized the recent achievements in application of metal and metal oxide-based nanozymes, including sensing, therapeutics, antibacterial application and water treatment. Obviously substantial progress has been achieved in research field of nanozyme; however, there are still numerous challenges remain to be addressed. First, the diversity of nanozymes is very low compared to natural enzymes; in other words, though many nanomaterials have been applied to mimic natural enzymes. Currently the redox enzyme mimics are still prevailing in the peroxidase-like nanozymes. Thus, new strategies are required to design and prepare other types of nanozymes. Second, in comparison with natural enzyme, nanozymes should provide a competitive catalytic selectivity and efficiency for practical applications. The surface modifications of nanomaterials by functional groups to make the active site for 


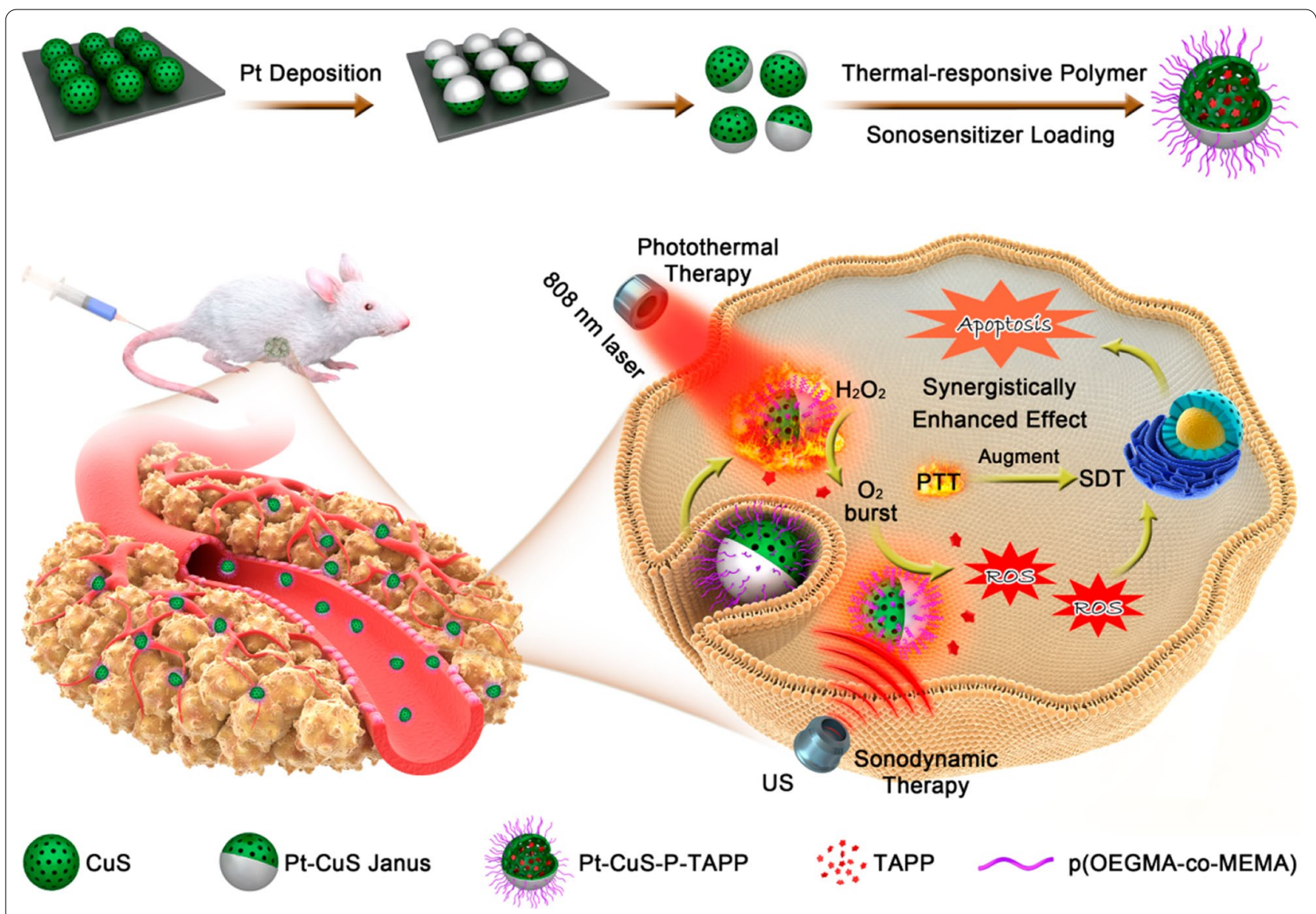

Fig. 22 Schematic illustration of the main synthesis procedures and antitumor mechanism of Pt-CuS NPS

substrate recognition can boost the binding affinity and specificity of nanozymes. Furthermore, designing hybrid nanomaterials with synergetic effect can help to improve their activity. Third, in general, the developed nanozymes just have one enzymatic activity. The researchers need to pay more attention to construct nanozymes which catalyze cascade reactions to mimic the complex natural enzyme systems. Forth, although nanozymes offer costeffective methods for application in various fields, noble metal nanomaterials ( $\mathrm{Au}, \mathrm{Pt}$ and $\mathrm{Pd}$ ) don't take advantage of low cost. Therefore, the efforts should be propelled to synthesis and application of non-noble nanozymes as low cost and available materials. Fifth, potential toxicities of nanozymes should be carefully considered for biomedical applications. Sixth, the current research on applications of nanozymes are mainly limited to medicine and biotechnology. Future research should be focused on widening the practical applications of nanozymes in other fields including food, industry, agriculture or environment. The spread of the novel coronavirus disease (COVID19) has been a challenge that requires an emergent deployment of diagnostic and therapeutic options available. Development of a simple and sensitive immunodiagnostic method based on nanozymes can be useful for monitoring COVID19. Recently, a nanozyme chemiluminescence immunosensor for rapid and portable detection of SARSCoV-2 spike antigen (S antigen) is developed [109]. The test paper platform based on a peroxidase nanozyme combines traditional enzymatic chemiluminescence analysis (CLIA) with lateral flow assay, which, facilitates 


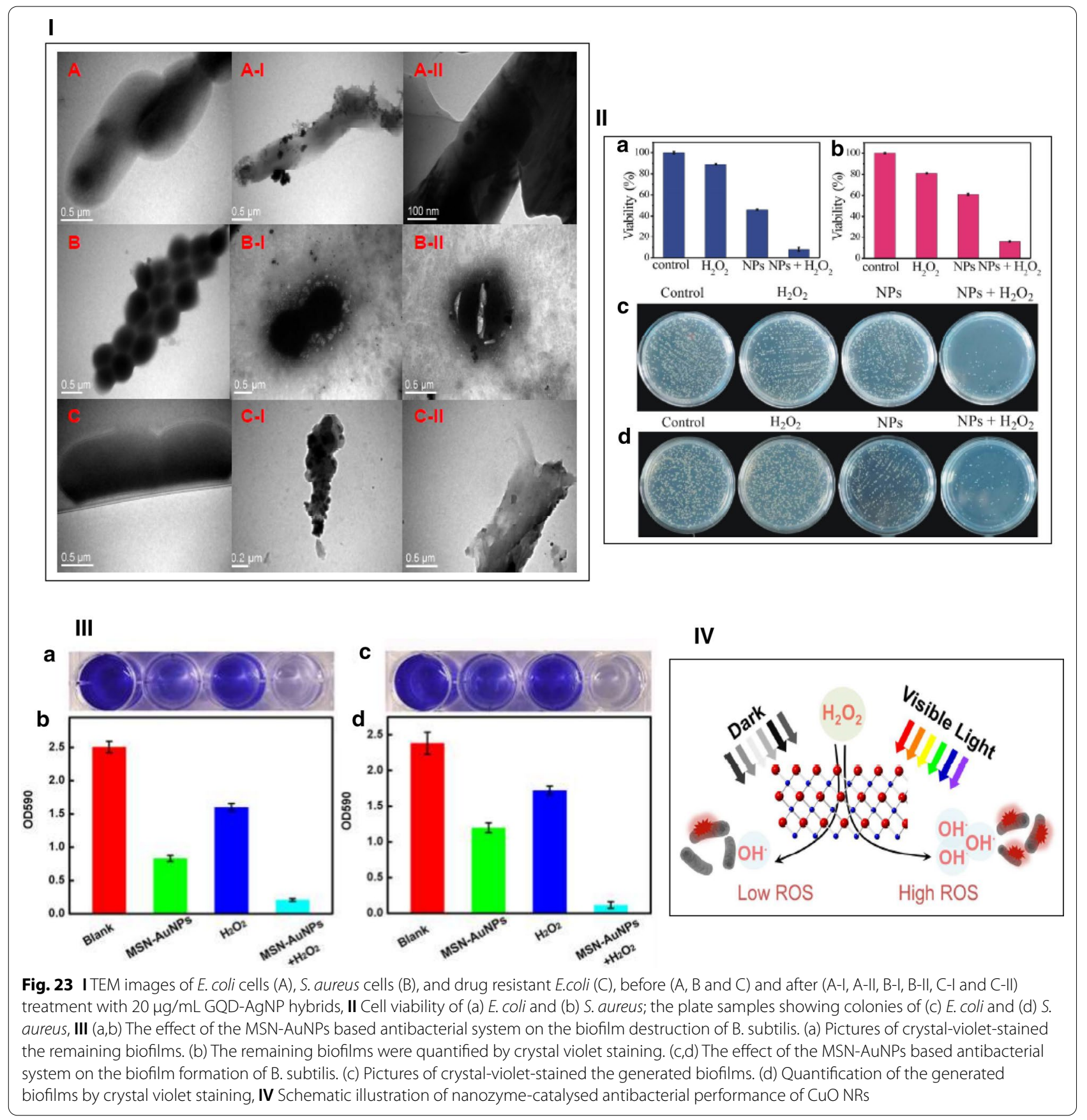

early screening of SARS-CoV-2 infections. Furthermore, nanozymes possess the antiviral activity through catalyzing lipid peroxidation of the viral lipid envelope. Thus, nanozymes have the ability to prevent COVID19 transmission and infection.

\section{Acknowledgments}

This work was supported by the Research Office of University of Kurdistan (Grant: 130645), and Iranian Nanotechnology Initiative (Grant: 116748).

\section{Authors' contributions}

NA wrote the paper with support from AS. All authors contributed to the general discussion. All authors read and approved the final manuscript.

\section{Funding}

This work is financially supported by the Research Office of University of Kurdistan (Grant Number 4.1261) and Iranian Nanotechnology initiative.

\section{Availability of data and materials}

All data generated or analyzed during this study are included in the article. 


\section{Consent for publication}

All authors have provided consent for the manuscript to be published.

\section{Competing interests}

The authors declare that they have no competing interests.

\section{Author details}

${ }^{1}$ Department of Chemistry, University of Kurdistan, 66177-15175 Sanandaj, Iran. ${ }^{2}$ Research Center for Nanotechnology, University of Kurdistan, 66177-15175 Sanandaj, Iran.

Received: 27 August 2020 Accepted: 8 January 2021

Published online: 19 January 2021

\section{References}

1. Chen Y, Xianyu Y, Dong M, Zhang J, Zheng W, Qian Z, Jiang X. Cascade reaction-mediated assembly of magnetic/silver nanoparticles for amplified magnetic biosensing. Anal Chem. 2018;90(11):6906-12.

2. Bornscheuer U, Huisman G, Kazlauskas RJ, Lutz S, Moore J, Robins K. Engineering the third wave of biocatalysis. Nature. 2012;485(7397):185.

3. Kavosi B, Salimi A, Hallaj R, Amani K. A highly sensitive prostatespecific antigen immunosensor based on gold nanoparticles/PAMAM dendrimer loaded on MWCNTS/chitosan/ionic liquid nanocomposite. Biosens Bioelectron. 2014;52:20-8.

4. Navaee A, Salimi A. Graphene-supported pyrene-functionalized aminocarbon nanotube: a novel hybrid architecture of laccase immobilization as effective bioelectrocatalyst for oxygen reduction reaction. J Mater Chem A. 2015;3(14):7623-30.

5. Singh A, Datta S, Sachdeva A, Maslanka S, Dykes J, Skinner G, Burr D, Whiting RC, Sharma SK. Evaluation of an enzyme-linked immunosorbent assay (ELISA) kit for the detection of botulinum neurotoxins A B, E, and $\mathrm{F}$ in selected food matrices. Health Security. 2015;13(1):37-44.

6. Tan DCL, Sato H. Enhancing catalytic activity of bioanode for glucose biofuel cell by compressing enzyme, mediator and carbon support through centrifugation. Chem A Eur J. 2017;23(48):11485-8.

7. Gao L, Yan X. Nanozymes: an emerging field bridging nanotechnology and biology. Sci China Life Sci. 2016;59(4):400-2.

8. Alizadeh N, Hallaj R, Salimi A. A highly sensitive electrochemical immunosensor for hepatitis $B$ virus surface antigen detection based on Hemin/G-quadruplex horseradish peroxidase-mimicking DNAzymesignal amplification. Biosens Bioelectron. 2017;94:184-92.

9. Ma C, Ma Y, Sun Y, Lu Y, Tian E, Lan J, Li J, Ye W, Zhang H. Colorimetric determination of $\mathrm{Hg}^{2+}$ in environmental water based on the $\mathrm{Hg}^{2+}$-stimulated peroxidase mimetic activity of MoS2-Au composites. J Colloid Interface Sci. 2019;537:554-61.

10. Jia H, Yang D, Han X, Cai J, Liu H, He W. Peroxidase-like activity of the $\mathrm{CO}_{3} \mathrm{O}_{4}$ nanoparticles used for biodetection and evaluation of antioxidant behavior. Nanoscale. 2016;8(11):5938-45.

11. Hu X, Saran A, Hou S, Wen T, Ji Y, Liu W, Zhang H, He W, Yin J-J, Wu X. Au@ PtAg core/shell nanorods: tailoring enzyme-like activities via alloying. Rsc Adv. 2013;3(17):6095-105.

12. Wei $H$, Wang E. Nanomaterials with enzyme-like characteristics (nanozymes): next-generation artificial enzymes. Chem Soc Rev. 2013;42(14):6060-93.

13. Alizadeh N, Salimi A, Sham T-K, Bazylewski P, Fanchini G. Intrinsic enzyme-like activities of cerium oxide nanocomposite and its application for extracellular $\mathrm{H}_{2} \mathrm{O}_{2}$ detection using an electrochemical microfluidic device. ACS Omega. 2020;12:5.

14. Duan D, Fan K, Zhang D, Tan S, Liang M, Liu Y, Zhang J, Zhang P, Liu W, Qiu X. Nanozyme-strip for rapid local diagnosis of Ebola. Biosens Bioelectron. 2015;74:134-41.

15. Yan-Yan H, You-Hui L, Fang P, Jin-Song R, Xiao-Gang Q. The current progress of nanozymes in disease treatments. Prog Biochem Biophys. 2018;45(2):256-67.

16. Farka ZK, Čunderlová V, Horáčková V, Pastucha MJ, Mikušová Z, Hlaváček AN, Skládal P. Prussian blue nanoparticles as a catalytic label in a sandwich nanozyme-linked immunosorbent assay. Analyt Chem. 2018:90:2348-54
17. Yan T, Zhi-Yue Q, Zhuo-Bin X, Li-Zeng G. Antibacterial mechanism and applications of nanozymes. Prog Biochem Biophys. 2018;45(2):118-28

18. Wang $X, H u Y$, Wei H. Nanozymes in bionanotechnology: from sensing to therapeutics and beyond. Inorg Chem Front. 2016;3(1):41-60.

19. Gao L, Zhuang J, Nie L, Zhang J, Zhang Y, Gu N, Wang T, Feng J, Yang D, Perrett S. Intrinsic peroxidase-like activity of ferromagnetic nanoparticles. Nat Nanotechnol. 2007;2(9):577.

20. Hu Y, Cheng H, Zhao X, Wu J, Muhammad F, Lin S, He J, Zhou L, Zhang C, Deng Y. Surface-enhanced Raman scattering active gold nanoparticles with enzyme-mimicking activities for measuring glucose and lactate in living tissues. ACS Nano. 2017;11 (6):5558-66.

21. Wang $Z$, Yang $X$, Yang J, Jiang $Y$, He N. Peroxidase-like activity of mesoporous silica encapsulated Pt nanoparticle and its application in colorimetric immunoassay. Anal Chim Acta. 2015;862:53-63.

22. Wang Q, Zhang L, Shang C, Zhang Z, Dong S. Triple-enzyme mimetic activity of nickel-palladium hollow nanoparticles and their application in colorimetric biosensing of glucose. Chem Commun. 2016;52(31):5410-3.

23. Zhang W, Dong J, Wu Y, Cao P, Song L, Ma M, Gu N, Zhang Y. Shapedependent enzyme-like activity of $\mathrm{CO}_{3} \mathrm{O}_{4}$ nanoparticles and their conjugation with his-tagged EGFR single-domain antibody. Colloids Surf B. 2017;154:55-62.

24. Huang L, Zhang W, Chen K, Zhu W, Liu X, Wang R, Zhang X, Hu N, Suo Y, Wang J. Facet-selective response of trigger molecule to $\mathrm{CeO} 2110$ for up-regulating oxidase-like activity. Chem Eng J. 2017;330:746-52.

25. Hu A-L, Deng H-H, Zheng X-Q, Wu Y-Y, Lin X-L, Liu A-L, Xia X-H, Peng H-P, Chen W, Hong G-L. Self-cascade reaction catalyzed by $\mathrm{CuO}$ nanoparticle-based dual-functional enzyme mimics. Biosens Bioelectron. 2017:97:21-5.

26. Han L, Shi J, Liu A. Novel biotemplated $\mathrm{MnO}_{2} 1 \mathrm{D}$ nanozyme with controllable peroxidase-like activity and unique catalytic mechanism and its application for glucose sensing. Sensors Actuat B. 2017;252:919-26.

27. Ghosh S, Roy P, Karmodak N, Jemmis ED, Mugesh G. Nanoisozymes: crystal-facet-dependent enzyme-mimetic activity of $\mathrm{V}_{2} \mathrm{O}_{5}$ nanomaterials. Angew Chem. 2018;130(17):4600-5.

28. Li D, Liu B, Huang P-JJ, Zhang Z, Liu J. Highly active fluorogenic oxidasemimicking NiO nanozymes. Chem Commun. 2018;54(88):12519-22.

29. Carpenter MA, Mathur S, Kolmakov A. Metal oxide nanomaterials for chemical sensors. Berlin: Springer; 2012.

30. He Q, Liu J, Liu X, Li G, Chen D, Deng P, Liang J. Fabrication of aminemodified magnetite-electrochemically reduced graphene oxide nanocomposite modified glassy carbon electrode for sensitive dopamine determination. Nanomaterials. 2018;8(4):194.

31. Tian Y, Deng P, Wu Y, Li J, Liu J, Li G, He Q. MnO 2 nanowires-decorated reduced graphene oxide modified glassy carbon electrode for sensitive determination of bisphenol A. J Electrochem Soc. 2020;167(4):046514

32. Tian Y, Deng P, Wu Y, Liu J, Li J, Li G, He Q. High sensitive voltammetric sensor for nanomolarity vanillin detection in food samples via manganese dioxide nanowires hybridized electrode. Microchem J. 2020;104:885.

33. Huang Y, Liu Z, Liu C, Ju E, Zhang Y, Ren J, Qu X. Self-assembly of multi-nanozymes to mimic an intracellular antioxidant defense system. Angew Chem Int Ed. 2016:55(23):6646-50.

34. Alizadeh N, Salimi A, Hallaj R. Mimicking peroxidase-like activity of $\mathrm{CO}_{3} \mathrm{O}_{4}-\mathrm{CeO}_{2}$ nanosheets integrated paper-based analytical devices for detection of glucose with smartphone. Sens Actuat B. 2019;288:44-52.

35. Lee LA, Niu Z, Wang Q. Viruses and virus-like protein assembliesChemically programmable nanoscale building blocks. Nano Res. 2009;2(5):349-64.

36. Kwon KC, Ko HK, Lee J, Lee EJ, Kim K, Lee J. Enhanced in vivo tumor detection by active tumor cell targeting using multiple tumor receptorbinding peptides presented on genetically engineered human ferritin nanoparticles. Small. 2016;12(31):4241-53.

37. Jiang B, Yan L, Zhang J, Zhou M, Shi G, Tian X, Fan K, Hao C, Yan X. Biomineralization synthesis of the cobalt nanozyme in SP94-ferritin nanocages for prognostic diagnosis of hepatocellular carcinoma. ACS Appl Mater Interfaces. 2019;11(10):9747-55.

38. Lopez-Ruiz N, Curto VF, Erenas MM, Benito-Lopez F, Diamond D, Palma AJ, Capitan-Vallvey LF. Smartphone-based simultaneous $\mathrm{pH}$ and nitrite colorimetric determination for paper microfluidic devices. Anal Chem. 2014:86(19):9554-62. 
39. Fu G, Sanjay ST, Li X. Cost-effective and sensitive colorimetric immunosensing using an iron oxide-to-Prussian blue nanoparticle conversion strategy. Analyst. 2016;141(12):3883-9.

40. Woo M-A, Kim M, Jung J, Park K, Seo T, Park H. A novel colorimetric immunoassay utilizing the peroxidase mimicking activity of magnetic nanoparticles. Int J Mol Sci. 2013;14(5):9999-10014.

41. Zhou Y, Huang X, Zhang W, Ji Y, Chen R, Xiong Y. Multi-branched gold nanoflower-embedded iron porphyrin for colorimetric immunosensor. Biosens Bioelectron. 2018;102:9-16.

42. Deng X, Fang Y, Lin S, Cheng Q, Liu Q, Zhang X. Porphyrin-based porous organic frameworks as a biomimetic catalyst for highly efficient colorimetric immunoassay. ACS Appl Mater Interfaces. 2017;9(4):3514-23.

43. Alizadeh N, Salimi A, Hallaj R. Mimicking peroxidase activity of $\mathrm{CO}_{2}(\mathrm{OH})_{2} \mathrm{CO}_{3}-\mathrm{CeO}_{2}$ nanocomposite for smartphone based detection of tumor marker using paper-based microfluidic immunodevice. Talanta. 2018;189:100-10.

44. Jiao L, Zhang L, Du W, Li H, Yang D, Zhu C. Au@ Pt nanodendrites enhanced multimodal enzyme-linked immunosorbent assay. Nanoscale. 2019;11(18):8798-802.

45. Fu G, Sanjay ST, Zhou W, Brekken RA, Kirken RA, Li X. Exploration of nanoparticle-mediated photothermal effect of TMB- $\mathrm{H}_{2} \mathrm{O}_{2}$ colorimetric system and its application in a visual quantitative photothermal immunoassay. Anal Chem. 2018;90(9):5930-7.

46. Salimi A, Khezrian S, Hallaj R, Vaziry A. Highly sensitive electrochemical aptasensor for immunoglobulin E detection based on sandwich assay using enzyme-linked aptamer. Anal Biochem. 2014;466:89-97.

47. Shahdost-fard F, Salimi A, Khezrian S. Highly selective and sensitive adenosine aptasensor based on platinum nanoparticles as catalytical label for amplified detection of biorecognition events through $\mathrm{H}_{2} \mathrm{O}_{2}$ reduction. Biosens Bioelectron. 2014;53:355-62.

48. Shahdost-fard F, Salimi A, Sharifi E, Korani A. Fabrication of a highly sensitive adenosine aptasensor based on covalent attachment of aptamer onto chitosan-carbon nanotubes-ionic liquid nanocomposite. Biosens Bioelectron. 2013;48:100-7.

49. Zhao R-N, Feng Z, Zhao Y-N, Jia L-P, Ma R-N, Zhang W, Shang L, Xue Q-W, Wang H-S. A sensitive electrochemical aptasensor for Mucin 1 detection based on catalytic hairpin assembly coupled with PtPdNPs peroxidase-like activity. Talanta. 2019;200:503-10.

50. Wang Y-W, Wang L, An F, Xu H, Yin Z, Tang S, Yang H-H, Song H. Graphitic carbon nitride supported platinum nanocomposites for rapid and sensitive colorimetric detection of mercury ions. Anal Chim Acta. 2017;980:72-8.

51. Cui W-R, Zhang C-R, Jiang W, Liang R-P, Wen S-H, Peng D, Qiu J-D. covalent organic framework nanosheet-based ultrasensitive and selective colorimetric sensor for trace $\mathrm{Hg}^{2+}$ detection. ACS Sust Chem Eng. 2019:15:9.

52. Huang D, Niu C, Ruan M, Wang X, Zeng G, Deng C. Highly sensitive strategy for $\mathrm{Hg}^{2+}$ detection in environmental water samples using long lifetime fluorescence quantum dots and gold nanoparticles. Environ Sci Technol. 2013;47(9):4392-8.

53. Hizir MS, Top M, Balcioglu M, Rana M, Robertson NM, Shen F, Sheng J, Yigit MV. Multiplexed activity of perAuxidase: DNA-capped AuNPs act as adjustable peroxidase. Anal Chem. 2015;88(1):600-5.

54. Cheng H, Wu C, Liu J, Xu Z. Thiol-functionalized silica microspheres for online preconcentration and determination of mercury species in seawater by high performance liquid chromatography and inductively coupled plasma mass spectrometry. RSC Advances. 2015;5(25):19082-90.

55. Guo Y, Tao Y, Ma X, Jin J, Wen S, Ji W, Song W, Zhao B, Ozaki Y. A dual colorimetric and SERS detection of $\mathrm{Hg}^{2+}$ based on the stimulus of intrinsic oxidase-like catalytic activity of Ag-CoFe2O4/reduced graphene oxide nanocomposites. Chem Eng J. 2018;350:120-30.

56. Lian Q, Liu H, Zheng X, Li X, Zhang F, Gao J. Enhanced peroxidase-like activity of $\mathrm{CuO} / \mathrm{Pt}$ nanoflowers for colorimetric and ultrasensitive $\mathrm{Hg} 2+$ detection in water sample. Appl Surf Sci. 2019;483:551-61.

57. Kong L, Yan L, Qu Z, Yan N, Li L. $\beta$-Cyclodextrin stabilized magnetic $\mathrm{Fe}_{3} \mathrm{~S}_{4}$ nanoparticles for efficient removal of $\mathrm{Pb}$ (ii). Journal of Materials Chemistry A. 2015;3(30):15755-63.

58. Bian S, Shen C, Hua H, Zhou L, Zhu H, Xi F, Liu J, Dong X. One-pot synthesis of sulfur-doped graphene quantum dots as a novel fluorescent probe for highly selective and sensitive detection of lead (II). Rsc Advances. 2016;6(74):69977-83.

59. Huang K, Li B, Zhou F, Mei S, Zhou Y, Jing T. Selective solid-phase extraction of lead ions in water samples using three-dimensional ionimprinted polymers. Anal Chem. 2016;88(13):6820-6.

60. Xu J, Zhang Y, Li L, Kong Q, Zhang L, Ge S, Yu J. Colorimetric and electrochemiluminescence dual-mode sensing of lead ion based on integrated lab-on-paper device. ACS Appl Mater Interfaces. 2018;10(4):3431-40.

61. Liao H, Liu G, Liu Y, Li R, Fu W, Hu L. Aggregation-induced accelerating peroxidase-like activity of gold nanoclusters and their applications for colorimetric $\mathrm{Pb}^{2+}$ detection. Chem Commun. 2017;53(73):10160-3.

62. Kim MI, Ye Y, Won BY, Shin S, Lee J, Park HG. A highly efficient electrochemical biosensing platform by employing conductive nanocomposite entrapping magnetic nanoparticles and oxidase in mesoporous carbon foam. Adv Func Mater. 2011;21(15):2868-75.

63. Hur J, Park HG, Kim MI. Reagentless colorimetric biosensing platform based on nanoceria within an agarose gel matrix. Biosens Bioelectron. 2017;93:226-33.

64. Qu K, Shi P, Ren J, Qu X. Nanocomposite incorporating $V_{2} \mathrm{O}_{5}$ nanowires and gold nanoparticles for mimicking an enzyme cascade reaction and its application in the detection of biomolecules. Chem A Eur J. 2014;20(24):7501-6.

65. He L, Lu Y, Gao X, Song P, Huang Z, Liu S, Liu Y. Self-cascade system based on cupric oxide nanoparticles as dual-functional enzyme mimics for ultrasensitive detection of silver ions. ACS Sust Chem Eng. 2018;6(9):12132-9.

66. Mao S, Chang J, Zhou G, Chen J. Nanomaterial-enabled rapid detection of water contaminants. Small. 2015;11(40):5336-59.

67. Amiri S, Navaee A, Salimi A, Ahmadi R. Zeptomolar detection of $\mathrm{Hg}^{2+}$ based on label-free electrochemical aptasensor: One step closer to the dream of single atom detection. Electrochem Commun. 2017;78:21-5.

68. Amiri S, Ahmadi R, Salimi A, Navaee A, Qaddare SH, Amini MK. Ultrasensitive and highly selective FRET aptasensor for $\mathrm{Hg}^{2+}$ measurement in fish samples using carbon dots/AuNPs as donor/acceptor platform. New J Chem. 2018;42(19):16027-35.

69. Chu KW, Chow KL. Synergistic toxicity of multiple heavy metals is revealed by a biological assay using a nematode and its transgenic derivative. Aquat Toxicol. 2002;61(1-2):53-64.

70. Peng C-F, Zhang Y-Y, Wang L-Y, Jin Z-Y, Shao G. Colorimetric assay for the simultaneous detection of $\mathrm{Hg} 2+$ and $\mathrm{Ag}+$ based on inhibiting the peroxidase-like activity of core-shell Au@ Pt nanoparticles. Anal Methods. 2017;9(30):4363-70.

71. Chen X, Zhai N, Snyder JH, Chen Q, Liu P, Jin L, Zheng Q, Lin F, Hu J, Zhou $\mathrm{H}$. Colorimetric detection of $\mathrm{Hg}^{2+}$ and $\mathrm{Pb}^{2+}$ based on peroxidaselike activity of graphene oxide-gold nanohybrids. Anal Methods. 2015;7(5):1951-7.

72. Huang P-C, Shen M-Y, Yu H-H, Wei S-C, Luo S-C. Surface Engineering of phenylboronic acid-functionalized poly (3,4-ethylenedioxythiophene) for fast responsive and sensitive glucose monitoring. ACS Appl Bio Mater. 2018;1(1):160-7.

73. Zou W-S, Ye C-H, Wang Y-Q, Li W-H, Huang X-H. A hybrid ratiometric probe for glucose detection based on synchronous responses to fluorescence quenching and resonance light scattering enhancement of boronic acid functionalized carbon dots. Sens Actuat B. 2018;271:54-63.

74. Guo Y, Wang H, Ma X, Jin J, Ji W, Wang X, Song W, Zhao B, He C. Fabrication of $\mathrm{Ag}-\mathrm{Cu}_{2} \mathrm{O} /$ reduced graphene oxide nanocomposites as surface-enhanced raman scattering substrates for in situ monitoring of peroxidase-like catalytic reaction and biosensing. ACS Appl Mater Interfaces. 2017:9(22):19074-81.

75. Lin Y, Yu P, Hao J, Wang Y, Ohsaka T, Mao L. Continuous and simultaneous electrochemical measurements of glucose, lactate, and ascorbate in rat brain following brain ischemia. Anal Chem. 2014;86(8):3895-901.

76. Feng L-L, Wu Y-X, Zhang D-L, Hu X-X, Zhang J, Wang P, Song Z-L, Zhang $X-B$, Tan W. Near infrared graphene quantum dots-based two-photon nanoprobe for direct bioimaging of endogenous ascorbic acid in living cells. Anal Chem. 2017;89(7):4077-84.

77. Ding Y, Zhao J, Li B, Zhao X, Wang C, Guo M, Lin Y. The CoOOH-TMB oxidative system for use in colorimetric and test strip based determination of ascorbic acid. Microchim Acta. 2018;185(2):131. 
78. Zhu Y, Yang Z, Chi M, Li M, Wang C, Lu X. Synthesis of hierarchical Co304@ NiO core-shell nanotubes with a synergistic catalytic activity for peroxidase mimicking and colorimetric detection of dopamine. Talanta. 2018;181:431-9.

79. Xu H-H, Deng H-H, Lin X-Q, Wu Y-Y, Lin X-L, Peng H-P, Liu A-L, Xia X-H, Chen W. Colorimetric glutathione assay based on the peroxidase-like activity of a nanocomposite consisting of platinum nanoparticles and graphene oxide. Microchim Acta. 2017;184(10):3945-51.

80. Chi M, Chen S, Zhong M, Wang C, Lu X. Self-templated fabrication of $\mathrm{FeMnO}_{3}$ nanoparticle-filled polypyrrole nanotubes for peroxidase mimicking with a synergistic effect and their sensitive colorimetric detection of glutathione. Chem Commun. 2018;54(46):5827-30.

81. Yang Z, Ma F, Zhu Y, Chen S, Wang C, Lu X. A facile synthesis of $\mathrm{CuFe}_{2} \mathrm{O}_{4} /$ $\mathrm{Cu}_{9} \mathrm{~S}_{8} /$ PPy ternary nanotubes as peroxidase mimics for the sensitive colorimetric detection of $\mathrm{H}_{2} \mathrm{O}_{2}$ and dopamine. Dalton Trans. 2017:46(34):11171-9.

82. Alizadeh N, Salimi A, Hallaj R, Fathi F, Soleimani F. Ni-hemin metalorganic framework with highly efficient peroxidase catalytic activity: toward colorimetric cancer cell detection and targeted therapeutics. J Nanobiotechnol. 2018;16(1):93.

83. Xie Y, Yin T, Wiegraebe W, He XC, Miller D, Stark D, Perko K, Alexander R, Schwartz J, Grindley JC. Detection of functional haematopoietic stem cell niche using real-time imaging. Nature. 2009;457(7225):97.

84. Shen Z, Wu A, Chen X. Current detection technologies for circulating tumor cells. Chem Soc Rev. 2017:46(8):2038-56.

85. Tian L, Qi J, Qian K, Oderinde O, Liu Q, Yao C, Song W, Wang Y. Copper (II) oxide nanozyme based electrochemical cytosensor for high sensitive detection of circulating tumor cells in breast cancer. J Electroanal Chem. 2018;812:1-9.

86. Tian L, Qi J, Qian K, Oderinde O, Cai Y, Yao C, Song W, Wang Y. An ultrasensitive electrochemical cytosensor based on the magnetic field assisted binanozymes synergistic catalysis of $\mathrm{Fe}_{3} \mathrm{O}_{4}$ nanozyme and reduced graphene oxide/molybdenum disulfide nanozyme. Sens Actuat B. 2018;260:676-84.

87. Zhang L-N, Deng H-H, Lin F-L, Xu X-W, Weng S-H, Liu A-L, Lin X-H, Xia X-H, Chen W. In situ growth of porous platinum nanoparticles on graphene oxide for colorimetric detection of cancer cells. Anal Chem. 2014;86(5):2711-8.

88. Tao Y, Lin Y, Huang Z, Ren J, Qu X. Incorporating graphene oxide and gold nanoclusters: a synergistic catalyst with surprisingly high peroxidase-like activity over a broad ph range and its application for cancer cell detection. Adv Mater. 2013;25(18):2594-9.

89. Maji SK, Mandal AK, Nguyen KT, Borah P, Zhao Y. Cancer cell detection and therapeutics using peroxidase-active nanohybrid of gold nanoparticle-loaded mesoporous silica-coated graphene. ACS Appl Mater Interfaces. 2015;7(18):9807-16.

90. Wang G-L, Xu X-F, Qiu L, Dong Y-M, Li Z-J, Zhang C. Dual responsive enzyme mimicking activity of $\mathrm{AgX}(\mathrm{X}=\mathrm{Cl}, \mathrm{Br}, \mathrm{I})$ nanoparticles and its application for cancer cell detection. ACS Appl Mater Interfaces. 2014;6(9):6434-42.

91. Alizadeh N, Salimi A, Hallaj R, Fathi F, Soleimani F. $\mathrm{CuO} / \mathrm{WO}_{3}$ nanoparticles decorated graphene oxide nanosheets with enhanced peroxidase-like activity for electrochemical cancer cell detection and targeted therapeutics. Mater Sci Eng, C. 2019;99:1374-83.

92. Mumtaz S, Wang L-S, Hussain SZ, Abdullah M, Huma Z, Iqbal Z, Creran B, Rotello VM, Hussain I. Dopamine coated Fe 3 O 4 nanoparticles as enzyme mimics for the sensitive detection of bacteria. Chem Commun. 2017;53(91):12306-8.

93. Kaittanis C, Santra S, Perez JM. Emerging nanotechnology-based strategies for the identification of microbial pathogenesis. Adv Drug Deliv Rev. 2010;62(4-5):408-23.

94. Das R, Dhiman A, Kapil A, Bansal V, Sharma TK. Aptamer-mediated colorimetric and electrochemical detection of Pseudomonas aeruginosa utilizing peroxidase-mimic activity of gold NanoZyme. Anal Bioanal Chem. 2019;411(6):1229-38.

95. Liu Y, Zhao C, Song X, Xu K, Wang J, Li J. Colorimetric immunoassay for rapid detection of Vibrio parahaemolyticus. Microchim Acta. 2017;184(12):4785-92.

96. Zhang L, Chen Y, Cheng N, Xu Y, Huang K, Luo Y, Wang P, Duan D, Xu W. Ultrasensitive detection of viable Enterobacter sakazakii by a continual cascade nanozyme biosensor. Anal Chem. 2017;89(19):10194-200.

97. Cheng N, Song Y, Zeinhom MM, Chang Y-C, Sheng L, Li H, Du D, Li L, Zhu M-J, Luo Y. Nanozyme-mediated dual immunoassay integrated with smartphone for use in simultaneous detection of pathogens. ACS Appl Mater Interfaces. 2017;9(46):40671-80.

98. D'Autréaux B, Toledano MB. ROS as signalling molecules: mechanisms that generate specificity in ROS homeostasis. Nat Rev Mol Cell Biol. 2007;8(10):813-24.

99. Trachootham D, Alexandre J, Huang P. Targeting cancer cells by ROSmediated mechanisms: a radical therapeutic approach? Nat Rev Drug Discovery. 2009;8(7):579.

100. Zhang C, Bu W, Ni D, Zhang S, Li Q, Yao Z, Zhang J, Yao H, Wang Z, Shi J. Synthesis of iron nanometallic glasses and their application in cancer therapy by a localized Fenton reaction. Angew Chem Int Ed. 2016;55(6):2101-6.

101. Tang Z, Zhang H, Liu Y, Ni D, Zhang H, Zhang J, Yao Z, He M, Shi J, Bu W. Antiferromagnetic pyrite as the tumor microenvironment-mediated nanoplatform for self-enhanced tumor imaging and therapy. Adv Mater. 2017;29(47):1701683.

102. Deák M, Horváth GV, Davletova S, Török K, Sass L, Vass I, Barna B, Király $Z$, Dudits $D$. Plants ectopically expressing the ironbinding protein, ferritin, are tolerant to oxidative damage and pathogens. Nat Biotechnol. 1999;17(2):192.

103. Bai J, Jia X, Zhen W, Cheng W, Jiang X. A facile ion-doping strategy to regulate tumor microenvironments for enhanced multimodal tumor theranostics. J Am Chem Soc. 2017;140(1):106-9.

104. Yu L, Chen Y, Chen H. H2O2-responsive theranostic nanomedicine. Chin Chem Lett. 2017;28(9):1841-50.

105. Szatrowski TP, Nathan CF. Production of large amounts of hydrogen peroxide by human tumor cells. Can Res. 1991;51(3):794-8.

106. Peng F, Tu Y, van Hest JC, Wilson DA. Self-guided supramolecular cargo-loaded nanomotors with chemotactic behavior towards cells. Angew Chem Int Ed. 2015;54(40):11662-5.

107. Ranji-Burachaloo H, Gurr PA, Dunstan DE, Qiao GG. Cancer treatment through nanoparticle-facilitated fenton reaction. ACS Nano. 2018;12(12):11819-37.

108. Wang X, Zhong X, Liu Z, Cheng L. Recent progress of chemodynamic therapy-induced combination cancer therapy. Nano Today. 2020;35:100946.

109. Zhong Y, Li X, Chen J, Wang X, Wei L, Fang L, Kumar A, Zhuang S, Liu J. Recent advances in MOF-based nanoplatforms generating reactive species for chemodynamic therapy. Dalton Trans. 2020;49(32):11045-58.

110. Lin LS, Song J, Song L, Ke K, Liu Y, Zhou Z, Shen Z, Li J, Yang Z, Tang W. Simultaneous fenton-like ion delivery and glutathione depletion by $\mathrm{MnO}_{2}$-based nanoagent to enhance chemodynamic therapy. Angew Chem Int Ed. 2018;57(18):4902-6.

111. Webb BA, Chimenti M, Jacobson MP, Barber DL. Dysregulated pH: a perfect storm for cancer progression. Nat Rev Cancer. 2011;11(9):671.

112. Massagué J, Obenauf AC. Metastatic colonization by circulating tumour cells. Nature. 2016:529(7586):298.

113. Ebos JM, Lee CR, Cruz-Munoz W, Bjarnason GA, Christensen JG, Kerbel RS. Accelerated metastasis after short-term treatment with a potent inhibitor of tumor angiogenesis. Cancer Cell. 2009;15(3):232-9.

114. Zhao P, Tang Z, Chen X, He Z, He X, Zhang M, Liu Y, Ren D, Zhao K, Bu W. Ferrous-cysteine-phosphotungstate nanoagent with neutral pH fenton reaction activity for enhanced cancer chemodynamic therapy. Materials Horizons. 2019;6(2):369-74.

115. Ma P, Xiao H, Yu C, Liu J, Cheng Z, Song H, Zhang X, Li C, Wang J, Gu Z. Enhanced cisplatin chemotherapy by iron oxide nanocarrier-mediated generation of highly toxic reactive oxygen species. Nano letters. 2017;17(2):928-37.

116. Lin L, Huang T, Song J, Ou X-Y, Wang Z, Deng H, Tian R, Liu Y, Wang J-F, Liu Y. Synthesis of copper peroxide nanodots for $\mathrm{H}_{2} \mathrm{O}_{2}$ self-supplying chemodynamic therapy. J Am Chem Soc. 2019;15:23.

117. Lin L-S, Cong Z-X, Li J, Ke K-M, Guo S-S, Yang H-H, Chen G-N. Graphiticphase $\mathrm{C}_{3} \mathrm{~N}_{4}$ nanosheets as efficient photosensitizers and $\mathrm{pH}$-responsive drug nanocarriers for cancer imaging and therapy. J Mater Chem B. 2014:2(8):1031-7.

118. Lee K-T, Lu Y-J, Mi F-L, BurnoufT, Wei Y-T, Chiu S-C, Chuang E-Y, Lu S-Y. Catalase-modulated heterogeneous Fenton reaction for selective 
cancer cell eradication: $\mathrm{SnFe}_{2} \mathrm{O}_{4}$ nanocrystals as an effective reagent for treating lung cancer cells. ACS Appl Mater Interfaces. 2017;9(2):1273-9.

119. Dai Y, Yang Z, Cheng S, Wang Z, Zhang R, Zhu G, Wang Z, Yung BC, Tian $R$, Jacobson $O$. Toxic reactive oxygen species enhanced synergistic combination therapy by self-assembled metal-phenolic network nanoparticles. Adv Mater. 2018;30(8):1704877.

120. Wang J, Yi J. Cancer cell killing via ROS: to increase or decrease, that is the question. Cancer Biol Ther. 2008;7(12):1875-84.

121. Kim H-J, Lee J-H, Kim S-J, Oh GS, Moon H-D, Kwon K-B, Park C, Park BH, Lee H-K, Chung S-Y. Roles of NADPH oxidases in cisplatin-induced reactive oxygen species generation and ototoxicity. J Neurosci. 2010;30(11):3933-46.

122. Sun $K$, Gao Z, Zhang Y, Wu H, You C, Wang $S$, An P, Sun C, Sun B. Enhanced highly toxic reactive oxygen species levels from iron oxide core-shell mesoporous silica nanocarrier-mediated Fenton reactions for cancer therapy. J Mater Chem B. 2018;6(37):5876-87.

123. Agostinis P, Berg K, Cengel KA, Foster TH, Girotti AW, Gollnick SO, Hahn SM, Hamblin MR, Juzeniene A, Kessel D. Photodynamic therapy of cancer: an update. CA Cancer J Clin. 2011;61(4):250-81.

124. Huang $P$, Lin J, Wang $X$, Wang Z, Zhang C, He M, Wang K, Chen F, Li Z, Shen G. Light-triggered theranostics based on photosensitizer-conjugated carbon dots for simultaneous enhanced-fluorescence imaging and photodynamic therapy. Adv Mater. 2012;24(37):5104-10.

125. Zhang C, Qin W-J, Bai X-F, Zhang X-Z. Nanomaterials to relieve tumor hypoxia for enhanced photodynamic therapy. Nano Today. 2020;35:100960.

126. Dang J, He H, Chen D, Yin L. Manipulating tumor hypoxia toward enhanced photodynamic therapy (PDT). Biomater Sci. 2017:5(8):1500-11.

127. Li X, Kwon N, Guo T, Liu Z, Yoon J. Innovative strategies for hypoxic-tumor photodynamic therapy. Angew Chem Int Ed. 2018;57(36):11522-31.

128. De Simone G, Vitale RM, Di Fiore A, Pedone C, Scozzafava A, Montero $J$-L, Winum J-Y, Supuran CT. Carbonic anhydrase inhibitors: hypoxiaactivatable sulfonamides incorporating disulfide bonds that target the tumor-associated isoform IX. J Med Chem. 2006;49(18):5544-51.

129. Fan W, Bu W, Zhang Z, Shen B, Zhang H, He Q, Ni D, Cui Z, Zhao K, $\mathrm{Bu}$ J. Inside back cover: $\mathrm{X}$-ray radiation-controlled NO-release for on-demand depth-independent hypoxic radiosensitization. Angewandte Chem Int. 2015;54(47):14191-14191.

130. Kim J, Cho HR, Jeon H, Kim D, Song C, Lee N, Choi SH, Hyeon T. Continuous $\mathrm{O}_{2}$-evolving $\mathrm{MnFe}_{2} \mathrm{O}_{4}$ nanoparticle-anchored mesoporous silica nanoparticles for efficient photodynamic therapy in hypoxic cancer. J Am Chem Soc. 2017;139(32):10992-5.

131. Li QF, Wang XR, Yang YW, Lin H. Hypoxia upregulates hypoxia inducible factor (HIF)-3a expression in lung epithelial cells: characterization and comparison with HIF-1a. Cell Res. 2006;16(6):548.

132. Zhang W, Li S, Liu X, Yang C, Hu N, Dou L, Zhao B, Zhang Q, Suo Y, Wang J. Oxygen-generating $\mathrm{MnO}_{2}$ nanodots-anchored versatile nanoplatform for combined chemo-photodynamic therapy in hypoxic cancer. Adv Func Mater. 2018;28(13):1706375.

133. Yang X, Yang Y, Gao F, Wei J-J, Qian C-G, Sun M-J. Biomimetic Hybrid Nanozymes with Self-Supplied $\mathrm{H}+$ and Accelerated $\mathrm{O}_{2}$ Generation for Enhanced Starvation and Photodynamic Therapy against Hypoxic Tumors. Nano letters. 2019:5:9.

134. Zhang Y, Wang F, Liu C, Wang Z, Kang L, Huang Y, Dong K, Ren J, Qu $X$. Nanozyme decorated metal-organic frameworks for enhanced photodynamic therapy. ACS Nano. 2018;12(1):651-61.

135. Singh N, Savanur MA, Srivastava S, D'Silva P, Mugesh G. A redox modulatory Mn3O4 nanozyme with multi-enzyme activity provides efficient cytoprotection to human cells in a Parkinson's disease model. Angew Chem Int Ed. 2017:56(45):14267-71.

136. Hu X, Li F, Xia F, Guo X, Wang N, Liang L, Yang B, Fan K, Yan X, Ling D. Biodegradation-mediated enzymatic activity-tunable molybdenum oxide nanourchins for tumor-specific cascade catalytic therapy. J Am Chem Soc. 2019:8:65.

137. Chen Q, Wen J, Li H, Xu Y, Liu F, Sun S. Recent advances in different modal imaging-guided photothermal therapy. Biomaterials. 2016;106:144-66.

138. Abdoon AS, Al-Ashkar EA, Kandil OM, Shaban AM, Khaled HM, El Sayed MA, El Shaer MM, Shaalan AH, Eisa WH, Eldin AAG. Efficacy and toxicity of plasmonic photothermal therapy (PPTT) using gold nanorods (GNRs) against mammary tumors in dogs and cats. Nanomed Nanotechnol Biol Med. 2016;12(8):2291-7.

139. Jung HS, Verwilst P, Sharma A, Shin J, Sessler JL, Kim JS. Organic molecule-based photothermal agents: an expanding photothermal therapy universe. Chem Soc Rev. 2018;47(7):2280-97.

140. Hu J-J, Cheng Y-J, Zhang X-Z. Recent advances in nanomaterials for enhanced photothermal therapy of tumors. Nanoscale. 2018;10(48):22657-72.

141. Zhi D, Yang T, Ohagan J, Zhang S, Donnelly RF. Photothermal therapy. J Controll Release. 2020;3:87.

142. Park D, Ahn K-O, Jeong K-C, Choi Y. Polypyrrole-based nanotheranostics for activatable fluorescence imaging and chemo/photothermal dual therapy of triple-negative breast cancer. Nanotechnology. 2016;27(18):185102.

143. Xi J, Wang W, Da L, Zhang J, Fan L, Gao L. Au-PLGA hybrid nanoparticles with catalase-mimicking and near-infrared photothermal activities for photoacoustic imaging-guided cancer therapy. ACS Biomater Sci Eng. 2018:4(3):1083-91.

144. Fan L, Xu X, Zhu C, Han J, Gao L, Xi J, Guo R. Tumor catalytic-photothermal therapy with yolk-shell Gold@ carbon nanozymes. ACS Appl Mater Interfaces. 2018;10(5):4502-11.

145. Murugan C, Murugan N, Sundramoorthy AK, Anandhakumar S. Nanoceria decorated flower-like molybdenum sulphide nanoflakes: an efficient nanozyme to tumour selective ros generation and photo thermal therapy. Chem Commun. 2019;2:7.

146. Zhu P, Chen Y, Shi J. Nanoenzyme-augmented cancer sonodynamic therapy by catalytic tumor oxygenation. ACS Nano. 2018;12(4):3780-95.

147. Pan X, Bai L, Wang H, Wu Q, Wang H, Liu S, Xu B, Shi X, Liu H. Metalorganic-framework-derived carbon nanostructure augmented sonodynamic cancer therapy. Adv Mater. 2018;30(23):1800180.

148. Gao Z, Zheng J, Yang B, Wang Z, Fan H, Lv Y, Li H, Jia L, Cao W. Sonodynamic therapy inhibits angiogenesis and tumor growth in a xenograft mouse model. Cancer Lett. 2013;335(1):93-9.

149. Wang X, Zhong X, Gong F, Chao Y, Cheng L. Newly developed strategies for improving sonodynamic therapy. Materials Horizons. 2020;7(8):2028-46.

150. Zhang C, Zhao K, Bu W, Ni D, Liu Y, Feng J, Shi J. Marriage of scintillator and semiconductor for synchronous radiotherapy and deep photodynamic therapy with diminished oxygen dependence. Angew Chem Int Ed. 2015;54(6):1770-4.

151. Liang S, Deng X, Chang Y, Sun C, Shao S, Xie Z, Xiao X, Ma P, Zhang H, Cheng Z. Intelligent hollow Pt-CuS janus architecture for synergistic catalysis-enhanced sonodynamic and photothermal cancer therapy. Nano letters. 2019;11:23.

152. Sun D, Pang $X$, Cheng Y, Ming J, Xiang S, Zhang C, Lv P, Chu C, Chen $X$, Liu G. Ultrasound-switchable nanozyme augments sonodynamic therapy against multidrug-resistant bacterial infection. ACS Nano. 2020;14(2):2063-76.

153. Choi K-H, Lee H-J, Park BJ, Wang K-K, Shin EP, Park J-C, Kim YK, Oh M-K, Kim Y-R. Photosensitizer and vancomycin-conjugated novel multifunctional magnetic particles as photoinactivation agents for selective killing of pathogenic bacteria. Chem Commun. 2012;48(38):4591-3.

154. Paladini F, Pollini M, Sannino A, Ambrosio L. Metal-based antibacterial substrates for biomedical applications. Biomacromol. 2015;16(7):1873-85.

155. Cocco AR, Rosa WL, Silva AF, Lund RG, Piva E. A systematic review about antibacterial monomers used in dental adhesive systems: Current status and further prospects. Dental Mater. 2015;31(11):1345-62.

156. Levy SB, Marshall B. Antibacterial resistance worldwide: causes, challenges and responses. Nat Med. 2004;10(12s):S122.

157. Natalio F, André R, Hartog AF, Stoll B, Jochum KP, Wever R, Tremel W. Vanadium pentoxide nanoparticles mimic vanadium haloperoxidases and thwart biofilm formation. Nat Nanotechnol. 2012;7(8):530.

158. Gao L, Giglio KM, Nelson JL, Sondermann H, Travis AJ. Ferromagnetic nanoparticles with peroxidase-like activity enhance the cleavage of biological macromolecules for biofilm elimination. Nanoscale. 2014;6(5):2588-93.

159. Chen S, Quan Y, Yu Y-L, Wang J-H. Graphene quantum dot/silver nanoparticle hybrids with oxidase activities for antibacterial application. ACS Biomater Sci Eng. 2017;3(3):313-21. 
160. Cai S, Jia X, Han Q, Yan X, Yang R, Wang C. Porous Pt/Ag nanoparticles with excellent multifunctional enzyme mimic activities and antibacterial effects. Nano Res. 2017;10(6):2056-69.

161. Swartjes JJ, Das T, Sharifi S, Subbiahdoss G, Sharma PK, Krom BP, Busscher HJ, van der Mei HC. A functional DNase I coating to prevent adhesion of bacteria and the formation of biofilm. Adv Func Mater. 2013;23(22):2843-9.

162. Hancock RE. A brief on bacterial biofilms. Nat Genet. 2001;29(4):360.

163. Wong GC, O'Toole GA. All together now: Integrating biofilm research across disciplines. MRS Bull. 2011;36(5):339-42.

164. Tao Y, Ju E, Ren J, Qu X. Bifunctionalized mesoporous silica-supported gold nanoparticles: intrinsic oxidase and peroxidase catalytic activities for antibacterial applications. Adv Mater. 2015;27(6):1097-104.

165. Velema WA, Van Der Berg JP, Hansen MJ, Szymanski W, Driessen AJ, Feringa BL. Optical control of antibacterial activity. Nat Chem. 2013;5(11):924.

166. Anderson SR, Mohammadtaheri M, Kumar D, O'Mullane AP, Field MR, Ramanathan R, Bansal V. Robust nanostructured silver and copper fabrics with localized surface plasmon resonance property for effective visible light induced reductive catalysis. Adv Mater Interf. 2016;3(6):1500632.

167. Karim MN, Singh M, Weerathunge P, Bian P, Zheng R, Dekiwadia C Ahmed T, Walia S, Della Gaspera E, Singh S. Visible-light-triggered reactive-oxygen-species-mediated antibacterial activity of peroxidasemimic CuO nanorods. ACS Appl Nano Mater. 2018;1(4):1694-704.

168. Gilroy KD, Ruditskiy A, Peng H-C, Qin D, Xia Y. Bimetallic nanocrystals: syntheses, properties, and applications. Chem Rev. 2016;116(18):10414-72.

169. Zhang Q, Zhou Y, Villarreal E, Lin Y, Zou S, Wang H. Faceted gold nanorods: nanocuboids, convex nanocuboids, and concave nanocuboids. Nano Lett. 2015;15(6):4161-9.

170. Fang G, Li W, Shen X, Perez-Aguilar JM, Chong Y, Gao X, Chai Z, Chen C, Ge C, Zhou R. Differential Pd-nanocrystal facets demonstrate distinct antibacterial activity against Gram-positive and Gram-negative bacteria. Nature communications. 2018:9(1):129.

171. Rasalingam S, Peng R, Koodali RT. An insight into the adsorption and photocatalytic degradation of rhodamine B in periodic mesoporous materials. Appl Catal B. 2015;174:49-59.

172. Soon AN, Hameed B. Degradation of Acid Blue 29 in visible light radiation using iron modified mesoporous silica as heterogeneous PhotoFenton catalyst. Appl Catal A. 2013;450:96-105.

173. Zhang J, Li F, Sun Q. Rapid and selective adsorption of cationic dyes by a unique metal-organic framework with decorated pore surface. Appl Surf Sci. 2018;440:1219-26.

174. Gupta V, Khamparia S, Tyagi I, Jaspal D, Malviya A. Decolorization of mixture of dyes: a critical review. Global J Environ Sci Manag. 2015;1(1):71-94

175. Marçal L, De Faria E, Saltarelli M, Calefi P, Nassar E, Ciuffi K, Trujillano R, Vicente M, Korili S, Gil A. Amine-functionalized titanosilicates prepared by the sol-gel process as adsorbents of the azo-dye Orange II. Ind Eng Chem Res. 2010:50(1):239-46.
176. Haber F, Weiss J. Über die katalyse des hydroperoxydes. Naturwissenschaften. 1932;20(51):948-50.

177. Kehrer JP. The Haber-Weiss reaction and mechanisms of toxicity. Toxicology. 2000;149(1):43-50.

178. Feng J, Hu X, Yue PL. Effect of initial solution $\mathrm{pH}$ on the degradation of Orange II using clay-based Fe nanocomposites as heterogeneous photo-Fenton catalyst. Water Res. 2006;40(4):641-6.

179. Bokare $A D$, Choi W. Review of iron-free Fenton-like systems for activating $\mathrm{H}_{2} \mathrm{O}_{2}$ in advanced oxidation processes. J Hazard Mater. 2014;275:121-35.

180. M. Pera-Titus, V. García-Molina, M.A. Baños, J. Giménez, S. Esplugas, Degradation of chlorophenols by means of advanced oxidation processes: a general review, Applied Catalysis B: Environmental 47(4) (2004) 219-256.

181. Navalon S, Alvaro M, Garcia H. Heterogeneous Fenton catalysts based on clays, silicas and zeolites. Appl Catal B. 2010;99(1-2):1-26.

182. Nsabimana A, Kitte SA, Wu F, Qi L, Liu Z, Zafar MN, Luque R, Xu G. Multifunctional magnetic Fe3O4/nitrogen-doped porous carbon nanocomposites for removal of dyes and sensing applications. Appl Surf Sci. 2019:467:89-97.

183. Xiao C, Li J, Zhang G. Synthesis of stable burger-like a-Fe2O3 catalysts: formation mechanism and excellent photo-Fenton catalytic performance. J Clean Prod. 2018;180:550-9.

184. Yu D, Ni H, Wang L, Wu M, Yang X. Nanoscale-confined precursor of CuFe2O4 mediated by hyperbranched polyamide as an unusual heterogeneous Fenton catalyst for efficient dye degradation. J Clean Prod. 2018;186:146-54

185. Wang M, Wang $\mathrm{N}$, Tang $\mathrm{H}$, Cao M, She Y, Zhu L. Surface modification of nano- $\mathrm{Fe}_{3} \mathrm{O}_{4}$ with EDTA and its use in $\mathrm{H}_{2} \mathrm{O}_{2}$ activation for removing organic pollutants. Catal Sci Technol. 2012;2(1):187-94.

186. Costa RC, Lelis M, Oliveira LC, Fabris JD, Ardisson JD, Rios RR, Silva CN, Lago RM. Remarkable effect of Co and Mn on the activity of $\mathrm{Fe}_{3}-\mathrm{xMxO}_{4}$ promoted oxidation of organic contaminants in aqueous medium with $\mathrm{H}_{2} \mathrm{O}_{2}$. Catal Commun. 2003;4(10):525-9.

187. Pouran SR, Aziz AA, Daud WMAW, Embong Z. Niobium substituted magnetite as a strong heterogeneous Fenton catalyst for wastewater treatment. Appl Surf Sci. 2015;351:175-87.

188. Chen F, Xie S, Huang X, Qiu X. lonothermal synthesis of $\mathrm{Fe}_{3} \mathrm{O}_{4}$ magnetic nanoparticles as efficient heterogeneous Fenton-like catalysts for degradation of organic pollutants with H2O2. J Hazard Mater. 2017;322:152-62.

189. Hamoud HI, Finqueneisel G, Azambre B. Removal of binary dyes mixtures with opposite and similar charges by adsorption, coagulation/flocculation and catalytic oxidation in the presence of $\mathrm{CeO}_{2} / \mathrm{H}_{2} \mathrm{O}_{2}$ Fenton-like system. J Environ Manage. 2017;195:195-207.

\section{Publisher's Note}

Springer Nature remains neutral with regard to jurisdictional claims in published maps and institutional affiliations.
Ready to submit your research? Choose BMC and benefit from:

- fast, convenient online submission

- thorough peer review by experienced researchers in your field

- rapid publication on acceptance

- support for research data, including large and complex data types

- gold Open Access which fosters wider collaboration and increased citations

- maximum visibility for your research: over 100M website views per year

At BMC, research is always in progress.

Learn more biomedcentral.com/submissions 